Rejane Rimazza Dalberto Casagrande

\title{
Avaliação da prevalência da asma e dos fatores de risco assoc iados em escolares de 6 a 7 anos na região oeste da cidade de São Paulo
}

Dissertação apresentada à Faculdade de Medicina da Universidade de São Paulo para obtenção do título de Mestre em Ciências

Área de concentração: Pediatria

Orientadora: Dra. Cristina Miuki Abe Jacob

São Paulo

2005 


\section{DEDI CATÓRI AS}

Ao meu marido, Edson, que durante todo esse trabalho esteve sempre ao meu lado, demonstrando muito amor, compreensão e incentivo.

Aos meus pais, Sylvio e Ariete, sempre presentes em minha vida, a quem devo minha formação e eterna gratidão. 


\section{AGRADECI MENTOS}

Aos Professores: Prof. Dr. Yassuhiko Okay, Prof. Dr. Flávio A. Costa Vaz, Profa. Dra. Sandra Josefina Ferraz E. Grise e Profa. Dra. Magda Maria Salles Carneiro-Sampaio pelo apoio neste projeto.

À Dra. Cristina Miuki Abe Jacob, orientadora atuante e exemplo de profissionalismo, pela oportunidade de aprimoramento profissional e pela amizade, atenção e carinho.

Ao Dr. Antonio Carlos Pastorino, por sua dedicação e inestimável auxílio neste projeto, principalmente nos momentos mais difíceis, e pela amizade e exemplo profissional.

Ao Coordenador Nacional do Projeto ISAAC, Prof. Dr. Dirceu Solé, pela oportunidade de participar deste projeto e pelas valiosas sugestões.

Às assistentes da Unidade de Alergia e Imunologia do Instituto da Criança: Dra. Ângela Bueno Ferraz Fomin, Dra Ana Paula Moschione Castro e Dra. Eugenia Maria Grilo Carnide pela amizade, apoio e incentivo de sempre.

À Pós-graduanda e amiga Dra. Renata Gontijo Lima de Souza, companheira fiel na coleta de dados, pela amizade e otimismo durante toda a execução deste projeto.

Aos meus amigos do grupo da Imunologia do Instituto da Criança pela amizade e incentivo durante todo este projeto.

Ao Prof. Dr. Cláudio Leone pelo constante auxílio, importantes sugestões e competência na análise estatística.

Ao meu marido, Edson pelo auxílio e paciência na digitação dos dados e na informática.

À Dra. Marta Miranda Leal, pela objetividade e clareza nas correções finais.

À Bibliotecária do Instituto da Criança Sra. Mariza pelo auxílio na correção das referências.

Às Diretoras, Coordenadoras e Professoras das Escolas Municipais da NAE12 pela disponibilidade e auxílio durante a aplicação dos questionários.

Aos alunos das escolas Municipais da região oeste de São Paulo pela participação no estudo ISAAC.

À Sra. Elisabete, pela eficiência e organização na realização do contato telefônico com os responsáveis dos alunos para aplicação do questionário. 
“Aprender é a única coisa de que a mente nunca se cansa, nunca tem medo e nunca se arrepende". (Leonardo da Vinci) 


\section{SUMÁRIO}

Listas de Abreviaturas

Lista de Tabelas, Quadro e Figuras

Lista de Anexos

Resumo

Summary

1. INTRODUÇÃO 02

1.1 Métodos Epidemiológicos para estudo de doenças alérgicas e o estudo ISAAC International Study of Asthma and Allergies in Childhood

1.2 Hipótese da Higiene e Fatores de Risco para doenças alérgicas 13

2. OBJETIVOS 24

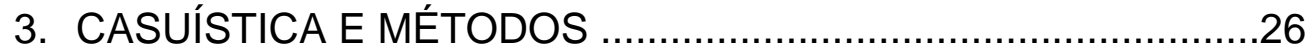

3.1 Características da região oeste da cidade

de São Paulo 26

3.2 Descrição do Questionário Escrito do estudo ISAAC. 26

3.3 Descrição do Questionário Complementar do estudo ISAAC 29 
3.4 Seleção dos fatores de risco relacionados

à asma 29

3.5 Seleção das escolas e metodologia de aplicação dos questionários 31

3.6 Métodos estatísticos 37

3.6.1 Questionário Escrito do estudo ISAAC. 37

3.6.2 Questionário Complementar..... 38

3.6.3 Metodologia utilizada para o cálculo do valor de prevalência corrigido referente aos resultados do QE do estudo ISAAC. 39

3.7 Aspectos éticos 41

4. RESULTADOS .43

4.1 Prevalências de Asma e sintomas associados

(Módulo 1) 43

4.2 Associação entre asma, rinite e eczema. 46

4.3 Prevalência de fatores de risco relacionados à

presença de sintomas de asma no último ano 48

5. DISCUSSÃO

6. CONCLUSÕES. 82

7. ANEXOS 85

8. REFERÊNCIAS. 


\section{LISTA DE ABREVIATURAS}

ATS-DLD American Thoracic Society - Division of Lung Disease

BCG Bacilo de Calmette-Guérin

BMRC British Medical Research Council

EMEFs Escolas Municipais de Ensino Fundamental

EMEls Escolas Municipais de Ensino Infantil

EUA Estados Unidos da América

HH Hipótese da Higiene

IgE Imunoglobulina E

ISAAC International Study of Asthma and Allergies in Childhood

NAE-12 Núcleo de Ação Educativa 12

NHLI National Heart and Lung Institute

OR Odds Ratios ou Razão das Chances

QC Questionário Complementar

QE Questionário Escrito ISAAC

TAFQ Asthma Foundation of Tasmânia Questionnaire

TCHI Teste cutâneo de hipersensibilidade imediata

TCLE Termo de Consentimento Livre e Esclarecido

Th-1 Linfócitos T helper 1

Th-2 Linfócitos $\mathrm{T}$ helper 2

VQ Vídeo-Questionário ISAAC 


\section{LISTA DE TABELAS, QUADRO E FIGURAS}

Tabela 1 Distribuição dos alunos de 6 a 7 anos nas escolas participantes, número de alunos incluídos, distrito de localização e percentagem de participação de cada escola

Tabela 2 Número de alunos participantes da segunda fase do projeto, distribuição por escola em relação ao preenchimento do QE e QC e percentual de resposta para o QC

Tabela 3 Prevalência dos sintomas de Asma (\%), segundo o sexo, em 3312 escolares de 6 a 7 anos, na região oeste da cidade de São Paulo ......

Tabela 4 Prevalência encontrada nos QE devolvidos, QE não devolvidos e prevalência corrigida final dos sintomas de Asma (\%) em escolares de 6 a 7 anos, na região oeste da cidade de São Paulo

Tabela 5 Prevalência da associação de sintomas de rinite e eczema com a presença de sibilos no último ano em 3312 escolares de 6 a 7 anos na região oeste da cidade de São Paulo.

Tabela 6 Análise Univariada dos fatores de risco do Questionário Complementar (QC) para presença ou não de Asma, respectivas

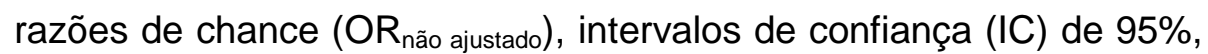
nível de significância $(p)$, total de asmáticos expostos, seus percentuais e a amostra para cada fator analisado

Tabela 7 Fatores de risco relacionados à positividade da questão 2 sobre Asma, incluídos na análise multivariada, com seus $\mathrm{OR}_{\text {não ajustados }}$

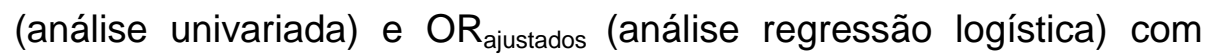
respectivos intervalos de confiança (IC95\%) e nível de significância $(p)$..... 


\section{LISTA DE TABELAS, QUADRO E FIGURAS}

Quadro 1 Características demográficas e sócio-econômicas dos distritos Butantã, Vila Sônia, Raposo Tavares, Itaim Bibi, Jaguaré, Morumbi, Pinheiros e Rio Pequeno do Município de São Paulo, incluídos no estudo ISAAC região oeste de São Paulo, na faixa etária de 6 a 7 anos

Figura 1 Diagrama de distribuição das respostas afirmativas às questões 2 em relação aos sintomas de asma, rinite e eczema e suas associações em 3312 escolares de 6 a 7 anos, na região oeste da cidade de São Paulo

Figura 2 Análise multivariada dos fatores de risco relacionados à prevalência de asma através da resposta afirmativa para sibilos no último ano $\left(\mathrm{OR}_{\text {ajustados, }}\right.$ IC $95 \%$ e $\left.p\right)$ 


\section{LISTA DE ANEXOS}

ANEXO A Carta de oficialização do Registro do centro 072014 com a denominação São Paulo West no ISAAC International Data Centre ..

ANEXO B Questionário Escrito (QE) do estudo ISAAC aplicado aos 3312 alunos de 6 a 7 anos incluídos no estudo - páginas 1 e 2

ANEXO C Questionário Complementar (QC) aplicado em 561 alunos incluídos no estudo - páginas 1 a 4

ANEXO D Mapa da cidade de São Paulo com sua distribuição de acordo com os núcleos de ação educativa (NAE) - Secretaria de Educação. Na ampliação a localização da NAE 12 - Bairros da região oeste, distribuição das escolas municipais de ensino fundamental (EMEFs), escolas municipais de ensino infantil (EMEls) e localização das favelas de cada bairro

ANEXO E Escolas pertencentes a NAE-12 que não participaram do estudo ISAAC

ANEXO F Carta aos diretores das escolas pertencentes a NAE-12 participantes do estudo ISAAC

ANEXO G Termo de Consentimento Livre e Esclarecido - TCLE resumido

ANEXO H Carta de orientação aos pais dos alunos que apresentaram respostas sugestivas de doenças alérgicas no estudo ISAAC, com os endereços dos serviços médicos mais próximos para atendimento especializado

ANEXO I Carta de aprovação na Comissão de Ética para Análise de Projetos de Pesquisa - CAPPesq da Diretoria Clínica do Hospital das Clínicas e da Faculdade de Medicina da Universidade de São Paulo

ANEXO $\mathbf{J}$ Termo de Consentimento Livre e Esclarecido - TCLE

ANEXO K Distribuição das respostas às questões de número 2 dos módulos de asma, rinite e eczema e suas associações em 3312 escolares de 6 a 7 anos na região oeste da cidade de São Paulo

ANEXO L Análise Univariada (Tabelas 2x2) dos fatores de risco incluídos na análise multivariada $(p<0,2)$ em relação à presença ou não de asma, com respectivos $\mathrm{OR}_{\text {não ajustado, }} \mathrm{IC} 95 \%$ e $p$. O percentual (\%) referem-se ao valor total da amostra 


\section{RESUMO}

Casagrande, RRD. Avaliação da prevalência de asma e dos fatores de risco associados em escolares de 6 a 7 anos na região oeste da cidade de São Paulo [dissertação]. São Paulo: Faculdade de Medicina, Universidade de São Paulo;2005. 132p.

INTRODUÇÃO: O aumento da prevalência da asma nos últimos anos, em muitos países, tem sido associado a vários fatores de risco. A avaliação da prevalência de asma e dos fatores de risco em diferentes locais, são essenciais para melhorar o conhecimento sobre esta doença. $\mathrm{O}$ protocolo padronizado ISAAC (International Study of Asthma and Allergies in Childhood), possibilitou a comparação destes dados epidemiológicos em diferentes regiões. Os OBJETIVOS deste estudo foram: avaliar a prevalência da asma e sintomas relacionados entre escolares de 6 a 7 anos, na região oeste da cidade de São Paulo, utilizando-se o questionário escrito ISAAC e identificar possíveis fatores de risco associados à presença de asma nesta mesma população. MÉTODOS: Entre fevereiro de 2002 e outubro de 2003, 3312 pais ou responsáveis por crianças de 6 a 7 anos, na região oeste da cidade de São Paulo, responderam ao questionário escrito ISAAC. Após amostragem sistemática, 561 pais responderam a um questionário complementar sobre antecedentes familiares e condições ambientais. Foram constituídos grupos de alunos com ou sem asma, considerando-se a presença de sintomas de sibilos nos últimos 12 meses. A análise dos fatores de risco foi realizada pelo teste do qui-quadrado ou teste exato de Fisher e por regressão binária logística (Backward Stepwise). Após obtenção dos primeiros resultados, efetuou-se nova análise incluindo uma 
amostra dos pacientes que não haviam devolvido o questionário, sendo estes novos resultados considerados na análise final RESULTADOS: As prevalências encontradas foram: asma $24,4 \%$, diagnóstico médico de asma $5,7 \%$ e sintomas relacionados à gravidade da asma, como limitação da fala em $9,2 \%$ e distúrbio do sono em $17,4 \%$. Houve associação entre asma e rinite em $14,5 \%$ dos escolares e entre asma, rinite e eczema em $3,8 \%$. A prevalência da asma foi maior em meninos. Após a análise de regressão logística, os seguintes fatores de risco associados à asma permaneceram significantes : sintomas de rinoconjuntivite no último ano $\left(\mathrm{OR}_{\mathrm{ajustado}}=2,4\right)$; sexo masculino $\left(\mathrm{OR}_{\text {ajustado }}=2,4\right)$; mãe fumante no primeiro ano de vida da criança $\left(\mathrm{OR}_{\mathrm{ajustado}}=2,0\right)$; e presença de eczema em locais característicos $\left(\mathrm{OR}_{\text {ajustado }}=3,0\right)$. CONCLUSÕES: A prevalência de asma neste estudo mostrou valores mais elevados que o diagnóstico médico de asma. A prevalência de sintomas que demonstram a gravidade da asma, através das questões sobre limitação da fala e distúrbio do sono, também apresentaram elevada prevalência, semelhante aos centros de maiores prevalências de gravidade do estudo ISAAC. Houve predomínio do sexo masculino na maioria das questões sobre asma. Os fatores de risco associados à asma foram: rinoconjuntivite no último ano, sexo masculino, mãe fumante no primeiro ano de vida da criança e presença de eczema em locais característicos.

Descritores: asma, epidemiologia, fatores de risco, infância, escolares. 


\section{SUMMARY}

Casagrande, RRD. Evaluation of the asthma prevalence and associated risk factors in school children from 6 to 7 years in the west area of the city of São Paulo [dissertation]. São Paulo: Faculdade de Medicina, Universidade de São Paulo; 2005. 132p.

INTRODUCTION: The increase of asthma prevalence in the last years, in many countries, has been associated to several risk factors. The evaluation of asthma prevalence and the risk factors in different places are essential to improve the knowledge about this disease. The protocol standardized by "International Study of Asthma and Allergies in Childhood" - ISAAC, allowed the comparison of epidemiologic data in different regions. The aims of the present study were: to evaluate the prevalence of asthma and related symptoms, among students from 6 to 7 years in the west area of São Paulo city, through the standardized ISAAC's written questionnaire and to identify possible risk factors associated to asthma in this population. METHODS: In the period from February/2002 to October/2003, 3312 student's parents or guardians from 6 to 7 years old children, in the west area of São Paulo city, answered the ISAAC's written questionnaire. After selection by systematic samples, 561 parents answered a complementary questionnaire about family history and environmental conditions. The students' groups were constituted by students with or without asthma according the positive answer to asthma symptoms in the last 12 months. The risk factors analysis was accomplished by chi-square or Fisher' exact test and by binary logistic regression (Backward Stepwise). After the first results, a new analysis was done, including a sample of patients which questionnaires were not returned, being 
these new results considered to final analysis RESULTS: The prevalences founded were: asthma $24.4 \%$, medical diagnosis of asthma $5.7 \%$ and symptoms related to asthma severity as speech difficulties in $9,2 \%$ and sleep disturbance in $17,4 \%$. There was association between asthma and rhinitis in $14,5 \%$ of students, and among asthma, rhinitis and atopic eczema in $3,8 \%$. The prevalence of asthma was higher among boys. After the multivariated analysis, the following risk factors remained significantly associated with asthma were: rhinoconjunctivitis in the last year (ORadjusted $=$ 2,4 ); male gender (ORadjusted $=2,4$ ); mother smoking in the first year of child's life (ORadjusted $=2,0)$; eczema in characteristic areas (ORadjusted $=3,0$ ). CONCLUSIONS: The prevalence of asthma in this study was higher than the medical diagnosis. The prevalence of symptoms related to severe asthma including to difficulties of speech and sleep disturbance, is similar to other centers with high prevalence to asthma severity according ISAAC study. The male gender predominated in the majority positive responses regarding asthma. The risk factors associated with asthma were: rhinoconjunctivitis in the last year, male gender and mother smoking in the first year of child's life. eczema in characteristic areas

Descriptors: asthma, epidemiology, risk factors, infancy, students 
1. INTRODUÇÃO 


\section{INTRODUÇÃO}

A asma é uma das doenças crônicas mais comuns da infância, com estudos realizados em diversos países demonstrando aumento em sua prevalência, em várias partes do mundo, nas últimas décadas. ${ }^{1}$ Esse aumento vem estimulando a realização de grande número de estudos epidemiológicos transversais na tentativa de descrever os padrões da doença, assim como identificar possíveis fatores de risco a ela associada, e com isso determinar possíveis ações de prevenção.

Weitzman M et al. ${ }^{2}$, em 1992, avaliaram através de questionários as mudanças na prevalência de asma em crianças de zero a 17 anos nos Estados Unidos da América (EUA), entre os anos de 1981 ( $n=15224)$ e 1988 ( $n=17110)$, observaram um aumento na prevalência de asma na população avaliada de $3,1 \%$ para $4,3 \%(p<0,0001)$, esse aumento foi semelhante em crianças e adolescentes, não havendo diferenças entre os sexos. Sly et al. ${ }^{3}$, em 1999, avaliaram a prevalência de asma e rinite alérgica, a partir de 1978, em estudos populacionais realizados nos EUA, e concluíram que entre os anos de 1980 e 1994 ocorreu um aumento na prevalência de asma de 3,1\% para $5,4 \%$, ressaltando que este fenômeno foi observado, principalmente, na população mais pobre residente nas grandes cidades.

Heinrich et al. ${ }^{4}$ analisaram a prevalência de asma, rinite e eczema em crianças de cinco a 14 anos de idade, residentes no leste da Alemanha unificada durante a década de noventa, utilizando questionários respondidos 
pelos responsáveis, e observaram um aumento na prevalência de asma de 2,6\% em 1992/1993 para 3,5\% em 1995/1996 e 4,8\% em 1998/1999.

$\mathrm{Na}$ Austrália, em Wagga Wagga, Downs et al. ${ }^{5}$ descreveram as mudanças na prevalência de sibilância e diagnóstico de asma entre os anos de 1982 e 1997, em crianças de oito a 11 anos, através de questionários preenchidos por seus pais, observando um aumento na prevalência de asma de 12,9\% em 1982 para 38,6\% em 1997. Nesse mesmo período, a prevalência de sibilos no último ano também aumentou de 15,5\% para 27,2\%. Em relação à gravidade da asma, 5,2\% das crianças em 1982 apresentavam quatro crises ou mais no último ano, enquanto em 1997 esse número cresceu para $16,9 \%$.

Nystad et al. ${ }^{6}$ avaliaram a prevalência de asma em Oslo na Noruega em escolares de seis a 16 anos, através de questionários respondidos por seus responsáveis, entre os anos de 1981 e 1994, e observaram um aumento de três vezes na prevalência de asma nesses 13 anos (3,4\% versus 9,3\%), além do aumento na prevalência de sibilos no último ano e no diagnóstico médico de asma.

Na Suécia, estudando a prevalência de asma na cidade de Sundsvall, em escolares entre sete e 16 anos, Braback et al. ${ }^{7}$ observaram aumento significante de 4,8\% em 1985 para 6,9\% em 1995.

Em Patras, na Grécia, Anthracopoulos et al. ${ }^{8}$ avaliaram a prevalência de asma, nos anos de 1978, 1991 e 1998, incluindo nesse estudo escolares do terceiro e quarto anos do ensino primário, e observaram um aumento 
crescente e significante na prevalência de asma, de 1,5\% em 1978, para 4,6\% em 1991 e 6,0\% em 1998.

Em Roma, na Itália, Ronchetti et al. ${ }^{9}$ avaliaram escolares entre seis e 14 anos, nos anos de 1974, 1992 e 1998, através de questionários respondidos pelos pais e observaram um aumento significante na prevalência de asma de 5,5\% em 1974 para 12,2\% em 1992, sendo que esta se manteve estável até 1998.

Outros estudos epidemiológicos mais recentes e descritos a seguir, demonstraram uma certa estabilização na prevalência de asma.

Zollner et al. ${ }^{10}$ avaliaram as tendências temporais entre 1992 e 2001, em escolares de nove a 11 anos, através do relato dos responsáveis, em três regiões do sudoeste da Alemanha e concluíram que nesses nove anos não foi observado aumento na prevalência de asma e sibilância, sugerindo que houve uma estabilidade neste período.

Nos EUA, em Seattle, Carter et al. ${ }^{11}$, avaliando estudantes do ensino médio com idade média de 13 anos, através da aplicação de questionários, constataram que ocorreu um declínio na prevalência de asma entre 1995 e 2003, de 12,0\% para 6,2\%; e em relação ao diagnóstico médico de asma, no entanto houve um aumento de $3,0 \%$ para $6,2 \%$, nesta mesma população.

Getahun et al. ${ }^{12}$, também avaliando o período de 1995 a 2002 nos EUA observaram que houve uma diminuição nas taxas de hospitalização e mortalidade por asma.

Robertson et al. ${ }^{13}$, na Austrália, avaliaram as mudanças na prevalência de asma, rinite e eczema em escolares de seis a sete anos na cidade de 
Melbourne, entre os anos de 1993 e 2002. Estes autores observaram uma redução de $26 \%$ na prevalência de asma no período.

Apesar da vasta literatura existente sobre epidemiologia da asma, os estudos são, em sua maioria, americanos e europeus. No Brasil, poucos estudos foram desenvolvidos,sendo alguns citados a seguir:

Carrasco $^{14}$, em 1987, publicou dados relativos à prevalência de asma na América Latina utilizando estatísticas do Uruguai, Peru, Chile, Argentina, Venezuela, México e Brasil, e observou grandes variações, desde 0,4\% no Peru até $4,3 \%$ no Brasil.

Ramos et al. ${ }^{15}$, no Brasil, em 1983, avaliaram 3353 pacientes residentes no município de Ribeirão Preto, com sintomas sugestivos de asma e com idade superior a três anos, através de questionário padronizado respondido pelos responsáveis e observaram uma prevalência de asma de $2,4 \%$ em meninos e $3,4 \%$ em meninas.

Em Botucatu, interior de São Paulo, Carandina ${ }^{16}$ descrevendo a prevalência de sintomas sugestivos de doenças respiratórias crônicas na população urbana, através de questionário de doenças respiratórias "American Thoracic Society - Division of Lung Disease -78" (ATS-DLD-78), observou que a asma ocorreu em 5,3\% dos indivíduos avaliados, especialmente entre os menores de 15 anos.

Braga et al. ${ }^{17}$, utilizando questionário padronizado em escolares de cinco cidades do estado de São Paulo (Catanduva, Fernandópolis, São José do Rio Preto, Presidente Prudente e São Paulo), entre os anos de 1994 e 1995, observaram uma prevalência média de asma de 15,9\%, com menores 
taxas em Catanduva $(7,7 \%)$ e maiores taxas em São José do Rio Preto $(20,0 \%)$.

Em Curitiba, Paraná, a prevalência de atendimentos por asma em crianças acompanhadas em ambulatório geral de pediatria foi de 5,0\% em 1986. ${ }^{18} \mathrm{Na}$ mesma cidade, em 1993, Ferrari et al. ${ }^{19}$ constataram que os atendimentos por asma corresponderam a $11,9 \%$ de todas as consultas realizadas no serviço de urgência pediátrica. .

Fritscher et al. ${ }^{20}$, em 1995, realizaram estudo em escolares de 10 a 18 anos em três escolas de Porto Alegre, através de entrevistas, e demonstraram prevalência de asma de $16,5 \%$, observando um aumento na prevalência da asma nessa região, quando comparada à prevalência de $6,7 \%$ observada anteriormente.

Dados nacionais também indicam que a mortalidade por asma, apesar de ser baixa, vem aumentando no Brasil, nos últimos anos. No estado de São Paulo, na faixa etária de cinco a 34 anos, as taxas de mortalidade dobraram entre 1970 e 1996, principalmente em maiores de 15 anos, sendo a cidade de São Paulo responsável pela maior parte deste aumento ${ }^{21}$. 


\subsection{Métodos epidemiológicos para estudo de doenças alérgicas e o estudo ISAAC - International Study of Asthma and Allergies in Childhood}

A falta de uma definição para a asma, que seja amplamente aceita em estudos epidemiológicos, e a ausência de uma padronização dos instrumentos utilizados para o seu diagnóstico têm dificultado sua avaliação. Para a análise da prevalência da asma ao longo do tempo, os estudos epidemiológicos devem ser repetidos pelo menos em dois momentos distintos, empregando-se o mesmo instrumento de diagnóstico, na mesma faixa etária e na mesma região geográfica. ${ }^{22}$

Nas últimas décadas, os instrumentos mais utilizados em estudos epidemiológicos sobre asma foram os questionários aplicados à população por um entrevistador treinado ou respondidos pelo próprio entrevistado.

A partir da década de 60, foram criados diferentes questionários: "Asthma Foundation of Tasmânia Questionnaire (TAFQ)", o do "British Medical Research Council (BMRC)", o do "National Heart and Lung Institute (NHLI Questionnaire)" e o da "American Thoracic Society - Division of Lung Disease (ATS-DLD)" validados pela prova de função pulmonar, e elaborados para a aplicação em diferentes localidades. ${ }^{23-25}$ Devido ao seu baixo custo, fácil execução e boa cooperação por parte dos indivíduos investigados, os questionários tornaram-se o instrumento mais utilizado em epidemiologia das doenças respiratórias, representando uma ferramenta muito conveniente para análise de grandes amostras populacionais. 
Com o objetivo de padronizar um método de investigação epidemiológica das doenças alérgicas na infância, foi criado em 1991, na Austrália, o "International Study of Asthma and Allergies in Childhood (ISAAC)", permitindo assim, comparações entre diferentes regiões, com a utilização de um método único e padronizado. ${ }^{26}$

O ISAAC utiliza um questionário escrito (QE) e um vídeo-questionário (VQ) onde são avaliados os sintomas relacionados à asma, rinite e eczema atópico. Seus principais pontos de interesse são: 1) Descrever a prevalência e gravidade de asma, rinite e eczema em crianças, em diferentes centros, e realizar comparações intra e entre países; 2) Obter medidas iniciais para avaliação de futuras tendências na prevalência e gravidade dessas doenças; 3) Fornecer dados epidemiológicos para futuras pesquisas em genética, fatores ambientais e cuidados médicos que possam afetar estas doenças. ${ }^{26}$

O primeiro estudo piloto do ISAAC foi realizado por Pearce et al. ${ }^{27}$, em 1991, que aplicaram o QE e o VQ em escolares de 12 a 15 anos, em cinco regiões de quatro países: Adelaide $(n=1428$ alunos $)$ e Sidnei $(n=1519)$ na Austrália; West Sussex $(n=2097)$ na Inglaterra; Bochum $(n=1928)$ na Alemanha e Wellington $(n=1863)$ na Nova Zelândia. O estudo foi conduzido para comparar as respostas entre o VQ e o QE e avaliar a possibilidade do seu uso em diferentes culturas, assim como para obter algumas informações preliminares sobre as diferenças internacionais na prevalência de sintomas de asma nas crianças. 
O QE se mostrou de fácil aplicação, sendo posteriormente validado em vários países, confirmando sua aplicabilidade e reprodutibilidade, e passando a ser utilizado em todo o mundo, inclusive no Brasil. ${ }^{28}$

O QE também foi traduzido para diferentes línguas; sua metodologia recomenda uma amostra de 3000 crianças de seis a sete anos e outra de 3000 adolescentes entre 13 e 14 anos, devendo ser o questionário respondido pelos pais das crianças menores ou pelos próprios adolescentes. ${ }^{26} \mathrm{O}$ VQ foi aplicado em alguns países, não compulsoriamente, apenas no grupo de 13 a 14 anos, não sendo aplicado no Brasil por não estar validado até o momento.

O QE, originalmente em inglês, foi traduzido para o português pelo Dr. Renato T. Stein, pneumologista pediátrico, e a tradução conferida por sua versão para o inglês ("back translation"). Posteriormente, o autor do estudo fez a comparação entre as questões do questionário original e as questões correspondentes traduzidas para o inglês e julgou que não houve mudanças significativas no sentido das questões originais. ${ }^{29}$

O QE para idade de 6 a 7 anos inclui oito questões sobre asma (módulo 1), seis sobre rinite (módulo 2) e sete sobre eczema atópico (módulo 3).

Para asma, tem sido sugerido que a questão referente à sibilância nos últimos 12 meses é a mais sensível para o seu diagnóstico; para rinite, a associação entre as respostas sobre sintomas nasais e sintomas oculares nos últimos 12 meses mostrou-se de alto valor preditivo positivo; e as questões referentes a sintomas de eczema e localização típica em dobras no últimos 12 meses aumentam muito a especificidade para eczema atópico. ${ }^{30}$ 
O Estudo ISAAC foi elaborado para ser realizado em três fases, descritas a seguir:

A Fase I teve como objetivo descrever a prevalência de asma, rinite e eczema atópico, cujo rationale, metodologia e os questionários utilizados foram descritos no Manual da Fase ${ }^{30}$ e também por Asher et al. ${ }^{25}$, sendo concluída em 193 centros de 79 países nas duas faixas etárias (6-7 e 13-14 anos de idade). Na faixa etária de 6 a 7 anos, a prevalência de sibilos nos últimos 12 meses variou de 4,1\% na Indonésia a 32,1\% na Costa Rica, permanecendo a prevalência global em 11,8\%. Para asma alguma vez, a prevalência foi semelhante à de sibilos (10,2\%), também com grande variação, 1,4\% na Estônia e 27,1\% na Austrália. De modo geral, as menores prevalências de sibilos no último ano foram encontradas na Ásia $(9,6 \%)$ e as maiores na América Latina (19,6\%) e Oceania $(24,6 \%) .{ }^{30,31}$

Na América Latina, nove países participaram da Fase I do estudo ISAAC com 17 centros envolvidos, englobando as duas faixas etárias 6/7 anos e 13/14 anos, sendo sete centros no Brasil, possibilitando a comparação da prevalência da asma entre os diferentes países. Em relação à faixa etária de 6 a 7 anos, foram analisados 36.264 pacientes pertencentes a 13 centros, demonstrando uma variação da prevalência de sibilos nos últimos 12 meses de 8,6\% em Cuernavaca no México, para 32,1\% na Costa Rica. A cidade de São Paulo apresentou a quinta maior prevalência de sibilos no últimos 12 meses $(21,3 \%)$ e a maior prevalência de sibilos alguma vez $(49,3 \%)$. As menores prevalências de asma foram encontradas em centros com altos níveis de poluição atmosférica, e as maiores prevalências, 
em regiões com altos níveis de infestação parasitária gastrintestinal e alto índice de infecção respiratória aguda na infância, sugerindo que estes fatores, considerados como protetores em outras regiões, não apresentaram o mesmo efeito na América Latina. ${ }^{32}$

Em relação ao Brasil, a Fase I do ISAAC foi realizada em seis cidades: Porto Alegre (RS), Curitiba (PR), São Paulo (SP), Uberlândia (MG), Itabira (MG) e Recife (PE). Os resultados encontrados para a questão de sibilos nos últimos 12 meses na faixa etária de 6 a 7 anos variaram de 16,1\% em Itabira a $27,8 \%$ em Recife, sendo a prevalência média de $20,9 \% .{ }^{33}$

Em São Paulo, a Fase I foi aplicada em 1995, em escolas públicas e privadas, por Solé e cols. na região centro - sul da cidade. Para a faixa etária de 6 a 7 anos, a prevalência de sibilos nos últimos 12 meses foi de 21,3\% com apenas $6,1 \%$ dos escolares tendo o diagnóstico prévio de asma, o que pode demonstrar o desconhecimento ou sub-diagnóstico desta doença nesta população. Sinais de gravidade da asma, como alterações do sono pelo menos uma noite por semana, foram encontrados em $12,9 \%$ das crianças avaliadas. ${ }^{34}$

No Brasil, o módulo 1 do QE sobre asma foi validado por Solé et al. ${ }^{35}$ em 1998; a validação do módulo 2 de rinite ocorreu em 2001 por Vanna et al. ${ }^{36}$;e o módulo 3 de eczema foi validado por Yamada et al. ${ }^{37}$ em 2002.

A Fase II iniciou-se em 1998 e esta fase foi projetada para investigar a importância relativa de hipóteses de interesse que surgiram da Fase I.

Na Fase II foram incluídos, além dos QE, questionários sobre fatores de risco (questionário complementar - QC) e tratamento médico de asma, rinite 
e eczema, exame da pele, testes cutâneos de hipersensibilidade imediata (TCHI), testes de broncoprovocação, dosagem de Imunoglobulina E (IgE) total e específica e quantificação dos ácaros e endotoxinas na poeira doméstica, além de validar o questionário escrito, como descrito no Manual da Fase $1 .^{38}$

A Fase II do estudo ISAAC foi iniciada e concluída em 36 centros de 22 países, sendo 25 centros na Europa: Albânia, Estônia, França (6 centros), Alemanha (2 centros), Grécia (2 centros), Itália, Islândia, Holanda, Noruega, Portugal, Espanha (4 centros), Suécia, Turquia e Inglaterra. Os demais 11 centros estão localizados em 8 países: Brasil, China (3 centros), Equador, Geórgia, Ghana, Índia (2 centros), Oman e Nova Zelândia.

A validação construtiva do módulo asma, utilizando o teste de broncoprovocação com metacolina, foi realizada no Brasil por CameloNunes et al. ${ }^{39}$

A Fase III foi elaborada aplicando-se a mesma metodologia utilizada na Fase I, examinando as tendências temporais na prevalência e gravidade da asma, rinite e eczema atópico nos centros que participaram da primeira fase, incentivando a participação de "novos" centros, e obtendo uma visão mais global da prevalência destas doenças. A Fase III é uma parte crucial do processo pelo qual podem ser entendidas a extensão, natureza e causas dos aumentos globais na prevalência destas doenças alérgicas, pois além de poder determinar as tendências nas prevalências de asma, rinite e eczema atópico, permite também observar se essas tendências são uniformes no mundo, além de identificar fatores que podem ser relacionados 
a estas tendências, sendo sua metodologia descrita Ellwood et al. ${ }^{40}$ no Manual da Fase $\mathrm{III}^{41}$ e em 2005.

Na América do Sul, a Fase III iniciou em 2001 com mais de 40 centros participantes em 9 países, sendo que 16 centros estão repetindo a Fase I e foram considerados Fase III A e os demais centros iniciaram sua inclusão no estudo ISAAC sem a realização da Fase I, sendo considerados como Fase III B (Anexo A).

\subsection{Hipótese da Higiene e Fatores de risco para asma}

Nos últimos 30 anos, a prevalência de asma vem aumentando em proporções epidêmicas em países desenvolvidos, principalmente na infância. Evidências indicam que fatores ambientais atuando no início da vida e sua interação com genes específicos para atopia seriam os eventos chaves para o desenvolvimento de uma doença crônica e persistente como a asma. $^{42}$

Vários estudos vêm demonstrando o papel da poluição, mudanças dietéticas, maior exposição alergênica e melhores condições de higiene, como fatores responsáveis pelo aumento na prevalência da asma. ${ }^{43-46}$

A teoria que relacionou condições de higiene e desenvolvimento de doenças alérgicas foi elaborada inicialmente por Strachan, em 1989. Este autor observou que determinadas infecções em lactentes jovens, transmitidas pelo contato com irmãos mais velhos ou adquiridas durante a 
gestação, poderiam prevenir o desenvolvimento de doenças alérgicas. Tal teoria ficou conhecida como Hipótese da Higiene $(\mathrm{HH}) .{ }^{47}$

A Hipótese da Higiene propõe que o estilo de vida ocidental, que reduz a exposição a microorganismos, facilitaria a resposta atópica, devido a um desbalanço do sistema imunológico com maior tendência para resposta dos linfócitos $\mathrm{T}$ helper 2 (Th-2), conseqüente $\operatorname{lgE}$ e desencadeamento da inflamação alérgica.

A partir dos anos 90, a Hipótese da Higiene foi discutida em inúmeras publicações, sendo algumas delas destacadas a seguir.

Matricardi et al. ${ }^{48}$, em 1997, demonstraram a relação inversa entre atopia e presença de anticorpos contra hepatite $\mathrm{A}$ em um grupo de militares italianos. O mesmo autor, em 2000, demonstrou que asma e rinite alérgica estavam inversamente relacionadas a infecções de transmissão orofecal (Toxoplasma gondii, Helicobacter pylori e vírus Hepatite A), sugerindo que infecções do trato gastrintestinal pudessem influenciar a resposta imune de mucosa, afetando também a resposta a alérgenos inalados e os níveis de reatividade imune do nariz e brônquios. ${ }^{49}$

A relação inversa entre atopia e reatividade à tuberculina, através do teste cutâneo de hipersensibilidade tardia, foi demonstrada por Shirakawa et al. ${ }^{50}$ Esses autores, avaliando escolares japoneses, verificaram que sintomas de asma e sensibilização alérgica foi significantemente menor nos indivíduos com teste tuberculínico positivo em comparação com aqueles cujo teste foi negativo. 
Alm et al. ${ }^{51}$, na Suécia, demonstraram que a simples imunização com BCG após o nascimento não afetava a prevalência de doenças alérgicas na idade escolar.

Infecções adquiridas precocemente na infância teriam um efeito protetor no desenvolvimento de doenças alérgicas como asma, conforme demonstrado por Shaheen et al. ${ }^{52}$,Martinez et al. ${ }^{53}$ e Illi et al. ${ }^{54}$, talvez devido a um estímulo do sistema imunológico para uma resposta dos linfócitos $T$ helper 1(Th-1). Por outro lado, infecções instaladas após a sensibilização alérgica funcionariam como fatores de risco para atopia, sugerindo existir uma uma correlação entre época da exposição e risco ou proteção para atopia.

Outros estudos associaram famílias mais numerosas ${ }^{55-56}$, presença de número elevado de irmãos ${ }^{57}$ e frequência em creche em idade precoce ${ }^{58}$ como fatores de proteção para desenvolvimento de doenças alérgicas, confirmando a hipótese descrita acima.

Viver em fazendas também se mostrou fator de proteção em relação à asma como foi encontrado por Braun-Fahrlander et al. ${ }^{59} \mathrm{e}$ Von Ehrenstein et al. ${ }^{60}$. O estilo de vida nas fazendas difere do estilo de vida urbano em vários aspectos como: famílias mais numerosas, contato maior e mais precoce com animais e diferentes hábitos dietéticos como consumo de leite não pasteurizado. Uma das hipóteses para relacionar ambientes de fazenda e proteção para doenças atópicas seria a exposição a maiores concentrações de produtos bacterianos tais como endotoxinas e lipopolissacarídeos que 
podem estimular o sistema imunológico, favorecendo uma resposta do tipo Th-1.

As diferenças no tipo de flora intestinal entre atópicos e não atópicos também foram investigadas por Sepp et al. ${ }^{61}$ e Bjorksten et al. ${ }^{62}$ que compararam lactentes residentes na Estônia, país com baixa prevalência de atopia, com grupo semelhante da Suécia, país com alta prevalência de atopia. Nos lactentes estonianos houve um predomínio de lactobacilos e bifidobactérias na flora fecal, nos lactentes suecos houve predomínio de clostrídios e outros anaeróbios.

Os hábitos alimentares das sociedades ocidentais também foram modificados nas últimas décadas e podem estar favorecendo a maior prevalência de atopia e asma, mas as evidências são ainda conflitantes. ${ }^{63,64}$

A menor ingestão de antioxidantes, especialmente frutas e vegetais, o aumento na dieta de ácidos graxos poliinsaturados dos óleos e margarinas e a redução da ingestão de ácidos graxos de cadeia longa presente nos peixes têm sido implicados no risco de atopia e asma. ${ }^{65,66}$

Outros fatores de risco para asma relacionados ao hospedeiro e ao ambiente, também extensamente discutidos na literatura, serão descritos a seguir:

Os fatores de risco relacionados ao hospedeiro são aqueles que predispõem o indivíduo ao desenvolvimento da asma, são eles: predisposição genética para o desenvolvimento de atopia, hiperresponssividade brônquica, sexo e raça. ${ }^{67}$ 
Vários estudos têm demonstrado que múltiplos genes podem estar envolvidos na patogênese da asma ${ }^{68}$ sendo os cromossomos 11,12 e 13 responsáveis por conter a grande maioria destes genes, podendo desta forma ter um papel importante no desenvolvimento de asma. ${ }^{69}$

O sexo masculino é um fator de risco para asma durante toda a infância, mas na adolescência esta tendência reverte. As justificativas para esta diferença seriam o menor tamanho das vias aéreas e fluxos pulmonares menores durante o primeiro ano de vida e hiperrreatividade brônquica mais evidente em meninos do que em meninas. ${ }^{70-73}$

A maioria dos dados indica que fatores socioeconômicos e ambientais são responsáveis pelas diferenças raciais na prevalência da asma. A prevalência de sibilância é a mesma em crianças de diferentes raças vivendo em Londres ou na Austrália. ${ }^{74}$ Nos Estados Unidos, a prevalência de asma é maior nos negros do que nos brancos, sendo este fato relacionado a condições de vida precárias por parte da raça negra. ${ }^{75}$

A história familiar positiva para doenças alérgicas tem sido freqüentemente associada a risco aumentado de atopia em crianças. Duffy et al. ${ }^{76}$ demonstraram a importância desta associação e concluíram que a presença de doença alérgica em um dos pais implica em $50 \%$ de chance da criança desenvolver alguma doença alérgica, enquanto que a presença de doença alérgica em ambos acarreta uma chance de $70 \%$. A presença de mais de uma manifestação alérgica nos pais além de determinar um risco maior para atopia nos filhos, pode implicar no desenvolvimento mais precoce dos sintomas. ${ }^{77}$ Alguns estudos, como o de Litonjua et al. ${ }^{78}$ demonstram 
que a história de asma materna está associada a maior risco para asma na criança.

Muitos pacientes atópicos iniciam seus sintomas na infância com eczema e evoluem para asma e rinite, sendo esta seqüência de manifestações clínicas denominada de marcha atópica. ${ }^{79}$ A rinite alérgica tem sido considerada um importante fator de risco para o desenvolvimento da asma em crianças e adultos. ${ }^{80-82}$ Peroni et al. ${ }^{83}$ utilizando o QE ISAAC demonstraram que a presença de rinite alérgica pode ser um fator de risco para asma em pré-escolares.

A dermatite atópica, também tem sido identificada como um fator de risco para o desenvolvimento da asma. ${ }^{84}$ Rhodes et al. ${ }^{85}$ avaliaram 100 famílias atópicas na Inglaterra, em um estudo longitudinal de 22 anos de seguimento, e observaram que eczema foi diagnosticado em $30 \%$ das crianças, sibilância em $5 \%$ e rinite em $3 \%$ no primeiro ano de vida e ao final do estudo, a asma estava presente em $40 \%$, rinite em $15 \%$ e eczema em $5 \%$ dos adultos.

Em relação aos fatores de risco para asma relacionados ao ambiente, ou seja, aqueles que influenciam a susceptibilidade para asma em indivíduos predispostos, merecem destaque: a exposição aos alérgenos e ao tabagismo, o aleitamento materno, o peso de nascimento e tipo de parto e as infestações parasitárias.

A sensibilização aos aeroalérgenos intradomiciliares (ácaros, cão, gato e baratas) parece ser mais importante que os extradomiciliares, para o desenvolvimento de asma. ${ }^{86,87}$ Estudos têm demonstrado que o risco do 
desenvolvimento de asma é maior nas crianças cujas casas têm altos níveis de alergénos relacionados aos ácaros durante os primeiros anos de vida. ${ }^{88}$

Em relação à exposição nos primeiros anos de vida aos animais de estimação, como cães e gatos, estudos correlacionam a exposição precoce com a redução no risco de sensibilização alérgica e menor prevalência de asma e rinite na idade escolar. ${ }^{89-91}$ Além disso, o alérgeno do gato pode ser um importante fator de risco para exacerbações da asma em indivíduos sensibilizados a este alérgeno. ${ }^{92}$

A exposição aos fungos intra-domiciliares tem sido considerado como fator de risco para asma, doenças atópicas e sintomas respiratórios em crianças. ${ }^{93}$ Downs et al. ${ }^{94}$ avaliaram 399 crianças com teste cutâneo de resposta imediata para um ou mais alérgenos e mediram as concentrações de Alternaria no ar dentro de casa; verificaram que episódios de sibilância e hiperrresponsividade brônquica aumentaram significantemente em associação com o aumento da concentração de esporos, sugerindo que a exposição a elevadas concentrações de fungos pode contribuir para o aumento da gravidade da asma.

Os efeitos do aleitamento materno no desenvolvimento da asma ainda permanecem em discussão. Gdalevich et al.$^{95} \mathrm{em}$ avaliação por metánalise encontraram um efeito protetor do leite materno, especialmente em famílias com história positiva de atopia $(\mathrm{OR}=0,52)$. Outros autores ao contrário têm demonstrado risco entre aleitamento materno e desenvolvimento de asma. $^{96,97}$ Enquanto que estudo desenvolvido em Tucson, Wright et al. ${ }^{98}$ 
descreveram que leite materno oferece proteção para sibilância em crianças $(\mathrm{OR}=0,45)$ apenas nos dois primeiros anos de vida.

Outro fator de risco importante para o desenvolvimento de asma na infância é o tabagismo materno durante a gestação, com vários estudos mostrando aumento dos níveis de lgE no sangue de cordão e redução na função pulmonar das crianças expostas. ${ }^{99,100}$ Noakes et al. ${ }^{101}$ demonstraram existir um aumento na produção de interleucina -13 pelas células do cordão de recém-nascidos de mães que fumaram durante a gestação em comparação com aqueles recém nascidos cujas mães nunca fumaram. Outro estudo realizado por Macaúbas et al. ${ }^{102}$ concluíram haver uma relação direta entre tabagismo materno durante a gestação e baixas concentrações de interleucina-4 e interferon-gama no sangue de cordão e relacionaram o tabagismo com aumento da sibilância aos seis anos de idade.

A exposição passiva da criança à fumaça do cigarro é outro fator relacionado com aumento na prevalência e gravidade da asma, e o risco parece ser maior quanto mais precoce e mais longa for a exposição. ${ }^{102} \mathrm{Em}$ um estudo prospectivo, Martinez et al. ${ }^{53}$ concluíram que o tabagismo materno foi o único fator de risco associado tanto aos lactentes sibilantes transitórios quanto aos persistentes. Na metánalise realizada por Cook et al. ${ }^{103}$, o tabagismo em ambos os pais determinou os maiores riscos para asma, seguido pelo tabagismo exclusivamente materno e depois pelo paterno. 
Em relação ao peso de nascimento, Chatkin e Menezes em 2005 revisaram a literatura e encontraram relação de risco entre peso menor de 2500 gramas e asma na maioria dos artigos avaliados. ${ }^{104}$

Quanto ao tipo de parto e sua influência no desenvolvimento da asma, especialmente o parto cesáreo, existem resultados conflitantes. Bager et al. ${ }^{105}$ na Dinamarca mostraram a associação entre parto cesáreo e risco para asma, assim como Xu et al. ${ }^{106}$, na Finlândia, em estudo com 1953 adultos, demonstraram forte associação entre adultos jovens asmáticos e parto cesáreo. Uma das hipóteses para tal associação seria uma menor estimulação e maturação do sistema imune em lactentes nascidos de parto cesáreo, evidenciada pela diferença na microflora intestinal. No entanto, outros autores como McKeener et al. ${ }^{107}$, em estudo realizado na Inglaterra com 24690 crianças, não encontraram relação entre este tipo de parto e aumento do risco para desenvolvimento de doenças alérgicas.

Larrick et al. ${ }^{108}$, em 1983, foram os primeiros autores a sugerir a relação inversa entre infestações parasitárias e a ocorrência de doenças atópicas, através da observação de altos níveis de lgE sérica e baixas taxas de atopia, em índios latino-americanos os quais apresentavam freqüentes parasitoses intestinais . Biggellaar et al. ${ }^{109}$ demonstraram a associação entre elevados níveis de interleucina 10, produzidas por células polimorfonucleares estimuladas pelos antígenos do parasita, e uma diminuição na resposta induzida por alérgenos. A ativação de citocinas anti-inflamatórias nas infestações crônicas por helmintos, parece ter um importante papel na 
imunomodulação e prevenção das doenças atópicas em populações cronicamente infectadas por helmintos. ${ }^{110}$

O conhecimento dos fatores responsáveis pelo aumento da prevalência da asma se faz necessários para a compreensão dos fenômenos biológicos e instituição de medidas de prevenção eficazes para o controle desta doença. Em especial no Brasil, essas pesquisas se revelam de importância, pelo desafio da coexistência entre alta prevalência de asma e precárias condições socioeconômicas. Com esse enfoque, esse estudo se propõe a avaliar a prevalência de asma, sintomas relacionados e fatores de risco em escolares de seis a sete anos residentes na região oeste de São Paulo. 
2. OBJETIVOS 


\section{OBJETIVOS}

1. Avaliar a prevalência de asma e sintomas relacionados entre escolares de 6 a 7 anos na região oeste da cidade de São Paulo, através do questionário escrito ISAAC.

2. Identificar possíveis fatores de risco associados à prevalência de asma nesta mesma população. 
3. CASUÍSTICA E MÉTODOS 


\section{CASUÍSTICA E MÉTODOS}

\section{1 Características da região oeste da cidade de São Paulo}

O município de São Paulo se constitui no terceiro maior conglomerado urbano do mundo, com cerca de 10 milhões de pessoas, numa área de 1509 $\mathrm{km}^{2}$, o município apresenta $870 \mathrm{~km}^{2}$ de área urbanizada onde vivem cerca de $65 \%$ da sua população. Possui altitudes de 720 a $850 \mathrm{~m}$, e sua topografia é marcada por variações desde planícies aluviais (várzeas), até colinas, morros, serras e maciços. Na região oeste da cidade de São Paulo, onde se concentrou esse estudo, encontram-se diferentes variações climáticas e topográficas, há menor dispersão de poluentes tanto pelas condições naturais, como pelo principal eixo rodoviário de fluxo pesado do município de São Paulo (marginais, rodovias Raposo Tavares e Régis Bitencourt), o que faz com que seja a área mais poluída da cidade. ${ }^{111,112}$

Os aspectos demográficos e sócio-econômicos e as características da população avaliada estão apresentadas no Quadro 1.

\section{2 Descrição do questionário escrito do ISAAC:}

O questionário escrito do ISAAC (QE) é constituído por um número mínimo de perguntas simples e objetivas, abordando sintomas cardinais, o que permite que seja auto-aplicável ou aplicado por entrevistador e reprodutível em várias nações ${ }^{30}$. O QE está dividido em três partes (Anexo B), sendo que para a idade de 6 a 7anos, o questionário 1 relativo à asma 
inclui oito questões, o questionário 2, relativo à rinite inclui seis questões e o questionário 3 , relativo ao eczema atópico inclui sete questões. As perguntas relativas à asma, rinite e eczema atópico são relacionadas aos sintomas de cada uma dessas patologias, sendo que a questão sobre a presença de sintomas nos últimos 12 meses é considerada a principal questão para a avaliação da prevalência, por reduzir os erros de memória e impedir a interferência dos fatores sazonais no mês de aplicação do estudo.

As justificativas para cada questão referente à asma, são as seguintes:

- Questão 1: “Alguma vez na vida seu filho teve sibilos (chiado no peito)?" foi baseada no "International Union Against Tuberculosis and Lung Disease (IUATLD) Bronquial Symptoms Questionnaire”, essa questão não usa, propositalmente, o termo "ataque" de sibilância para identificar crianças com sintomas persistentes, sendo considerada uma questão de muita sensibilidade.

- Questão 2: "Nos últimos 12 meses, seu filho teve sibilos (chiado no peito)?” Essa questão é considerada a de maior utilidade na avaliação da prevalência de asma, pois com a limitação do tempo para os últimos 12 meses, diminuem os erros de memória e torna-se independente do mês de preenchimento do questionário.

- Questão 3: “Nos últimos 12 meses, quantas crises de sibilos (chiado no peito) seu filho teve?” e Questão 4: “Nos últimos 12 meses, com que frequência seu filho teve seu sono perturbado por chiado no peito?" Essas questões quantificam a frequência dos episódios de sibilância. Problemas com o conceito de crises e dificuldades em 
quantificar a freqüência de asma recorrente fizeram com que a questão 4 fosse incluída para identificar e quantificar os pacientes com sibilos persistentes.

- Questão 5: "Nos últimos 12 meses o chiado do seu filho foi tão forte a ponto de impedir que ele conseguisse dizer mais de 2 palavras entre cada respiração?" O objetivo dessa pergunta é estimar a prevalência de crises agudas de asma grave, dado pouco encontrado em estudos epidemiológicos. É uma questão de relevância direta para comparações internacionais de admissões hospitalares e estatísticas de mortalidade.

- Questão 6: "Alguma vez na vida seu filho já teve asma?" Avalia se houve diagnóstico médico de asma.

- Questão 7: “Nos últimos 12 meses, seu filho teve chiado no peito após exercícios físicos?" Apesar de parecer uma continuação da questão 2, essa questão é capaz de identificar crianças com resposta negativa para sibilos nas questões 1 ou 2 .

- Questão 8: "Nos últimos 12 meses, seu filho teve tosse seca à noite, sem estar gripado ou com infecção respiratória?" Como tosse noturna é amplamente aceita como apresentação alternativa de asma, essa questão foi incluída para aumentar a sensibilidade geral do questionário. 


\section{3 Descrição do questionário complementar:}

Além do $\mathbf{Q E}$, foi elaborado um questionário complementar (QC) contendo 33 questões referentes a dados epidemiológicos como: dados do nascimento, amamentação, número de membros da família, admissão precoce em creche ou berçário, tipo de alimentação e exposição a agentes infecciosos e alergênicos, com a finalidade de avaliar a possível associação entre esses fatores e o desenvolvimento de asma (Anexo C). Este QC foi baseado no questionário complementar da Fase II do estudo ISAAC e modificado pelo Dr. Antonio Carlos Pastorino e Prof. Dr. Dirceu Solé (coordenador nacional do estudo ISAAC - Brasil), abrangendo fatores de risco relacionados à asma e atopia.

\section{4 Descrição dos fatores de risco relacionados à asma}

Os fatores de risco relacionados à asma (presença de sibilos no último ano) avaliados pelo QE foram: rinite isolada, rinoconjuntivite, dermatite atópica e presença de eczema em locais característicos. Para isso, foram selecionadas as seguintes questões:

- Rinite isolada: questão 2, Módulo rinite: "Nos últimos 12 meses o seu(a) filho(a) teve algum problema com espirros, coriza ou obstrução nasal quando não estava gripado ?" (na ausência de sintomas oculares).

- Rinoconjuntivite: questão 3, Módulo rinite: "Nos últimos 12 meses, esse problema nasal foi acompanhado por lacrimejamento ou coceira nos olhos?".

- Dermatite atópica: questão 2, Módulo eczema: "Nos últimos 12 meses, seu(a) filho(a) teve essas manchas na pele (eczema)?". 
- Eczema em locais característicos: questão 3, Módulo eczema: "Alguma vez essas manchas com coceira (eczema) afetaram algum dos seguintes locais: dobras de cotovelos, atrás dos joelhos, na frente dos tornozelos, abaixo das nádegas ou em volta do pescoço ou olhos?".

A presença dessas doenças foram consideradas como fatores de risco, sendo essas perguntas selecionadas, devido ao seu alto valor de sensibilidade e especificidade para o diagnóstico das doenças acima relacionadas. Em relação à variável rinite isolada, a positividade desta questão foi obtida quando a questão 2 módulo rinite era afirmativa e a questão 3 módulo rinite era negativa.

Em relação aos fatores de risco avaliados no QC, de um total de 63 variáveis, foram selecionadas aquelas de maior relevância na literatura, listadas a seguir:

- Dados Familiares: mãe e pai atópicos (asma, rinite alérgica ou eczema)

- Dados Pessoais: sexo masculino, peso de nascimento inferior a 2500 gramas, parto cesáreo, gemelaridade, ausência de sarampo,

- Fatores Ambientais: aleitamento materno por tempo inferior a seis meses, não admissão em creche, berçário ou jardim da infância, idade de admissão em creche, berçário ou jardim da infância maior ou igual há um ano, não ter irmãos mais velhos na família, ausência de divisão do quarto no primeiro ano de vida, presença de animais dentro de casa no primeiro ano de vida, presença de animais dentro de casa atualmente, presença de cão ou gato dentro de casa no primeiro ano de vida, presença de cão ou gato dentro de casa atualmente, mãe fumante durante a gestação, mãe 
fumante no primeiro ano de vida da criança, mãe fumante atualmente, outra pessoa fumante dentro de casa, umidade dentro da casa, ausência de peixe na dieta, ausência de frutas frescas na dieta, ausência de vegetais crus na dieta, presença de refrigerante na dieta de três a seis vezes por semana.

\subsection{Seleção das escolas e metodologia de aplicação dos questionários}

Para participação nesse estudo, optamos por trabalhar com as escolas públicas localizadas na área geográfica correspondente a região oeste da cidade de São Paulo, Regional do Butantã, que vem participando de diversos projetos de pesquisa e programas de Saúde Escolar desenvolvidos pela Seção de Assistência Comunitária do Instituto da Criança, o que facilitaria a adesão à pesquisa por parte dos pais ou responsáveis pelas crianças, assim como dos responsáveis das escolas.

Participaram do estudo escolas públicas municipais pertencentes ao Núcleo de Ação Educativa - NAE 12 (administração regional do Butantã), localizadas nos distritos Butantã, Vila Sônia, Raposo Tavares, Morumbi, Rio Pequeno, Alto de Pinheiros, Jaguaré e Itaim Bibi. O ISAAC padroniza um número mínimo de 10 escolas para que a amostra seja representativa. A Tabela 1 apresenta as escolas participantes do estudo, divididas em Escolas Municipais de Ensino Infantil (EMEls) e Escolas Municipais de Ensino Fundamental (EMEFs), o distrito onde estão localizados, os números de 
alunos de cada escola e o número de alunos que participaram do presente estudo.

A opção pela participação no estudo apenas de escolas municipais, baseou-se no fato de que a freqüência a estas escolas é feita de acordo com o endereço de moradia dos escolares, restringindo a pesquisa a uma determinada região. Além disso, essa região é caracterizada por incluir famílias moradoras em núcleos com condições de vida precárias como aglomerados urbanos, incluindo favelas. A distribuição das escolas por distritos, assim como as localizações das favelas estão apresentadas no Anexo D.

A faixa etária selecionada para o preenchimento do QE incluiu crianças de seis anos e um dia de vida até aquelas com sete anos, 11 meses e 29 dias. Essa idade é adotada na metodologia ISAAC por refletir os primeiros anos da infância, quando a asma é mais comum e os índices de consultas médicas são particularmente elevados. Nesta faixa etária, para a região geográfica estipulada, havia 52 escolas municipais, sendo escolhidas, por sorteio, 35 escolas. A inclusão da última escola ocorreu quando ultrapassamos o número de 3000 alunos exigidos pela metodologia do estudo ISAAC. A lista das escolas pertencentes à região oeste que não foram incluídas no estudo encontra-se no Anexo $E$. Previamente ao início do estudo, o pesquisador se reuniu com o coordenador da NAE-12 para explicar a metodologia e descrever os objetivos. Este, ciente das informações, enviou a todos os diretores das escolas pertencentes à área estudada, uma carta explicando os objetivos da pesquisa (Anexo F). Uma vez selecionadas as escolas, os diretores ou coordenadores educacionais foram contatados por telefone pelo pesquisador, e após autorizada a participação, foi feita uma reunião para a explicação do questionário e a entrega dos mesmos.

Em algumas escolas, como havia dúvidas a respeito do projeto, foi necessário que o pesquisador marcasse uma reunião com os coordenadores para esclarecimentos, antes do início do estudo. 
Nesses encontros com diretores, coordenadores e professores houve 0 cuidado de, em nenhum momento, se mencionar os termos asma, rinite ou eczema. O pesquisador se referia ao estudo como "um estudo de doenças no pulmão, no nariz e na pele", conforme a orientação fornecida pelo manual do ISAAC. ${ }^{113}$

Os QEs foram distribuídos pelas professoras responsáveis pelas classes, as quais ficaram encarregadas do recolhimento dos mesmos após três dias da entrega. Os alunos levaram os questionários para casa para serem preenchidos por seus pais ou responsáveis num envelope onde, além do questionário, constava os termos de consentimento livre e esclarecido (Anexo $G$ ), a ser assinado pelo responsável da criança. Uma semana após a distribuição, os questionários eram recolhidos pelo pesquisador. Os QEs foram entregues e recolhidos durante os meses de junho a outubro de 2002 e foram incluídos na análise somente os QEs com todas as questões preenchidas. 
Quadro 1 - Características demográficas e socioeconômicas dos distritos Butantã, Vila Sônia, Raposo Tavares, Itaim Bibi, Jaguaré, Morumbi, Pinheiros e Rio Pequeno do Município de São Paulo, incluídos no estudo ISAAC região oeste de São Paulo, na faixa etárias de 6 a 7 anos.

\begin{tabular}{|c|c|c|c|c|c|c|c|c|}
\hline \multirow[b]{2}{*}{ DESCRIÇÃO } & \multicolumn{8}{|c|}{ DISTRITOS* } \\
\hline & BUTANTÃ & VILA SÔNIA & $\begin{array}{l}\text { RAPOSO } \\
\text { TAVARES }\end{array}$ & ITAIM BIBI & JAGUARÉ & MORUMBI & PINHEIROS & $\begin{array}{c}\text { RIO } \\
\text { PEQUENO }\end{array}$ \\
\hline Área (hectares) ${ }^{1}$ & 1.250 & 990 & 1.260 & 990 & 503 & 1.140 & 800 & 970 \\
\hline População residente ${ }^{1}$ & 52.649 & 87.379 & 91.204 & 81.456 & 42.479 & 34.588 & 62.997 & 111.756 \\
\hline População com 5-14 anos de idade ${ }^{1}$ & 5.953 & 13.401 & 16.297 & 7.725 & 6.689 & 15.462 & 5.578 & 18.479 \\
\hline Densidade demográfica $\left(\mathrm{hab} / \mathrm{km}^{2}\right)^{1}$ & 4.212 & 8.826 & 7.238 & 8.228 & 6.436 & 3.034 & 7.875 & 11.521 \\
\hline População residente em favela ${ }^{1,2}$ & 660 & 17.466 & 8.542 & 86 & 12.784 & 3.301 & $506^{* *}$ & 19.479 \\
\hline Área favelada $\left(\mathrm{m}^{2}\right)^{1,2}$ & $11.956,78$ & $422.459,64$ & $200.239,08$ & $23.897,45$ & $192.602,97$ & $114.340,57$ & $5139,75^{* *}$ & $353.008,60$ \\
\hline Densidade populacional favelada ${ }^{1,2}$ & 0,014 & 0,01 & 0,011 & 0,001 & 0,017 & 0,006 & $0,098^{\star *}$ & 0,014 \\
\hline $\mathbf{N}^{\circ}$ de favelas ${ }^{4}$ & 04 & 20 & 27 & 03 & 09 & 05 & 01 & 25 \\
\hline Abastecimento de água (em \%) ${ }^{1,3}$ & 99,93 & 98,94 & 99,23 & 99,99 & 99,69 & 99,30 & 99,98 & 99,78 \\
\hline $\begin{array}{l}\% \text { de domicílios com escoadouro da instalação } \\
\text { sanitária ligados à rede geral }{ }^{1,3}\end{array}$ & 98,7 & 95,6 & 97 & 99,8 & 77,2 & 96,1 & 99,7 & 89,9 \\
\hline $\begin{array}{l}\mathrm{N}^{\circ} \text { de estabelecimentos } \\
\text { fundamental (EMEl/EMEFs) }\end{array}$ & 6 & 10 & 19 & 3 & 2 & 2 & 2 & 14 \\
\hline $\begin{array}{l}\text { RENDA MENSAL } \# 1,3 \\
\text { Até } 0,5 \text { Salário Mínimo } \quad(\%) \\
\end{array}$ & 2,5 & 7,5 & 11,85 & 2,53 & 12,74 & 3,93 & 1,1 & 10,76 \\
\hline$>0,5$ a 1 Salário Mínimo & 5,27 & 12,36 & 18,62 & 1,62 & 13,92 & 6,85 & 1,92 & 14,3 \\
\hline > 1 a 3 Salários Mínimos (\%) & 20,64 & 28,34 & 44,22 & 12,53 & 33,13 & 12,13 & 11,16 & 34,93 \\
\hline$>3$ a 5 Salários Mínimos (\%) & 17,78 & 13,87 & 13,06 & 11 & 13,73 & 7,64 & 12,63 & 14,35 \\
\hline > 5 a 10 Salários Mínimos (\%) & 26,98 & 17,41 & 9,11 & 23,84 & 16,37 & 15,43 & 24,08 & 15,56 \\
\hline$>10 \quad$ Salários Mínimos $(\%)$ & 26,83 & 20,51 & 3,14 & 48,48 & 10,13 & 54,03 & 48,35 & 10,1 \\
\hline
\end{tabular}

Salários Mínimos (\%)

\begin{tabular}{l|r|}
26,83 & 20,51 \\
\hline
\end{tabular}

3,14

2. Prefeitura Municipal de São Paulo - SEHAB-HABI/CEM

FONTES: 1. IBGE (Instituto Brasileiro de Geografia e Estatística) - Censo 2000

3. Secretaria municipal de Planejamento Urbano/ Sempla - Depto de informações/ Deinfo 4. Listagem de Favelas do Município de São Paulo - SEHAB/ HABI 2000

5. Secretária de Estado da Educação / SE - Centro de Informações Educacionais / CIE e Secretaria Municipal de Planejamento Urbano / Sempla - Departamento de Informações / Deinfo

\# Renda média da pessoa responsável pelo Domicílio. Valores em Reais - Salário mínimo de setembro/ 2000: R\$151,00 
TABELA 1 - Distribuição dos alunos de 6 a 7anos nas escolas participantes, número de alunos incluídos, distrito de localização e percentagem de participação de cada escola.

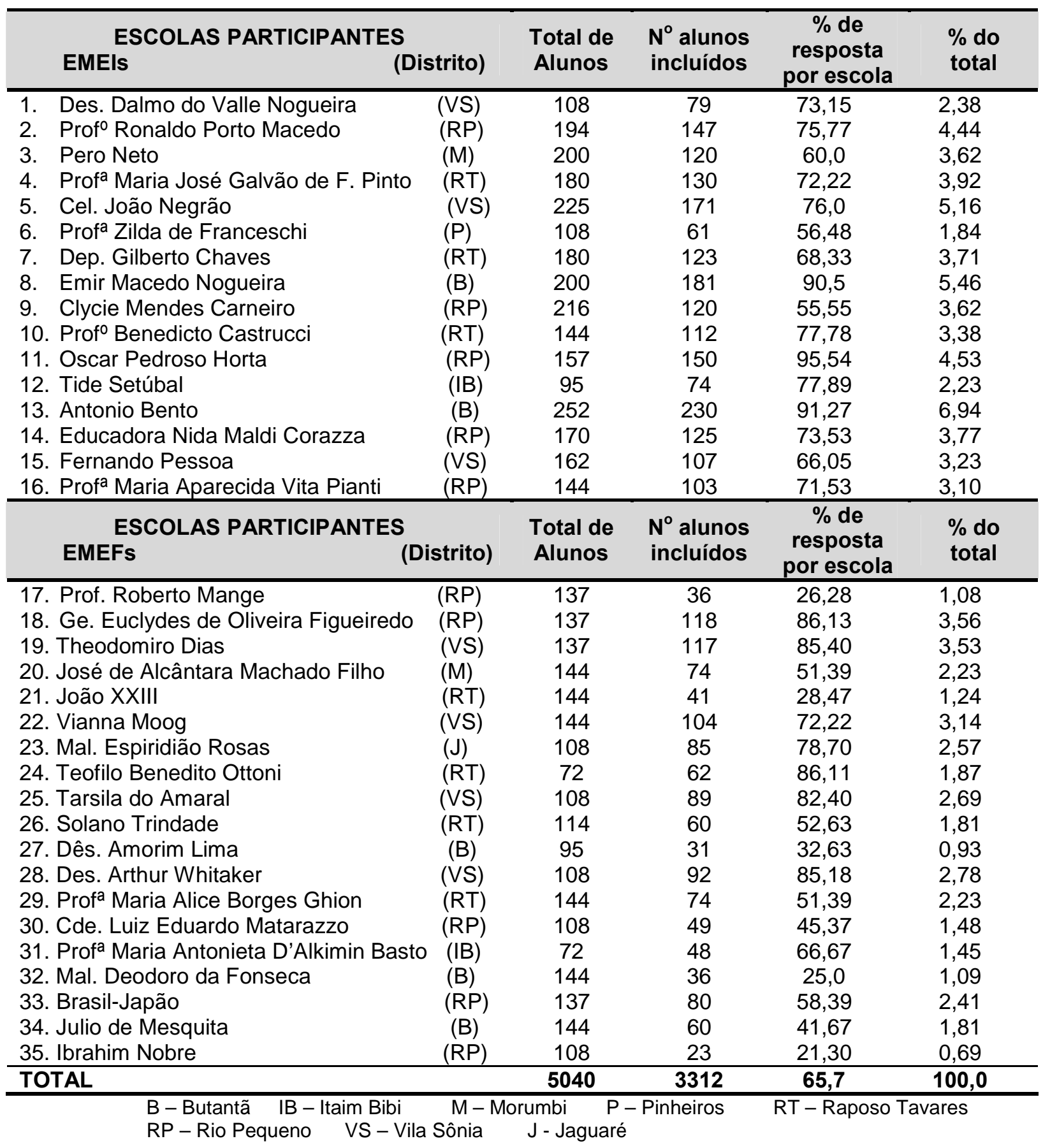


Com o término do ano letivo em dezembro de 2002 e a possibilidade de mudança escolar da maioria dos alunos, 0 pesquisador selecionou as escolas participantes da primeira fase do projeto para a aplicação do Questionário Complementar (QC), correspondente à segunda fase da pesquisa, utilizando como critério de inclusão número de alunos participantes da primeira fase maior que 100 / escola e retorno do QE maior ou igual a 70\%. Doze escolas preencheram o critério de inclusão e seis foram selecionadas por sorteio. A Tabela 2 apresenta o número de alunos participantes e sua distribuição em relação ao preenchimento do $Q E$ e do $Q C$. $A$ distribuição do QC iniciou-se em novembro de 2002, sendo a diretora de cada escola selecionada, novamente contatada pelo pesquisador e as professoras orientadas a distribuir o QC já identificado com o nome de cada aluno, solicitando o retorno do mesmo devidamente preenchido em até 7 dias.

Ao final do estudo (dezembro de 2002), foi enviada uma carta de orientação aos pais dos alunos que apresentaram respostas sugestivas de doenças alérgicas, com os endereços dos serviços médicos mais próximos, para que procurassem atendimento especializado (Anexo $H$ ). 
Tabela 2 - Número de alunos participantes da segunda fase do projeto, distribuição por escola em relação ao preenchimento do QE e QC e percentual de resposta para o QC

\begin{tabular}{|c|c|c|c|}
\hline Escolas selecionadas (Distrito) & $\begin{array}{c}\text { Total de } \\
\text { alunos com } \\
\text { QE } \\
\text { preenchidos }\end{array}$ & $\begin{array}{c}\text { Total de } \\
\text { alunos com } \\
\text { QC } \\
\text { preenchidos }\end{array}$ & $\begin{array}{c}\% \text { de resposta } \\
\text { para o QC }\end{array}$ \\
\hline $\begin{array}{lc}\text { EMEI Antonio Bento } & \text { (B) } \\
\text { EMEI Prof }{ }^{\circ} \text { Benedicto Castrucci } & \text { (RT) } \\
\text { EMEI Prof }{ }^{\circ} \text { Ronaldo Porto Macedo } & \text { (RP) } \\
\text { EMEF Ge Euclydes de Oliveira Figueiredo (RP) } \\
\text { EMEI Prof }{ }^{\circ} \text { Maria Aparecida Vita Pianti } & \text { (RP) } \\
\text { EMEF Theodomiro Dias } & \text { (VS) } \\
\text { Total } & \\
\end{array}$ & $\begin{array}{l}230 \\
112 \\
147 \\
118 \\
103 \\
117 \\
\mathbf{8 2 7}\end{array}$ & $\begin{array}{c}172 \\
77 \\
129 \\
35 \\
65 \\
83 \\
\mathbf{5 6 1}\end{array}$ & $\begin{array}{c}20,8 \\
9,3 \\
15,6 \\
4,2 \\
7,9 \\
10,0 \\
\mathbf{6 7 , 8}\end{array}$ \\
\hline $\begin{array}{l}\text { B - Butantã IB - Itaim Bibi } \quad \text { M- Morumbi } \\
\text { Tavares } \\
\text { RP - Rio Pequeno VS - Vila Sônia }\end{array}$ & $P$ - Pinheiros & $\mathrm{RT}$ & Raposo \\
\hline
\end{tabular}

\subsection{Métodos Estatísticos}

3.6.1 Questionário Escrito do estudo ISAAC - QE

O número de 3000 crianças adotado pelo estudo ISAAC foi calculado levando-se em conta que o tamanho da amostra necessária para detectar diferenças na gravidade da asma é maior que o necessário para detectar a mesma magnitude de diferenças na prevalência da asma, já que a asma grave é menos comum. Com essa amostra se pretende detectar diferenças de prevalência de até $5 \%$ entre os diferentes centros, com nível de significância ( $\alpha$ ) de $1 \%$, o que atinge um poder de estudo de $\mathbf{9 9 \%}$. Por outro lado, na determinação da gravidade, considerando uma diferença de $2 \%$ entre os centros, com uma amostra de 3000 o poder do estudo será de $90 \%$ com $\alpha$ de $1 \%{ }^{30}$

Os dados relativos ao QE foram digitados, conforme solicitação do Comitê Central do ISAAC, utilizando-se o programa Epi-Info versão 6.0 enviado aos centros participantes da pesquisa pelo próprio Comitê Central. O sistema operacional DOS foi o adotado pelo ISAAC. Foi feita uma segunda digitação, segundo as recomendações do ISAAC, que foi 
comparada à primeira, para que erros fossem minimizados. Quando algum erro era encontrado, o questionário era consultado como referência. Os dados foram enviados ao Centro Internacional de Dados (IIDC) através de email e posteriormente, enviados em diskette 3,5 "HD via correio. Diferenças nas proporções foram avaliadas utilizando o teste Exato de Fisher.

\subsubsection{Questionário Complementar - QC}

Para o cálculo da amostra dos subgrupos Asma (presença de sibilos nos últimos 12 meses) e não Asma (ausência de sibilos nos últimos 12 meses), que foram submetidos ao QC, utilizou-se o programa Instat 3/Statmate, considerando um estudo de caso-controle com dois controles para cada caso, supondo que a prevalência do fator de risco a ser estudado seria de $20 \%$ no grupo controle, e querendo detectar um estimador de risco Odds Ratio 1,5, com alfa de $5 \%$, e um poder de teste de $85 \%$, calculou-se a mostra necessária de 120 casos (asmáticos) para 240 controles (não asmáticos).

Em relação aos dados do $\mathrm{QC}$, os diversos fatores de risco foram analisados utilizando-se o programa SPSS 10.0 para o cálculo da razão de chances (OR - Odds Ratio), intervalo de confiança de 95\% (IC 95\%) e obtenção das análises univariada e multivariada. Os fatores de risco que apresentavam valores de $p<0,20$ foram incluídos no modelo de regressão logística (Bakward wald). ${ }^{114,115} \mathrm{Na}$ avaliação final do modelo de regressão logística os valores de $p<0,05$ foram considerados suficientes para estabelecer significância estatística. 
3.6.3 Metodologia utilizada para o cálculo do valor de prevalência corrigida referente aos resultados do QE do estudo ISAAC

Participaram do estudo 35 escolas, com um total de 5040 questionários enviados e um retorno de 3312 questionários respondidos adequadamente (65,7\%). Os índices de resposta ao QE na primeira fase do ISAAC variaram entre 60 a $100 \%,{ }^{116}$ entretanto objetivando um cálculo mais preciso e mais acurado das prevalências das questões relacionadas ao módulo asma e partindo do pressuposto de que todas as perdas amostrais superiores a $20 \%$ introduzem um risco elevado de viés, decorrente do fato de estar lidando com duas subpopulações com motivações diferentes para responder 0 questionário, optou-se por coletar uma amostra do grupo de escolares que não devolveu o QE, e comparar esses valores àqueles obtidos na amostra dos QEs devolvidos e, caso necessário, efetuar as devidas correções nas prevalências observadas.

O cálculo da amostra necessária para que houvesse condições de concluir se o número devolvido não interferiria na prevalência encontrada, seguiu o seguinte raciocínio: dividiu-se o total dos 5040 QE enviados em 2 grupos: Grupo I = 3312 que corresponde ao número de $Q E$ devolvidos e Grupo II = 1728, número de $Q E$ não devolvidos. A amostra aleatória probabilística de 250 alunos do Grupo II foi obtida considerando uma proporção de $31 \%$ de resposta positiva à questão 2 de sibilos nos últimos 12 meses no Grupo I, para um poder de teste de $80 \%$ e alfa de $5 \%$. A correção deveria ser realizada se os valores obtidos diferissem em pelo menos $10 \%$ a mais ou a menos dos valores obtidos inicialmente.

A amostra de 250 escolares foi selecionada de forma probabilística aleatória (amostragem por conglomerado), inicialmente as escolas foram ordenadas de maneira probabilística, na seqüência das 35 escolas. A 
diretoria de cada escola forneceu o telefone de contato de cada aluno e a aplicação e preenchimento do QE foi realizado por uma pessoa devidamente treinada, via telefone e o responsável por cada um dos escolares foi entrevistado. O contato telefônico foi feito seguindo a ordem das escolas até completar o lote amostral de 250 escolares, o que aconteceu na $17^{\underline{a}}$ escola da listagem. Os dados do QE foram digitados no programa Epi-Info 6.0, e posteriormente as freqüências de cada questão foram calculadas nesse grupo.

Verificou-se diferenças estatisticamente significantes nos Grupos I e II e portanto, calculou-se a prevalência corrigida de cada questão (através de uma média ponderada das prevalências) para estimar a real proporção na população como um todo ( $\mathrm{n}=5040$ alunos), com o respectivo cálculo do IC $95 \%$ através do programa estatístico $\mathrm{CI}^{\circledR}$. 


\subsection{Aspectos Éticos}

Este protocolo de pesquisa de número 242/02 e o termo de consentimento livre esclarecido foram aprovados pelo Comitê de Ética e Pesquisa (CEP) do Departamento de Pediatria e pela Comissão de Ética para Análise de Projetos de Pesquisa - CAPPesq da Diretoria Clínica do Hospital das Clínicas e da Faculdade de Medicina da Universidade de São Paulo. (Anexo I e Anexo J) 


\section{RESULTADOS}

Foram distribuídos 5040 questionários escritos (QE), 3312 retornaram adequadamente preenchidos, com um índice de retorno de 65,7\%, sendo que 1637 (49,4\%) eram do sexo masculino e 1675 (50,6\%) do sexo feminino. Quanto à faixa etária, 1978 (59,7\%) apresentavam seis anos de idade e $1334(40,3 \%)$ sete anos de idade. $O$ questionário complementar (QC) foi distribuído a 827 escolares, com 561 QCs corretamente preenchidos, correspondendo a um índice de retorno de $67,8 \%$, sendo $274(48,8 \%)$ pertencentes ao sexo masculino e 287 $(51,2 \%)$ ao sexo feminino e apresentando uma relação de 168 asmáticos para 393 não asmáticos, identificados através da questão sobre presença de sibilos no último ano.

\section{1 Prevalência de asma e sintomas associados (Módulo 1)}

A prevalência dos sintomas de asma, referentes ao QE do estudo ISAAC, em relação ao sexo, assim como o Odds Ratio (OR) e Intervalo de Confiança (IC95\%), estão apresentados na Tabela 3. Entre as crianças avaliadas, $55,2 \%$ dos pais relataram que seus filhos apresentavam sibilos alguma vez na vida. Nos últimos 12 meses, 31,2\% dos escolares apresentaram sibilos, sendo que 6,6\% apresentaram quatro ou mais crises nesse período, $8,4 \%$ apresentaram uma crise suficientemente grave com limitação da fala no último ano e $23,3 \%$ apresentaram distúrbio de sono causado por sibilos. A presença de sibilos após exercícios físicos foi relatada por $\mathbf{8 , 6 \%}$ dos pais, enquanto que tosse noturna não associada a infecções foi relatada por $37,9 \%$. Quanto ao diagnóstico de asma alguma vez na vida $7,1 \%$ dos pais responderam positivamente à esta questão. Além disso, pode-se observar que o sexo masculino mostrou maior prevalência, estatisticamente significante $(p<0,05)$, em relação à maioria dos sintomas relativos à asma, com exceção da limitação da fala. 
Os dados da prevalência de asma e sintomas associados avaliados inicialmente e corrigidos para a amostra total ( $n=5040$ escolares), encontram-se na Tabela 4. Pode-se observar uma diminuição na maioria dos resultados após correção: sibilos alguma vez $(55,1 \%$ versus $43,5 \%)$, sibilos no último ano $(31,2 \%$ versus $24,4 \%)$, mais de 4 crises de sibilos no último ano (6,6\% versus $4,1 \%)$, distúrbio do sono causado por sibilos $(23,3 \%$ versus $17,4 \%)$, diagnóstico de asma $(7,1 \%$ versus $5,7 \%)$, sibilos após exercício físico $(8,6 \%$ versus $8,3 \%)$, e tosse seca noturna $(37,9 \%$ versus $25,3 \%)$. Quanto à questão sobre limitação na fala no último ano esta apresentou aumento na sua prevalência após correção $(8,4 \%$ versus $9,2 \%)$. 
Tabela 3 - Prevalência dos sintomas de Asma (\%), segundo o sexo, em 3312 escolares de 6 a 7 anos na região oeste da cidade de São Paulo\#

\begin{tabular}{|c|c|c|c|c|}
\hline QUESTÃO & $\begin{array}{c}\text { MASC } \\
(n=1637) \\
\end{array}$ & $\begin{array}{c}\text { FEM } \\
(n=1671)\end{array}$ & $\begin{array}{c}\text { TOTAL } \\
(n=3181)\end{array}$ & $\begin{array}{c}\text { OR } \\
\text { (IC 95\%) } \\
\end{array}$ \\
\hline 1. Sibilos alguma vez & $59,0^{\star}(966)$ & $51,5(863)$ & $55,2(1829)$ & $1,3(1,2-1,5)$ \\
\hline 2. Sibilos no último ano & $33,7^{\star}(552)$ & $28,7(481)$ & $31,2(1033)$ & $1,3(1,1-1,5)$ \\
\hline \multicolumn{5}{|l|}{$\begin{array}{l}\text { 3. Número de crises no } \\
\text { último ano }\end{array}$} \\
\hline 1 - 3 crises & $24,8^{*}(407)$ & $22,1(370)$ & $23,5(777)$ & $1,2(1,0-1,4)$ \\
\hline $4-12$ crises & $6,3^{*}(104)$ & $4,7(78)$ & $5,5(182)$ & $1,4(1,0-1,9)$ \\
\hline$>12$ crises & $1,3^{*}(22)$ & $0,9(15)$ & $1,1(37)$ & $1,5(0,8-3,0)$ \\
\hline Nenhuma crise & $67,4(1104)$ & $72,3(1212)$ & $69,9(2316)$ & $1,3(1,1-1,5)$ \\
\hline \multicolumn{5}{|l|}{$\begin{array}{l}\text { 4. Sono prejudicado por } \\
\text { chiado no último ano }\end{array}$} \\
\hline$<1$ noite/semana & $14,5^{\star}(239)$ & $12,0(201)$ & $13,3(440)$ & $1,3(1,1-1,6)$ \\
\hline$\geq 1$ noite/semana & $11,3^{*}(185)$ & $8,7(146)$ & $10,0(331)$ & $1,3(1,1-1,7)$ \\
\hline Nunca & $74,0(1213)$ & $79,3(1328)$ & $76,7(2541)$ & $0,6(0,5-0,7)$ \\
\hline $\begin{array}{l}\text { 5. Limitação da fala por } \\
\text { sibilos no último ano }\end{array}$ & $9,2(150)$ & $7,6(128)$ & $8,4(278)$ & $1,2(1,0-1,6)$ \\
\hline 6. Diagnóstico de Asma & $8,1^{*}(132)$ & $6,1(102)$ & $7,1(234)$ & $1,4(1,0-1,8)$ \\
\hline $\begin{array}{l}\text { 7. Sibilos aos exercícios } \\
\text { no último ano }\end{array}$ & $9,7^{\star}(159)$ & $7,6(127)$ & $8,6(286)$ & $1,3(1,0-1,7)$ \\
\hline $\begin{array}{l}\text { 8. Tosse seca noturna no } \\
\text { último ano }\end{array}$ & $39,7^{*}(650)$ & $36,5(606)$ & $37,9(1256)$ & $1,2(1,0-1,3)$ \\
\hline
\end{tabular}


Tabela 4 - Prevalência encontrada nos QE devolvidos, QE não devolvidos e prevalência corrigida final dos sintomas de Asma (\%) em escolares de 6 a 7 anos, na região oeste da cidade de São Paulo.

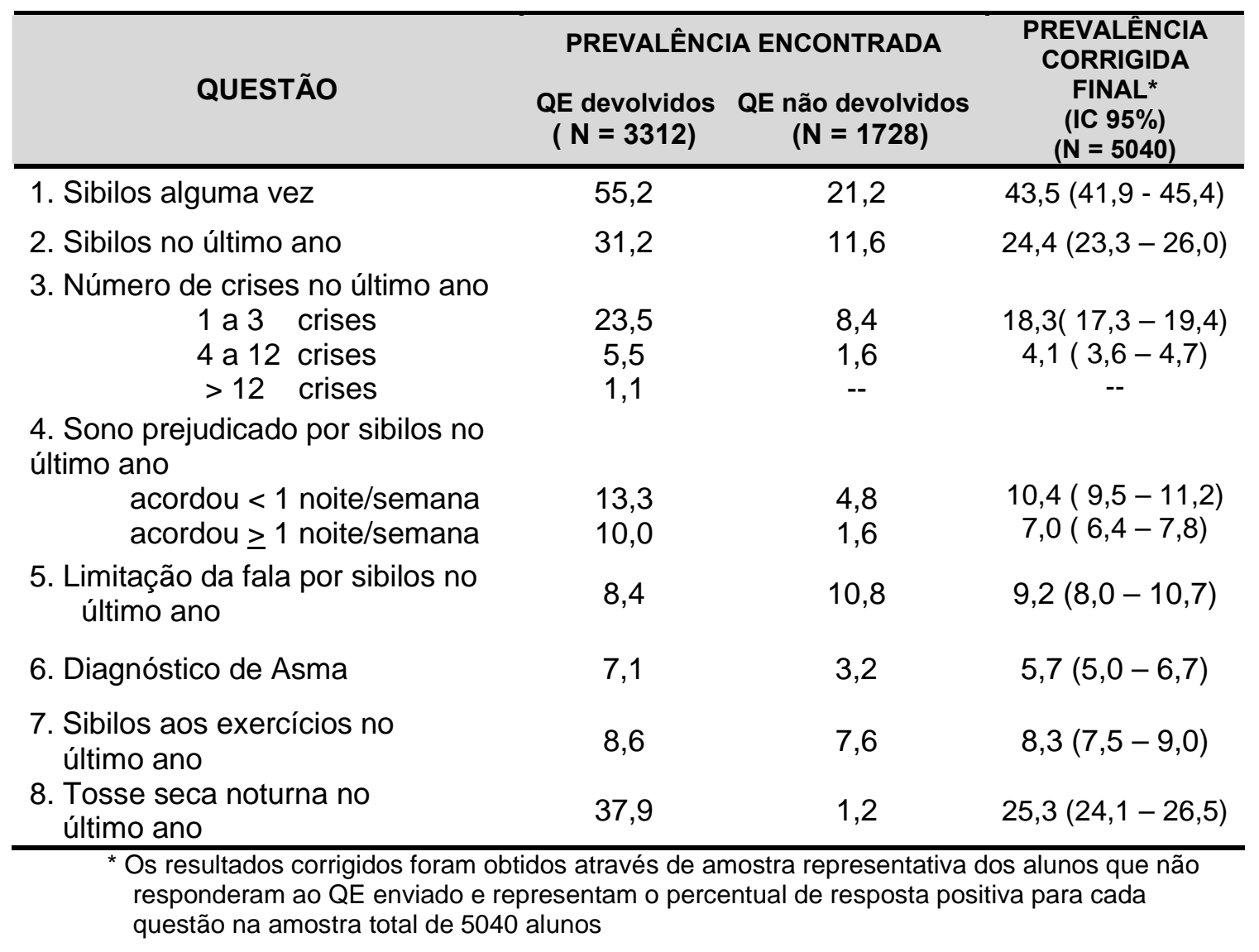

\section{2 Associação entre asma, rinite e eczema}

Houve associação estatisticamente significante entre os sintomas de asma e rinite (OR = 3,3; IC 95\%: 2,8 a 3,9; $p<0,001$ ), e asma e eczema (OR $=2,2$; IC: $95 \% 1,8$ a 2,8; $p<0,001$ ) avaliados pela resposta positiva da questão número 2 de cada módulo do QE do estudo ISAAC, conforme apresentado na Tabela 5. A Figura 1 mostra a distribuição das respostas afirmativas à questão número 2 em relação aos sintomas da asma, rinite e eczema. A associação entre asma e rinite ocorreu em $14,5 \%$ dos escolares, enquanto a associação entre asma, rinite e eczema ocorreu em $3,8 \%$ e entre asma e eczema em $6,1 \%$ dos escolares. A percentagem de escolares que não apresentou doenças 
alérgicas, ou seja, respondeu negativamente às três questões referente à asma, rinite e eczema foi de $50,1 \%(n=1662)$, demonstrado no Anexo $\mathrm{K}$.

Tabela 5 - Prevalência da associação de sintomas de rinite e eczema com a presença de sibilos no último ano em 3312 escolares de 6-7 anos na região oeste da cidade de São Paulo.

\begin{tabular}{c|c|c|c}
\hline $\begin{array}{c}\text { Respostas à questão 2 } \\
\text { QE - ISAAC }\end{array}$ & SIM & NÃO & Total \\
\hline Rinite Sim & $480(14,5)$ & $476(14,5)$ & $958(28,9)$ \\
Rinite Não & $553(16,7)$ & $1803(54,3)$ & $2354(71,1)$ \\
Total & $1033(31,2)$ & $2279(68,8)$ & $3312(100)$ \\
$\boldsymbol{p}>\mathbf{0 , 0 0 1 ~ - ~ 4 6 \% ~ d o s ~ e s c o l a r e s ~ a s m a ́ t i c o s ~ a p r e s e n t a r a m ~ r i n i t e ~}$ \\
Eczema Sim & $202(6,1)$ & $223(6,7)$ & $425(12,8)$ \\
Eczema Não & $831(25,1)$ & $2056(62,1)$ & $2887(87,2)$ \\
Total & $1033(31,2)$ & $2279(68,8)$ & $3312(100)$ \\
p > 0,001 - 19,5\% dos escolares asmáticos apresentaram eczema \\
\hline
\end{tabular}


Figura 1 - Diagrama de distribuição das respostas afirmativas às questões 2 em relação aos sintomas de asma, rinite e eczema e suas associações em 3312 escolares de 6 a 7 anos na região oeste da cidade de São Paulo.

\section{Asma}

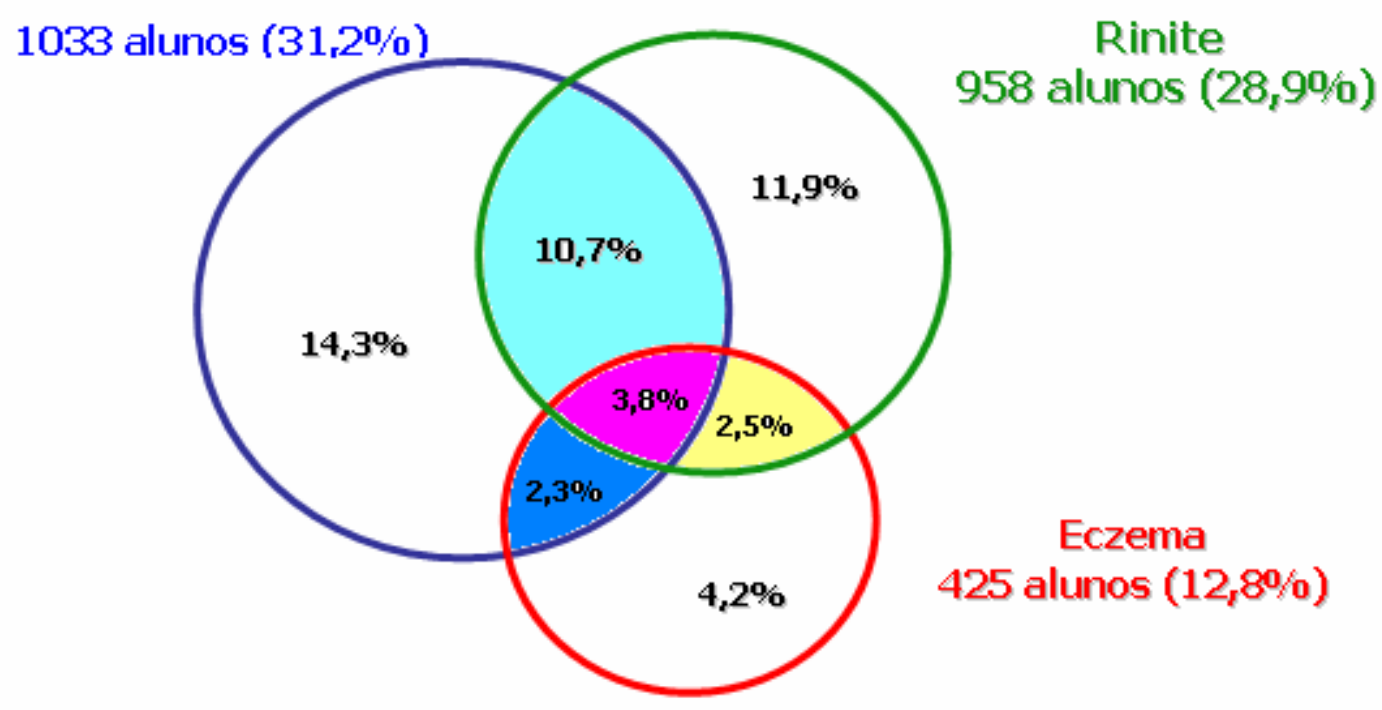

4.3 Prevalência de fatores de risco relacionados à presença de sintomas de asma no último ano

Na Tabela 6 (análise univariada) encontram-se todas as possíveis associações dos fatores de risco do QC relacionados à resposta afirmativa sobre sibilos no último ano. Como pode ser observado na Tabela 7 , os fatores utilizados para a análise multivariada $(p<0,20)$ em relação aos fatores ambientais foram: umidade na casa $\left(0 R_{\text {não ajustado }}=\right.$ 2,2; IC 95\% 1,5 a 3,3), presença de cão dentro de casa no primeiro ano de vida $\left(O R_{\text {não ajustado }}=1,5\right.$; IC $95 \% 1,0$ a 2,4), mãe fumante no primeiro ano de vida $\left(O R_{\text {não ajustado }}=1,5 ; I C 95 \% 0,9\right.$ a 2,6) e aleitamento materno $<6$ meses $\left(O R_{\text {não ajustado }}=1,3 ; \mathrm{IC} 95 \%\right.$ 0,9 a 2,0). Em relação à história familiar de doenças alérgicas o único fator incluído foi mãe atópica $\left(O R_{n a ̃ o ~ a j u s t a d o ~}=\right.$ 
2,4; IC95\% 1,6 a 3,6), e dentre os fatores pessoais foram incluídos: peso de nascimento < 2500 gramas $\left(O R_{\text {não ajustado }}=1,4 ; I_{1 C 95 \%} 0,9\right.$ a 2,3) e sexo masculino $\left(O R_{\text {não ajustado }}=1,3 ; \operatorname{IC} 95 \%\right.$ 0,9 a 1,9). Quanto à associação com outras doenças alérgicas observou-se a inclusão dos seguintes fatores: rinite isolada $\left(O R_{\text {não ajustado }}=1,9 ; I C 95 \% 1,2\right.$ a 3,0), rinoconjuntivite $\left(O R_{\text {não ajustado }}=3,1\right.$; IC95\% 1,9 a 5,0), dermatite atópica $\left(O R_{\text {não ajustado }}=3,0\right.$; IC $95 \% 1,7$ a 5,0$)$ e presença de eczema em locais típicos $\left(\mathbf{O R}_{\mathbf{n a ̃ o ~ a j u s t a d o ~}}=\right.$ 3,0; IC95\% 1,7 a 5,7). Optou-se pela exclusão da variável ausência de divisão do quarto no primeiro ano de vida $\left(0 R_{\text {não ajustado }}=0,1\right.$; IC $95 \% 0,02$ a $0,5)$ na análise multivariada, por apresentar um número muito pequeno de indivíduos expostos, apesar do valor do $p<0,20$, o que poderia dificultar a interpretação dos resultados. A correlação detalhada entre asma e cada um dos fatores acima citados pode ser observada no Anexo L.

Após a análise de Regressão Binária Logística (análise multivariada), para asma (variável dependente), permaneceram significantes neste modelo final os seguintes fatores: presença de eczema em locais característicos $\left(\mathrm{OR}_{\mathrm{ajustado}}=3,0 ; \quad \mathrm{IC} 95 \%=1,2\right.$ a 7,$\left.6 ; p=0,018\right)$; rinoconjuntivite $\left(\mathrm{OR}_{\text {ajustado }}=2,4 ; \mathrm{IC} 95 \%=1,2\right.$ a 4,$\left.8 ; \mathrm{p}=0,012\right)$; mãe fumante no primeiro ano de vida $\left(O R_{\text {ajustado }}=2,0 ; I C 95 \%=1,1\right.$ a 3,$8 ; p=$ $0,031)$; e sexo masculino $\left(\mathrm{OR}_{\text {ajustado }}=2,4 ; \mathrm{IC} 95 \%=1,4\right.$ a 4,$\left.2 ; \mathrm{p}=0,002\right)$; representados na Figura 2. 
Tabela 6 - Análise Univariada dos fatores de risco do Questionário Complementar (QC) para

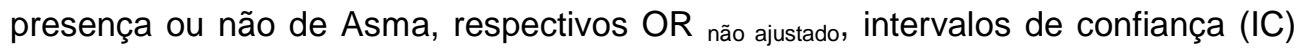
de 95\%, nível de significância $(p)$, total de asmáticos expostos, seus percentuais e amostra obtida para cada fator analisado.

\begin{tabular}{|c|c|c|c|c|c|}
\hline FATOR DE RISCO & $\begin{array}{c}\text { OR } \\
\text { não ajustado }\end{array}$ & IC $95 \%$ & $p$ & $\begin{array}{c}\text { Asmáticos } \\
\text { Expostos (\%) }\end{array}$ & Amostra \\
\hline $\begin{array}{l}\text { - Presença de gato dentro de casa } \\
\text { atualmente }\end{array}$ & 1,0 & $0,6-1,9$ & 1,000 & $17(3)$ & 561 \\
\hline - Mãe fumante & 1,0 & $0,7-1,5$ & 0,910 & $41(8)$ & 513 \\
\hline $\begin{array}{l}\text { - Idade de início em creche, } \\
\text { bercário ou jardim infância > 1ano }\end{array}$ & 1,0 & $0,6-1,6$ & 0,890 & $86(23)$ & 378 \\
\hline - Pai atópico & 1,1 & $0,6-1,9$ & 0,780 & $21(4)$ & 561 \\
\hline $\begin{array}{l}\text { - Presença de gato dentro de casa } \\
\text { no primeiro ano de vida }\end{array}$ & 0,8 & $0,4-1,8$ & 0,690 & $8(1)$ & 561 \\
\hline $\begin{array}{l}\text { - Não admissão em creche, } \\
\text { berçário ou jardim infância }\end{array}$ & 1,1 & $0,7-1,6$ & 0,680 & $49(9)$ & 558 \\
\hline $\begin{array}{l}\text { - Presença de refrigerante na dieta } \\
\text { de } 3 \text { a } 6 \text { vezes semana }\end{array}$ & 1,6 & $0,5-5,0$ & 0,600 & $57(26)$ & 220 \\
\hline $\begin{array}{l}\text { - Parto cesáreo } \\
\text { - Nerminose } \\
\text { - Não ter irmão mais velho } \\
\text { - Mamante durante gravidez }\end{array}$ & $\begin{array}{l}0,9 \\
1,2 \\
1,1 \\
1,2\end{array}$ & $\begin{array}{l}0,6-1,3 \\
0,7-2,2 \\
0,8-1,7 \\
0,7-2,1\end{array}$ & $\begin{array}{l}0,56 \\
0,54 \\
0,51 \\
0,47\end{array}$ & $\begin{array}{l}62(12) \\
19(4) \\
69(12) \\
24(7)\end{array}$ & $\begin{array}{l}513 \\
453 \\
559 \\
359\end{array}$ \\
\hline $\begin{array}{l}\text { - Presença de cão dentro de casa } \\
\text { atualmente }\end{array}$ & 1,2 & $0,8-1,8$ & 0,41 & $54(10)$ & 561 \\
\hline $\begin{array}{l}\text { - Presença de animais dentro de } \\
\text { casa no primeiro ano de vida }\end{array}$ & 1,2 & $0,8-1,8$ & 0,34 & $49(9)$ & 561 \\
\hline - Fumante dentro de casa & 1,2 & $0,8-1,8$ & 0,33 & $65(12)$ & 550 \\
\hline $\begin{array}{l}\text { - Ausência de frutas frescas na } \\
\text { dieta }\end{array}$ & 0,5 & $0,2-1,6$ & 0,31 & $4(3)$ & 133 \\
\hline $\begin{array}{l}\text { - Presença de animais dentro de } \\
\text { casa atualmente }\end{array}$ & 1,2 & $0,8-1,7$ & 0,30 & $78(14)$ & 561 \\
\hline - Irmãos gêmeos & 1,8 & $0,7-4,5$ & 0,30 & $8(1)$ & 552 \\
\hline $\begin{array}{l}\text { - Ausência de vegetais crus na } \\
\text { dieta }\end{array}$ & 1,5 & $0,7-3,1$ & 0,29 & $41(21)$ & 194 \\
\hline $\begin{array}{l}\text { - Ausência de doença sarampo } \\
\text { - Ausência de peixe na dieta } \\
\text { - Peso masculino } \\
\text { - Aleitamento materno < } 6 \text { meses } \\
\text { - Mãe fumante no } 10 \text { ano de vida }\end{array}$ & $\begin{array}{l}0,7 \\
1,5 \\
1,3 \\
1,4 \\
1,3 \\
1,5\end{array}$ & $\begin{array}{l}0,4-1,2 \\
0,8-2,8 \\
0,9-1,9 \\
0,9-2,3 \\
0,9-2,0 \\
0,9-2,6\end{array}$ & $\begin{array}{l}0,22 \\
0,21 \\
\mathbf{0 , 1 6} \\
\mathbf{0 , 1 6} \\
\mathbf{0 , 1 2} \\
\mathbf{0 , 1 1}\end{array}$ & $\begin{array}{l}126(25) \\
27(13) \\
90(16) \\
32(6) \\
64(14) \\
28(8)\end{array}$ & $\begin{array}{l}495 \\
205 \\
561 \\
525 \\
474 \\
345\end{array}$ \\
\hline $\begin{array}{l}\text { - Presença de cão dentro de } \\
\text { casa no primeiro ano de vida }\end{array}$ & 1,5 & $1,0-2,4$ & 0,045 & $40(7)$ & 561 \\
\hline $\begin{array}{l}\text { - Presença de eczema em locais } \\
\text { característicos }\end{array}$ & 3,0 & $1,7-5,7$ & $<0,001$ & $25(4)$ & 561 \\
\hline $\begin{array}{l}\text { - Ausência de divisão do quarto } \\
\text { no primeiro ano de vida }\end{array}$ & 0,1 & $0,02-0,5$ & 0,001 & $2(1)$ & 339 \\
\hline $\begin{array}{l}\text { - Dermatite atópica } \\
\text { - Rinoconjuntivite } \\
\text { - Rinite isolada } \\
\text { - Mãe atópica } \\
\text { - Umidade na casa }\end{array}$ & $\begin{array}{l}3,0 \\
3,1 \\
1,9 \\
2,4 \\
2,2 \\
\end{array}$ & $\begin{array}{l}1,7-5,0 \\
1,9-5,0 \\
1,2-3,0 \\
1,6-3,6 \\
1,5-3,3 \\
\end{array}$ & $\begin{array}{l}<0,001 \\
<0,001 \\
0,005 \\
<0,001 \\
<0,001\end{array}$ & $\begin{array}{l}33(6) \\
43(8) \\
42(7) \\
67(12) \\
66(12) \\
\end{array}$ & $\begin{array}{l}561 \\
561 \\
561 \\
561 \\
549 \\
\end{array}$ \\
\hline
\end{tabular}


Tabela 7 - Fatores de risco relacionados à positividade da questão 2 sobre Asma

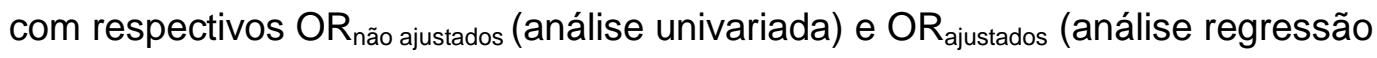
logística), com respectivos intervalo de confiança(IC 95\%) e significância ( $p$ )

\begin{tabular}{|c|c|c|c|c|c|}
\hline Fator de Risco & $\mathrm{OR}_{\text {bruto }}$ & IC $95 \%$ & $\begin{array}{c}\text { OR } \\
\text { ajustado }\end{array}$ & IC $95 \%$ & $p$ \\
\hline - Dermatite atópica - questão 2 & 3,0 & $1,7-5,0$ & $\mathrm{~ns}$ & ns & ns \\
\hline - Mãe atópica & 2,4 & $1,6-3,6$ & ns & ns & ns \\
\hline - Peso nascimento < 2500gr & 1,4 & $0,9-2,3$ & ns & ns & ns \\
\hline - Aleitamento materno $<6$ meses & 1,3 & $0,9-2,0$ & ns & ns & ns \\
\hline $\begin{array}{l}\text { - Rinite - questão } 2 \text { positiva e } \\
\text { questão } 3 \text { negativa }\end{array}$ & 1,9 & $1,2-3,0$ & 1,8 & $0,9-3,6$ & 0,099 \\
\hline $\begin{array}{l}\text { - Presença de cão dentro de casa } \\
\text { no primeiro ano de vida }\end{array}$ & 1,5 & $1,0-2,4$ & 1,66 & $0,9-3,0$ & 0,010 \\
\hline - Umidade & 2,2 & $1,5-3,3$ & 1,7 & $1,0-3,1$ & 0,065 \\
\hline $\begin{array}{l}\text { - Presença de eczema em locais } \\
\text { característicos - questão } 3\end{array}$ & 3,0 & $1,7-5,7$ & 3,0 & $1,2-7,6$ & 0,018 \\
\hline $\begin{array}{l}\text { Mãe fumante no primeiro ano } \\
\text { de vida }\end{array}$ & 1,5 & $0,9-2,6$ & 2,0 & $1,1-3,8$ & 0,031 \\
\hline - Rinoconjuntivite - questão 3 & 3,1 & $1,9-5,0$ & 2,4 & $1,2-4,8$ & 0,012 \\
\hline - Sexo masculino & 1,3 & $0,9-1,9$ & 2,4 & $1,4-4,2$ & 0,002 \\
\hline
\end{tabular}


Figura 2: Análise multivariada dos fatores de risco associados à prevalência de asma através da resposta afirmativa para sibilos no último ano $\left(\mathrm{OR}_{\text {ajustados }}, \mathrm{IC} 95 \%\right.$ e $\left.p\right)$

- Mãe fumante no primeiro ano vida

$(\mathrm{OR}=2,0 ; \mathrm{IC} 95 \%=1,1-3,8 ; p=0,031)$

- Rinoconjuntivite - questão 3 positiva

$(\mathrm{OR}=2,4 ; \mathrm{IC} 95 \%=1,2-4,8 ; p=0,012)$

- Sexo Masculino

$(\mathrm{OR}=2,4 ; \mathrm{IC} 95 \%=1,4-4,2 ; p=0,002)$

- Eczema em locais característicos- questão 3

$(\mathrm{OR}=3,0 ; \mathrm{IC} 95 \%=1,2-7,6 ; p=0,018)$

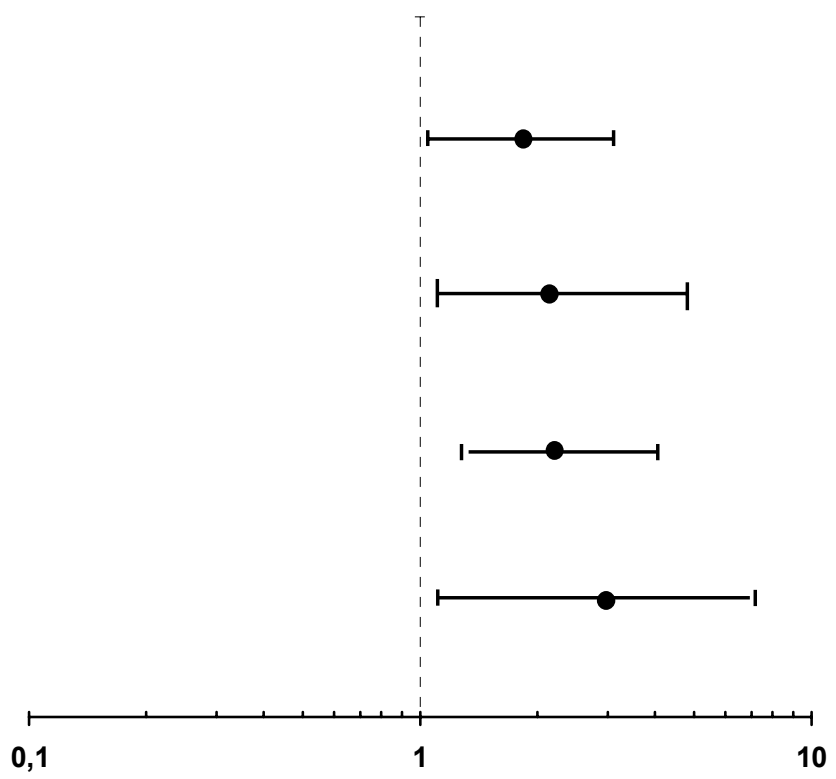

Odds ratio ajustados 
5. DISCUSSÃO

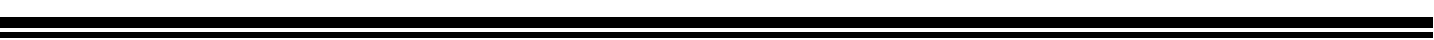




\section{DISCUSSÃO}

A prevalência da asma tem aumentado em várias regiões do mundo nas últimas décadas e em diferentes populações. ${ }^{1}$

Através de estudos epidemiológicos é possível avaliar a morbidade de uma doença a partir dos coeficientes de prevalência e incidência, procurando identificar fatores de risco relacionados a ela, visando a determinação de medidas que promovam a melhoria das condições de saúde e prevenção da doença em questão. ${ }^{117}$

Com relação à asma, os estudos epidemiológicos têm possibilitado a obtenção de informações importantes sobre sua prevalência e história natural. Porém, a falta de uma definição para asma que seja mundialmente aceita, a ausência de critérios uniformes que a identifiquem e o uso incorreto de sua denominação são algumas das circunstâncias que têm dificultado a realização desses estudos. ${ }^{118}$

$\mathrm{Na}$ década de 90, o estudo ISAAC foi elaborado com o intuito de avaliar a prevalência de asma, rinite e eczema atópico em duas faixas etárias de grande importância para estas doenças: infância e adolescência. O QE ISAAC, sendo um método reprodutível, de fácil aplicação e sem a necessidade da realização de exames, como prova de função pulmonar e 
testes de broncoprovocação, tornou-se um instrumento de aplicação universal. $^{30}$

Algumas das vantagens dos questionários utilizados em estudos epidemiológicos são o baixo custo; não necessitam de equipamentos especializados; independem da interferência de fatores externos como tempo, temperatura e umidade; e são úteis em estudos populacionais de diferentes culturas. ${ }^{35}$ Estas características tornaram possível o presente estudo, que utilizou o QE ISAAC em um número elevado de escolares, com ampla abrangência da região oeste de São Paulo, região esta na qual atua a Seção de Assistência Comunitária do Instituto da Criança através de projetos de pesquisa e programas de Saúde Escolar neste local desenvolvidos. Desta forma, este estudo conseguiu demonstrar, pela primeira vez, a prevalência de asma nesta região, sendo estes resultados de extrema importância para a realização de futuros estudos epidemiológicos, objetivando um conhecimento mais abrangente da evolução desta prevalência e dos fatores de risco a ela relacionados, facilitando a instituição de medidas preventivas que poderiam sugerir estratégias de controle da doença com interferência no meio ambiente e adequação dos serviços de saúde da região.

Por outro lado, em relação à asma, algumas desvantagens dos questionários envolvem o desconhecimento da sintomatologia da asma por parte da família, erros na denominação da doença e erros no diagnóstico médico, fatores estes que podem subestimar a doença. ${ }^{35}$ 
Mesmo assim, com todas estas ponderações o QE ISAAC é um método padronizado e comprovou ser um bom instrumento para se comparar o comportamento das doenças alérgicas em diferentes comunidades $^{27}$ e por isso vem sendo mundialmente utilizado em estudos epidemiológicos, inclusive no Brasil, onde foi validado e atingiu plenamente seus objetivos de avaliar a prevalência de asma e outras doenças alérgicas no país. ${ }^{35-37}$

Em relação aos dados de prevalência da asma encontrados no presente estudo, através da questão sobre presença de sibilos nos últimos 12 meses, observamos que $31,2 \%$ familiares responderam afirmativamente. Esse dado foi mais significativo em relação ao encontrado na região centrosul de São Paulo em 1995 de 21,3\% e em 1999 de 24,5\%.. ${ }^{29,119}$ Um dos motivos para tal diferença pode ser o baixo índice de devolução aqui obtido $(65,7 \%)$, apesar desta taxa de resposta ter sido aceita pelo Comitê Internacional do estudo ISAAC, por encontrar-se dentro da variação aceitável para Fase I do estudo. ${ }^{116}$ Dessa forma, os valores de prevalência obtidos em cada questão poderiam estar demonstrando valores diferentes da real prevalência na população avaliada, pois uma das razões para a não devolução do questionário poderia ser o fato do escolar não ter nenhuma doença alérgica. Por esse motivo, optamos por calcular a prevalência corrigida para cada questão do QE ISAAC, e verificamos que na maioria das questões os valores encontrados após estes ajustes eram inferiores aos inicialmente encontrados. Para a questão de sibilos no último ano a prevalência corrigida diminuiu de $31,2 \%$ para $24,4 \%$, valor este mais próximo 
ao encontrado na região centro-sul da cidade de São Paulo em 1999 e um pouco superior ao encontrado em 1995. Este fato demonstra a dificuldade da realização de estudos epidemiológicos em nosso meio, principalmente em populações carentes, com baixo índice de alfabetização e não conscientização da importância desses inquéritos populacionais.

Mesmo após a correção, a região oeste de São Paulo situa-se entre os centros de maior prevalência de asma encontrados no mundo em relação à Fase I do ISAAC. ${ }^{30}$ Uma das hipóteses para essa elevada prevalência encontrada, poderia ser o baixo nível socioeconômico do presente estudo, pois a região avaliada é caracterizada por grande número de famílias residentes em favelas com baixa renda mensal, fato que entra em conflito com a Hipótese da Higiene $(\mathrm{HH})$ que indiretamente demonstrou que as populações menos favorecidas, vivendo em condições precárias apresentariam menor prevalência de asma.

Na Fase I do estudo ISAAC na América Latina, Mallol et al. ${ }^{32}$ observaram que a prevalência de asma foi mais alta em centros localizados em regiões mais pobres, sugerindo que o nível socioeconômico poderia ser um fator de risco para o aumento na prevalência da asma na região, e não um fator protetor conforme a $\mathrm{HH}$ sugere. Outros relatos mostram baixa prevalência de asma em hispânicos vivendo nos EUA, em comparação com aqueles vivendo em seu país de origem, corroborando a hipótese da influência do nível socioeconômico como fator de risco para asma. ${ }^{120}$ Este fato sugere que não apenas fatores genéticos, mas a interação destes com 
condições ambientais é um fator fundamental para a expressão de determinadas doenças, incluindo a asma.

Em relação ao Brasil, a prevalência encontrada no atual estudo foi maior do que a média encontrada na Fase I do projeto ISAAC, estando abaixo somente dos valores encontrados em Recife, cidade esta que demonstrou a maior prevalência brasileira nesta fase do ISAAC. A mesma tendência foi observada em relação aos dados da América Latina, onde a média encontrada foi de 19,6\%, sugerindo que a região oeste de São Paulo encontra-se também entre as maiores prevalências da América Latina. ${ }^{32}$ Esses dados mostram que a área avaliada se destaca pela alta prevalência de asma, sugerindo a necessidade de posteriores estudos para identificação de fatores que possam estar envolvidos no desenvolvimento da asma nesta localidade.

A observação dos resultados finais após a correção, mostra que esta conduta foi adequada, pois os resultados se aproximaram de dados já existentes na cidade de São Paulo. Além disso, durante o contato telefônico com os pais ou responsáveis pelos escolares que não tinham devolvido o QE inicialmente, pode-se perceber que a principal justificativa foi à ausência de sintomatologia alérgica, demostrando um possível viez nos resultados iniciais.

Em estudos epidemiológicos estes cuidados são essenciais para a obtenção de dados fidedignos, que retratem, o mais próximo possível a realidade do local avaliado. 
Uma outra forma de se diagnosticar asma através do estudo ISAAC, seria pela investigação direta da doença, ou seja, pela questão "alguma vez na vida seu filho teve asma?". Essa questão avalia se houve diagnóstico médico de asma anteriormente à pesquisa. Encontrou-se, no presente estudo, um número reduzido de pais referindo diagnóstico de asma alguma vez, valor este quatro vezes menor ao encontrado na questão sobre sibilos no último ano, mesmo após a correção, demonstrando a provável existência de sub-diagnóstico da doença em nosso meio, como já verificado na região centro-sul de São Paulo que atingiu cerca de 6\% de diagnóstico de asma em 1995 e 1999. ${ }^{35,119} \mathrm{Na}$ América Latina, incluindo o Brasil, o estudo ISAAC também demonstrou prevalências mais baixas na questão sobre 0 diagnóstico médico de asma em relação à questão sobre sibilos no último ano, sugerindo uma dificuldade na informação médica sobre a asma para esta população ou mesmo um desconhecimento dos profissionais da saúde sobre a doença. ${ }^{32,33}$

Em locais onde a asma é identificada por outra denominação, esta questão embora tenha especificidade elevada, tem sensibilidade muito baixa; vários fatores podem interferir na sua resposta tais como: o diagnóstico correto por parte dos médicos e a compreensão, aceitação e a lembrança deste diagnóstico por parte dos pais. ${ }^{121}$

Amorim et al. ${ }^{122}$ avaliando a prevalência de asma em Cuiabá em 1998, através do QE ISAAC, utilizou a palavra bronquite como sinônimo para asma na questão sobre "alguma vez seu filho teve asma (bronquite)?", e observaram que a freqüência de respostas positivas foram superiores em 
relação à questão sobre sibilos no último ano, 28,2\% versus $22,7 \%$, demonstrando a dificuldade dos pais em diferenciar entre asma e bronquite.

Assim, constata-se que a asma continua sendo uma doença desconhecida para os médicos e para a população, sendo muitas vezes denominada erroneamente, inclusive por parte dos médicos que evitam este diagnóstico, e optam por reduzir o impacto da doença através de informações incorretas, provavelmente para diminuir o receio deste diagnóstico na população.

A questão sobre tosse seca noturna na ausência de quadros infecciosos é uma questão aceita como apresentação alternativa de asma no QE ISAAC, sendo incluída para aumentar a sensibilidade geral do questionário. ${ }^{30}$ No presente estudo, a resposta positiva à questão sobre tosse seca noturna no último ano foi superior à encontrada na questão sobre sibilos no último ano, mantendo-se a mesma diferença após a correção. Os dados mundiais da Fase I do ISAAC demonstram, também, elevadas prevalências da resposta positiva à essa questão, sugerindo que ela revele dados superestimados em relação à prevalência de asma, provavelmente por estar englobando outras patologias tais como sinusites, rinites e hiperreatividade brônquica. ${ }^{31}$ Este fato mostra que esta questão é sensível, mas pouco específica em relação ao diagnóstico de asma.

Embora o manual do ISAAC não considere a questão sobre distúrbio do sono por sibilos no último ano como marcador de gravidade e sim para avaliação dos sibiladores persistentes,$^{30}$ alguns autores têm incluído essa questão na análise da gravidade. ${ }^{119}$ 
No estudo atual, a prevalência da gravidade da asma avaliada pelas questões sobre limitação da fala e distúrbio do sono por sibilos no último ano apresentou percentual elevado, principalmente se for levada em conta a dificuldade da fala, que se apresentou três vezes maior na região oeste de São Paulo, quando comparada à região centro-sul em 1995 e em 1999. 29,119 Após a correção, os resultados encontrados apresentaram-se discretamente superiores aos iniciais. Portanto, em relação aos resultados do Brasil e aos dados mundiais da Fase I do estudo ISAAC, o presente estudo demonstrou estar entre os centros que apresentaram as maiores prevalências de gravidade.

Apesar de não ter sido o objetivo deste estudo comparar os níveis de poluentes existentes na região oeste de São Paulo com a prevalência e a gravidade da asma na região, uma das hipóteses que poderiam ser formuladas para interpretar a elevada gravidade encontrada seria a maior concentração de poluentes que pode existir nesta região, proveniente principalmente da combustão do diesel de caminhões, já que grandes rodovias cruzam os bairros onde se localizavam as escolas.

Os resultados da Fase I do ISAAC demonstraram que a poluição atmosférica não é o maior fator de risco para o desenvolvimento de asma nas populações, pois China e Europa Oriental, com níveis elevados de poluentes apresentaram baixas prevalências de asma, enquanto Nova Zelândia com menores índices de poluição apresentou elevada prevalência. ${ }^{31}$ Apesar disso, outros estudos demonstram que os poluentes podem ser considerados fatores agravantes da asma. ${ }^{123}$ 
Estudos têm demonstrado que a combustão do diesel pode desviar a resposta imune em direção à produção de $\lg E$ e induzir uma resposta inflamatória alérgica. ${ }^{124-127}$ Este poderia ser, portanto, outro fator de interferência na região.

Devalia et al. ${ }^{128}$ demonstraram que a exposição ao ozônio, dióxido de nitrogênio e dióxido de enxofre aumentou a resposta da via aérea em indivíduos asmáticos após inalação do alérgeno Der p, sugerindo uma maior hiperreatividade da via aérea quando existe a combinação da exposição a poluentes e alérgenos simultaneamente.

Na Fase I do ISAAC a cidade de Itabira localizada em uma região montanhosa, no estado de Minas Gerais, ${ }^{34}$ foi a que apresentou a maior gravidade de asma em relação aos dados brasileiros. Uma das hipóteses formulada para tal fato seria a presença, nesta cidade, de indústrias especializadas em extrações de minérios, que liberam material particulado e dispersam uma poeira vermelha por toda a cidade. Este fato demonstra que cada região pode ter uma particularidade em relação ao tipo de poluente e seus efeitos na saúde, daí a importância de análises individualizadas em populações diversas. Portanto, seriam necessários mais estudos para a avaliação dos tipos de poluentes encontrados na região oeste, para uma possível correlação com a gravidade da asma, o que não foi analisado, por não ser a proposta inicial deste estudo.

Outro fator que também poderia estar relacionado à gravidade da asma, encontrada na região oeste de São Paulo seria o possível tratamento inadequado da doença, fato este sugerido pela baixa prevalência do 
diagnóstico médico de asma encontrado neste estudo. Como consequência disso, poderíamos ter um subtratamento da doença, restrito apenas ao momento das exacerbações, o que contribuiria para a gravidade da doença.

Em relação ao sexo, os resultados do presente estudo mostraram que a prevalência de asma na região oeste da cidade de São Paulo foi mais alta no sexo masculino. Os meninos apresentaram maior prevalência de sibilos alguma vez, sibilos no último ano, sibilos ao exercício, tosse seca noturna e diagnóstico de asma. Em relação à gravidade, o distúrbio do sono no último ano também foi verificado mais em meninos do que em meninas. Esse dado deve ser observado com cuidado, já que não houve uma avaliação global da distribuição do sexo na população onde o estudo foi realizado. Esta predominância do sexo masculino, na faixa etária de 6 a 7 anos também foi verificada por Yamada ${ }^{29}$ em 1995 e por Wandalsen ${ }^{119}$ em 1999 e em outros centros que participaram da Fase I do ISAAC. ${ }^{122,129}$ A maior prevalência da asma no sexo masculino na infância tem sido relacionada ao menor diâmetro e maior tônus das vias aéreas, com menores fluxos pulmonares, a partir da adolescência a asma passa a ser mais prevalente no sexo feminino. ${ }^{70-73}$

Os resultados do presente estudo contribuíram para a Fase III do estudo ISAAC iniciada em 2002, cujo objetivo é o entendimento da evolução da prevalência e da gravidade da asma em todo o mundo. A compreensão da influência tanto do ambiente como do estilo de vida e fatores genéticos na evolução da asma é fundamental para se estabelecer medidas preventivas que possam auxiliar no controle da doença. 
As associações entre as doenças alérgicas têm sido constatadas principalmente em relação às doenças alérgicas das vias aéreas. O conceito da "via aérea única" descreve as doenças alérgicas como doenças sistêmicas, na qual eventos na via aérea superior influenciam a via aérea inferior e vice- $\quad$ versa. $^{130}$ Dessa forma, podemos verificar que as doenças alérgicas estão freqüentemente inter-relacionadas. A rinite alérgica pode estar presente em até $75 \%$ dos asmáticos, ${ }^{131}$ enquanto que a asma pode acometer até $30 \%$ dos indivíduos com rinite. ${ }^{132}$

Na presente casuística, utilizando-se as respostas afirmativas à questão número dois em relação aos sintomas de asma, rinite e eczema no último ano, observa-se uma maior associação entre asma e rinite, com 14,5\% dos escolares apresentando esta associação. No mesmo estudo, 3,8\% dos escolares apresentaram associação entre asma, rinite e eczema e 6,1\% entre asma e eczema. Em São Paulo, na região centro-sul, na mesma faixa etária, Wandalsen, ${ }^{119}$ em 1999, demonstrou resultados semelhantes aos encontrados neste relato.

Os resultados do presente estudo demonstraram também que metade dos escolares asmáticos apresentavam rinite e 19,5\% destes apresentavam eczema, concordando com a hipótese de que as doenças alérgicas estão interligadas e podem apresentar-se com diferentes fenótipos.

Embora o conceito de via aérea única seja aceito, existem pacientes que em determinado momento apresentam somente rinite e outros somente asma, sugerindo que outra forma de verificar a associação entre as doenças alérgicas, seria avaliando a história natural das mesmas ao longo de um 
período. Lombardi et al. ${ }^{133}$ acompanharam 99 pacientes alérgicos durante 10 anos e verificaram que dos pacientes que apresentaram somente rinite, $31,8 \%$ desenvolveram asma e $50 \%$ dos pacientes que apresentavam somente asma, desenvolveram rinite, sendo que o fator que mais influenciou essa evolução foi à história familiar positiva de atopia. Assim, os resultados de estudos transversais devem ser interpretados com cautela, pois avaliam a correlação existente em dado momento, podendo subestimar a associação entre as doenças, que podem ocorrer ao longo do tempo.

Diante de uma doença que apresente aumento em sua prevalência, é de extrema importância a determinação de possíveis fatores de risco que estejam contribuindo para o seu desenvolvimento. Este conhecimento é fundamental para a elaboração de estratégias de prevenção destas doenças.

Fatores de risco são características que estão associadas a um maior chance de ocorrência de determinada doença, ${ }^{134}$ podem ser classificados em genéticos e ambientais, sendo que um mesmo fator pode causar ou agravar uma doença. A interação entre fatores genéticos e fatores ambientais tem sido relacionada ao aumento na prevalência de asma e outras doenças alérgicas nas últimas décadas. Enquanto os fatores genéticos são claramente importantes em determinar risco para o desenvolvimento de asma, os fatores ambientais são os mais prováveis determinantes da expressão desta doença. ${ }^{135}$

Os fatores genéticos, apesar de serem importantes, não conseguem explicar as grandes diferenças existentes na prevalência da asma nos 
diversos continentes, nem o aumento desta prevalência, principalmente nos últimos quarenta anos, por ser um período muito curto para que alguma mudança genética tenha ocorrido. ${ }^{136,137}$

Estudos em populações de imigrantes que desenvolveram hiperreatividade das vias aéreas e atopia, quando mudaram de ambiente, demonstram a correlação entre fatores ambientais e desenvolvimento de asma. ${ }^{138}$ Além disso, fatores como mudanças no estilo de vida, na dieta e o aumento da exposição aos alérgenos intradomiciliares têm sido relacionados como potenciais determinantes da maior prevalência das doenças alérgicas. $^{139}$

Os fatores de risco podem ser diferentes para cada país, dependendo da característica genética e do ambiente a que cada população está exposta, o que poderia explicar a diferença nas prevalências de asma em cada continente demonstrada na Fase I do estudo ISAAC. Além disso, os fatores de risco também podem ser diferentes em relação aos distintos fenótipos existentes da asma como asma atópica, asma induzida por exercício e asma não alérgica. O conhecimento destes fatores pode permitir a identificação de crianças de alto risco para asma, permitindo dessa forma atuar em medidas de prevenção para evitar o desenvolvimento da mesma.

A forma mais adequada de se estudar os fatores de risco de uma doença é através de estudos de coorte. Entretanto, este tipo de estudo é difícil, de alto custo, demorado e sujeito a um número elevado de perdas. Os estudos transversais podem ser utilizados para investigar relações causais 
entre fatores de risco e uma doença, porém nestes estudos, a doença e seus possíveis fatores de risco são avaliados simultaneamente, sendo que não se pode determinar qual surgiu primeiro e por quanto tempo a pessoa foi exposta. ${ }^{134}$ Embora não seja o ideal, este tipo de estudo tem sido utilizado para este fim.

Os estudos populacionais em nosso meio apresentam dificuldades em sua realização, devido à falta de compreensão da importância destes estudos, além da dificuldade de entendimento das questões, pela baixa escolaridade existente nestas populações de baixo nível socioeconômico, como a avaliada aqui neste estudo.

A presente pesquisa apresenta características de um estudo transversal, avaliando os possíveis fatores de risco relacionados à asma, deles obtidos do QE ISAAC e outros do QC. Em relação aos fatores avaliados no QC, optamos por selecionar as perguntas relacionadas a fatores de risco já discutidos na literatura e excluir questões preenchidas por um número muito pequeno de pais.

A relação entre aparecimento precoce de eczema atópico e rinite precedendo o desenvolvimento de asma é bastante clara e o termo marcha atópica é utilizado para descrever tal fenômeno. ${ }^{140-143}$ Além disso, a presença de rinite e eczema atópico também tem sido relacionada com asma de maior gravidade. ${ }^{144}$ Os resultados aqui obtidos, após análise multivariada, demonstram a correlação entre doenças alérgicas e asma. A rinoconjuntivite foi a variável que permaneceu estatisticamente significante, enquanto que a variável rinite isolada foi excluída. Este fato é perfeitamente 
compreensível, já que sintomas nasais associados a sintomas oculares conferem maior sensibilidade ao diagnóstico de rinite alérgica.

Em relação ao eczema, a questão sobre manchas na pele no último ano demonstrou ser um fator de risco somente na análise univariada; após a análise multivariada, permaneceu como variável de maior significância a presença de eczema em locais típicos, demonstrando ser esta questão de maior sensibilidade e especificidade. Este dado foi mostrado por Yamada et al que observaram uma sensibilidade de $92 \%$ e especificidade de $96 \%$ para esta questão, durante a validação do QE ISAAC para eczema atópico. ${ }^{37}$

Rusconi et al. ${ }^{145}$ demonstraram associação significante entre história pessoal de rinite e eczema e crianças com sibilância. Em estudo multicêntrico, Illi et al. ${ }^{146}$ também demonstraram a associação entre eczema atópico de início precoce e desenvolvimento de asma aos sete anos. $\mathrm{Na}$ presente casuística, os dados obtidos confirmam a importância da associação entre as doenças alérgicas, demonstrando a necessidade da pesquisa dessas doenças alérgicas na abordagem do paciente asmático.

A hereditariedade da asma tem sido bem descrita na literatura, embora os mecanismos genéticos específicos envolvidos ainda necessitem ser melhor avaliados. Estudos em gêmeos sugerem o componente genético da asma, gêmeos monozigóticos têm $19 \%$ de chance de desenvolver esta doença, comparado com 4,8\% para os dizigóticos. ${ }^{147}$ Estudos têm demonstrado que a presença de atopia ou manifestações atópicas tais como eczema em indivíduos com asma, aumenta o risco de asma em seus parentes. ${ }^{148,149}$ De maneira geral, uma pessoa com história familiar de asma 
pode ter um risco quatro vezes maior de desenvolver a doença, sendo que se a história familiar for positiva para rinite alérgica este risco triplica. ${ }^{150}$ Assim concluímos que a presença de atopia na família também é um fator de risco para o desenvolvimento de asma.

Nesta avaliação, embora a presença de mãe atópica tenha sido significante na análise univariada, este fator foi excluído posteriormente, porém, na literatura este dado permanece de importância como fator de risco para asma. Esta associação pode estar relacionada à maior passagem de antígenos, anticorpos e citocinas através da placenta. ${ }^{151,152}$ Em relação ao pai atópico, a casuística atual não demonstraram risco significante para asma. Aberg et al. ${ }^{153}$ demonstrou que crianças com mães atópicas apresentaram duas vezes mais chance de doenças atópicas em relação àquelas somente com pai atópico. Em estudo de coorte, Alford et al. ${ }^{154}$ mostraram que crianças com pais que apresentaram asma na infância ou asma persistente possuem maior risco para atopia. A relação entre pai atópico e asma é menos citada na literatura, tendo uma importância menor em relação à mãe atópica.

Os animais domésticos são considerados fontes de alérgenos intradomiciliares. A relação entre exposição aos animais domésticos na infância, desenvolvimento de sensibilização e sintomas de asma ainda é complexa. ${ }^{155}$

O presente estudo analisou o contato atual e no primeiro ano de vida com cão, gato e outros animais dentro de casa e a presença de asma, observando-se que o contato com cão no primeiro ano de vida foi a única 
variável com significância na análise univariada, perdendo esta significância posteriormente na multivariada. Assim, neste estudo, a correlação entre animais domésticos e asma não foi observada.

Uma série de estudos de coorte demonstraram o papel protetor do contato precoce no primeiro ano de vida com cão e gato em relação ao desenvolvimento de asma. ${ }^{156,157}$ Outros autores mostram um aumento na sensibilização associada com exposição a esses animais nos primeiros dois a três anos de vida. ${ }^{158-160}$

Em estudo prospectivo de coorte, Ownby et al. ${ }^{161}$ demonstraram risco reduzido de sensibilização alérgica, somente em crianças expostas a dois ou mais cães ou gatos no primeiro ano de vida. Este fato também foi observado quando a exposição a elevados níveis do alérgeno do gato ocorria precocemente, promovendo diminuição dos níveis de $\lg E$ para o gato e menor risco de sibilância na infância. ${ }^{160}$

Em recente estudo transversal, realizado em regiões rurais da Alemanha, Áustria e Suíça, Waser et al. ${ }^{162}$ demonstraram relação inversa entre o contato atual com cão e asma nas crianças, vivendo em fazendas, com contato simultâneo com outros animais. Estes achados sugerem que o contato com níveis elevados de endotoxinas nesses locais poderia explicar o efeito protetor observado.

Em crianças com história familiar de atopia um estudo de coorte realizado na Suécia demonstrou efeito protetor do gato em relação à asma, sugerindo que o fenômeno de tolerância pode ocorrer nessas crianças. ${ }^{163}$ 
Como se pode observar em relação aos comentários anteriores, a associação da asma com os animais domésticos ainda parece controverso, provavelmente pela grande dificuldade em isolar apenas a presença do animal e desenvolvimento de sensibilização. Como citado na literatura, outros fatores tais como época da chegada do animal ao domicílio, idade da criança à exposição, número de animais, carga alergênica no ambiente e história familiar de atopia são fatores que modulam a expressão da sensibilização a estes alérgenos. Uma vez a sensibilização ocorrida e a asma expressa, a exposição a alérgenos persistentes está sem duvida associada ao aumento dos sintomas e a necessidade do uso de medicações.

A exposição passiva à fumaça de cigarro tem sido relacionada à doença sibilante nos primeiros anos de vida e a asma na idade escolar. ${ }^{164,165}$ Os resultados da presente casuística demonstraram que escolares com mães fumantes no primeiro ano de vida têm risco maior de desenvolver asma, podendo este fato estar associado ao maior contato da mãe com a criança nesta fase da infância. Este resultado está de acordo com dados relatados por Lau et al. ${ }^{166}$ que demonstraram que crianças expostas ao fumo materno tem 2,2 mais risco de sensibilização ao fumo, que aquelas não expostas. Os resultados do estudo longitudinal de Tucson mostram que crianças cujas mães fumavam mais de meio maço de cigarros por dia, principalmente nos primeiros dois anos de vida, tiveram cerca de duas vezes mais chance de desenvolver asma. ${ }^{165}$ Em estudo de meta-análise Strachan et al. ${ }^{167}$ correlacionaram fumo materno com maior incidência de sibilância até 
os seis anos de idade, e também observaram que ambos os pais fumantes aumenta, em média, 1,3 o risco para asma.

Apesar da literatura mostrar a importante relação entre fumo durante a gravidez e desenvolvimento de asma, o presente estudo não conseguiu demonstrar significância nesta associação. A predisposição genética e fatores ambientais, como a exposição ao fumo, parecem ter um importante efeito sinérgico no feto. Estudos demonstram que o fumo durante a gravidez é considerado fator de risco para sibilância durante os três primeiros anos de vida e para asma na idade escolar, além de propiciar o início mais precoce da sensibilização. ${ }^{166,168}$

Pelos resultados acima relatados, pode-se observar a importância de medidas preventivas primárias através da orientação, principalmente para as mães, sobre o efeito maléfico da exposição passiva ao fumo a seus filhos.

O aleitamento materno é considerado a melhor forma de nutrição de lactentes devido aos seus benefícios nutricionais, imunológicos e psicológicos. Em relação à asma e outras doenças alérgicas, vários estudos transversais e longitudinais tem demonstrado seu efeito protetor em relação a estas doenças. ${ }^{95,169-171}$ Entretanto, na literatura o papel do aleitamento materno na prevenção de doenças alérgicas permanece controverso. Isto ocorre, provavelmente, em decorrência de variabilidade do tempo de aleitamento e diferenças genéticas entre os pacientes analisados, devendo os resultados dos diversos trabalhos serem interpretados com cautela. No presente estudo o aleitamento materno por um período mínimo de seis meses não apresentou significância após a análise multivariada, não sendo 
encontrado correlação entre aleitamento materno e asma no resultado final desta casuística.

Alguns estudos demonstram que o aleitamento materno pode ser um fator de risco para a asma na idade escolar, ${ }^{96,97}$ enquanto que o estudo longitudinal Tucson concluiu que este risco só existe se a história materna de asma for positiva. ${ }^{98}$ Duas meta-análises realizadas em 2001 e 2003, foram concordantes em demonstrar que o aleitamento materno protege do desenvolvimento de asma na infância, sendo que esta proteção aumenta se a duração do aleitamento for superior a quatro meses. ${ }^{95,172}$ Mais recentemente, Friedman e Zeiger revisaram os artigos contra e a favor do aleitamento materno na prevenção de doenças alérgicas e concluíram que este deve ser encorajado por pelo menos quatro a seis meses em toda criança, independente de seu risco, ou da história materna positiva para asma. ${ }^{171}$ Até que estudos forneçam conclusões definitivas, o aleitamento materno deve ser incentivado como forma não só de proteção às doenças alérgicas, mas também em relação aos aspectos nutricionais e fortalecimento do vínculo mãe-filho.

Em relação ao baixo peso de nascimento, como fator de risco para asma, a atual casuística não encontrou correlação significante após a análise multivariada. A associação entre baixo peso de nascimento e asma permanece controversa na literatura, principalmente devido a fatores secundários associados ao baixo peso como nutrição materna deficiente e função pulmonar alterada do recém-nascido. Chatkin e Menezes, ${ }^{104}$ em recente revisão da literatura sobre o tema, avaliaram 41 artigos publicados 
entre 1990 e 2001, sendo a maioria estudos longitudinais e transversais, e concluíram que a maioria deles mostrou o baixo peso de nascimento como fator de risco para asma, sendo que esta associação ocorreu principalmente entre crianças até cinco anos, com diminuição progressiva desta relação com o aumento da idade.

No presente estudo, o parto cesáreo não se mostrou fator de risco para asma, embora na literatura este tipo de parto seja o mais correlacionado com risco para o desenvolvimento de asma. ${ }^{105-107}$ As possíveis causas apontadas para explicar este fato são: prejuízo da função das vias aéreas após anestesia, ausência de trabalho de parto prejudicando o desenvolvimento da função pulmonar e falta da passagem pelo canal de parto com redução da flora intestinal primária no recém-nascido. ${ }^{173}$

A exposição ao fungo certamente está relacionada à exacerbação dos sintomas da asma, mas vários estudos vêm demonstrando que a presença de umidade e mofo na casa pode ser também um fator de risco para desenvolvimento de asma, ${ }^{93,174-179}$ embora seja necessário um melhor entendimento sobre os mecanismos envolvidos nesta correlação. O presente estudo demonstrou existir uma correlação significante entre presença de umidade na casa e asma na análise univariada, mas após a regressão logística esse fator perdeu sua significância.

Simoni et al. ${ }^{173}$ em estudo transversal realizado na Itália, utilizando questionários semelhantes aos aqui utilizados, observaram que a presença de umidade ou mofo na casa é um fator de risco para sibilância e asma em crianças $(O R=1,98)$, especialmente quando esta exposição ocorre 
precocemente na infância. Uma diferença importante entre os dois estudos, apesar da mesma faixa etária avaliada, seria a amostra mais numerosa do estudo italiano, com cerca de 17000 questionários preenchidos. Uma possibilidade das diferentes conclusões obtidas, pode ser o menor número de crianças deste estudo, que pode ter interferido com o resultado final desta análise. Tais achados sugerem a importância da implementação de medidas preventivas em relação à exposição ao fungo, principalmente na infância.

A Hipótese da Higiene $(\mathrm{HH})$, a qual relaciona a menor exposição a microorganismos como fator de risco para desenvolvimento de doenças alérgicas, vem sendo extensamente discutida na literatura. ${ }^{180-182}$ De modo geral, a $\mathrm{HH}$ pode explicar o aumento na prevalência de atopia, mas em relação a asma as evidências parecem ser menos convincentes. A presente casuística não demonstrou associações entre asma e os fatores de risco relacionados à $\mathrm{HH}$, mesmo analisando uma população de escolares em sua maioria proveniente de classes econômicas desfavorecidas, moradores em comunidades faveladas ou com moradias precárias, provavelmente mais expostos a infecções.

Vários estudos têm demonstrado um efeito protetor do tamanho da família nas manifestações atópicas, a maioria dos dados publicados sugere um efeito protetor maior em relação à presença de irmãos mais velhos. $^{47,57,183}$ Em relação à asma e o número de irmãos ainda existem resultados conflitantes na literatura. Neste estudo avaliou-se a associação entre presença de irmãos mais velhos na família e asma, mas não foi encontrado resultado significante após a analise univariada. Svanes et al. ${ }^{184}$ 
em estudo transversal, não encontraram uma associação entre rinite alérgica e número de irmãos, mas esta associação demonstrou-se positiva quando correlacionou asma e número de irmãos. Em um estudo de 1440 famílias na Alemanha, Mattes et al. ${ }^{185}$ mostraram que o risco relativo para asma, rinite alérgica e eczema foi inversamente correlacionado ao número de irmãos mais velhos, mas isto ocorreu somente em crianças com história familiar positiva para atopia, demonstrando que outros fatores podem interferir nessa correlação. Várias hipóteses têm sido pontuadas na tentativa de explicar o efeito protetor de irmãos em relação às doenças alérgicas. A primeira delas, proposta por Strachan, ${ }^{47}$ relacionou irmãos mais velhos com maior número de infecções e menor risco para desenvolvimento de doenças alérgicas. Um outro fator que poderia estar implicado nesta relação é a idade materna, em outro estudo Strachan et al. ${ }^{186}$ relacionaram o aumento da idade materna com aumento da rinite alérgica e da sensibilização em seus filhos. Nos resultados obtidos no atual estudo as correlações entre idade materna, história familiar de atopia e asma não foram avaliadas.

Em relação à variável "ausência de divisão do quarto no primeiro ano de vida", os resultados aqui obtidos demonstraram ser este fator protetor em relação à asma, na análise univariada. Esses dados discordam da literatura que demonstram uma relação inversa entre maior número de pessoas no quarto com menor percentual de asma. ${ }^{187}$ Uma das possibilidades para este resultado discordante pode ser o número muito pequeno de indivíduos referindo estes dados, que provavelmente causam prejuízos na análise final dos dados. 
A freqüência à creches e berçários tem sido associada ao risco para sibilância precoce e proteção para asma na idade escolar. ${ }^{58,188,189} \mathrm{Na}$ infância, a maioria dos quadros de sibilância são associados com infecções virais. Nafstad et al. ${ }^{188}$, em estudo realizado na Noruega, demonstraram que freqüentar creche ou berçário no primeiro ano de vida foi associado ao maior número de episódios de obstrução das vias aéreas aos dois anos de idade. Da mesma forma, um estudo de coorte de dois anos, nos EUA, demonstrou que crianças que freqüentavam creches ou berçários tinham duas vezes mais infecções respiratórias inferiores em relação àquelas que permaneciam em casa, além de apresentarem 2,3 vezes mais chance de sibilância associada a estas infecções respiratórias. ${ }^{189}$ No atual estudo, analisando a frequência em creche ou berçário como fatores de risco para asma, observou-se que nenhuma das variáveis demonstraram significância após análise univariada, contrariando os achados presentes na literatura. Neste estudo não foi possível avaliar o número de escolares asmáticos com sibilância transitória na infância, que freqüentaram creche ou berçário e melhoraram aos seis anos. Este grupo representa um ponto de interesse em seu seguimento para no futuro saber se irão apresentar sibilância ou não.

Kramer et al. ${ }^{58}$ demonstraram, em estudo realizado na Alemanha Oriental, que houve uma redução na prevalência da asma e outras doenças alérgicas na idade de cinco a 14 anos, em crianças pertencentes a famílias pequenas, que freqüentavam creches entre seis a 11 meses de idade, em comparação com a entrada na creche entre 12 a 23 meses ou depois do segundo ano de vida. Dados do estudo de Tucson também mostraram que 
crianças que freqüentaram creches nos primeiros seis meses de vida tinham risco reduzido para atopia e sibilância na idade escolar e adolescência. ${ }^{190}$ Porém, estes estudos não avaliaram a influência da história familiar de atopia na relação entre freqüentar creche e asma na infância. Celedon et al. 191 acompanharam 453 crianças com história familiar positiva de atopia, do nascimento aos seis anos de idade, e concluíram que somente crianças sem historia materna para asma tiveram associação inversa entre freqüência em creche e asma na idade de seis anos, enquanto que crianças com historia materna positiva para asma apresentaram um risco maior de sibilância aos seis anos, demonstrando a influencia de fatores hereditários nessa relação. Este aspecto também não foi avaliado neste estudo.

A exposição a endotoxinas presente em creches e berçários tem sido correlacionada com diminuição da sensibilização e proteção para asma. ${ }^{192-}$ 196 Rullo et al. ${ }^{192}$, em São Paulo, analisando amostras de poeira presentes em creches, berçários e pré-escolas, encontraram níveis elevados de endotoxinas, indicando que estes locais são uma importante fonte de exposição. $O$ efeito da endotoxina promovendo uma resposta de linfócitos $T$ helper 1 tem sido considerado protetor em relação às doenças alérgicas, quando esta exposição é precoce, ou seja, antes da instalação dos sintomas de asma e alergia. ${ }^{193} \mathrm{Em}$ relação aos níveis de exposição, estudos demonstram que níveis elevados são mais protetores em relação ao desenvolvimento de doenças alérgicas, ${ }^{194,195}$ mas quando estes níveis são associados a história familiar positiva de atopia, a exposição a endotoxina pode ser um fator agravante da asma. ${ }^{196}$ 
As mudanças dietéticas que vêm ocorrendo no mundo moderno têm sido identificadas como possíveis fatores de risco para o aumento na prevalência da asma. A ação antiinflamatória de determinados tipos de alimentos também têm sido extensamente discutida na literatura. ${ }^{63-66,197}$ Estudos têm demonstrado que a ingestão de frutas frescas em maior quantidade, ricas em flavonóides com suas propriedades antioxidantes, tem reduzido o risco para asma. ${ }^{198-199}$ A ingestão freqüente de ômega 3 proveniente do óleo de peixe, devido aos seus efeitos antiinflamatórios, inibe a formação de leucotrienos e prostaglandinas, tendo sido demonstrado, em alguns estudos, seu efeito protetor em relação a asma. ${ }^{200}$ No presente estudo avaliamos a reduzida ingestão de frutas frescas, vegetais crus e peixe na dieta como fatores de risco para asma e não encontramos associação significante com esta doença, provavelmente pela dificuldade por parte dos pais em relação ao preenchimento correto das questões referentes à dieta no questionário complementar, sendo incluído na análise final dos dados uma amostra muito pequena de escolares. Assim quanto a este aspecto não podemos arbitrar sobre sua real relação com o desenvolvimento de asma.

As dificuldades encontradas tanto no desenvolvimento deste estudo, como na análise de seus dados tornam bastante evidente a gênese multifatorial dos fatores que interferem na prevalência da asma. Embora esta vivência tenha, às vezes, acarretado momentos de frustração, por outro lado nos conscientizou da necessidade do desenvolvimento de novos estudos na 
região aqui avaliada, para melhor compreensão dos fenômenos que interferem com a asma nesta localidade.

Outro fator que foi motivo de crescimento científico dos pesquisadores, foi o fato de clínicos desenvolverem este estudo epidemiológico, tornando possível o aprendizado de que apenas o conhecimento fisiopatológico das doenças é insuficiente para melhor abordagem das mesmas, incluindo seu tratamento. Hoje, para os pesquisadores, é bastante evidente que a necessidade do conhecimento dos fatores sócio-ambientais são fundamentais para a modulação da exposição da doença, representando este fato uma grande aquisição para aqueles que participaram deste estudo. 
6. CONCLUSÕES

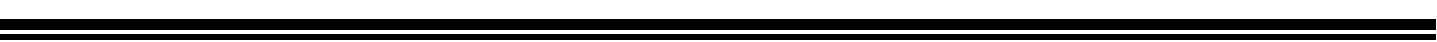




\section{CONCLUSÕES}

1. A prevalência de asma, neste estudo, avaliada pela resposta positiva à questão 2 do projeto ISAAC, se encontra em valores considerados elevados, enquanto que o diagnóstico médico de asma mostrou-se em menor percentual, o que pode sugerir um subdiagnóstico da doença nos escolares.

2. A prevalência de sintomas que demonstram a gravidade da asma neste estudo, avaliada pelas questões sobre limitação da fala e distúrbio do sono por sibilos no último ano, apresentou percentuais elevados, estando entre os centros que apresentaram as maiores prevalências de gravidade de asma do estudo ISAAC.

3. Em relação às questões sobre sibilos alguma vez, sibilos no último ano, sibilos ao exercício, tosse seca noturna, distúrbio do sono no último ano e diagnóstico de asma, houve predomínio do sexo masculino.

4. A associação mais freqüente entre as doenças alérgicas foi observada entre asma e rinite, seguida pela associação entre rinite e eczema atópico, asma e eczema atópico e em menor freqüência entre asma, rinite e eczema atópico. 
5. Os fatores de risco relacionados à asma detectados neste estudo foram: sexo masculino, sintomas de rinoconjuntivite no último ano, mãe fumante no primeiro ano de vida e presença de eczema em locais característicos. 


\section{ANEXOS}

\section{Anexo A - Carta de oficialização do Registro do centro 072014 com a denominação São Paulo West - Fase III, no ISAAC International Data Centre}

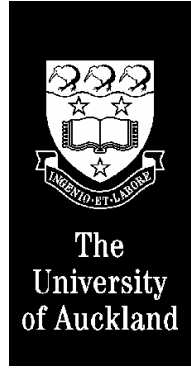

Department of Paediatrics

\author{
Faculty of Medicine and Health Science \\ University of Auckland \\ Private Bag 92019 \\ Auckland, New Zealand \\ Level 1, Starship Hospital \\ Park Road, Grafton \\ Fax: 64-9-373 7602 \\ Tel.: 64-9-373 7599 Ext. 6451 \\ Email: p.ellwood@auckland.ac.nz \\ Web: http://isaac.auckland.ac.nz/
}

Monday, 04 february 2002

Dr Antonio Carlos Pastorino

Medical Assistant of Allergy and Immunology Unit

Department of Pediatric _ Child Institute

University of Sâo Paulo

Rua Dona Luiza Tolle

519 apto CEP 02406-000

Sâo Paulo BRAZIL

Dear Dr Pastorino,

Re:ISAAC Phase Three Sâo Paulo West (072014) Registration for 6/7 \& 13/14 year age groups

Thank you for sending the Registration Document for your Phase Three ISAAC centre to the ISAAC International Data Centre (IIDC). The information has been entered into the data base of Registered Centres and we enclose for you a Phase Three Centre Report for you to complete as your study progresses. The centre report has now been revised to try and make this an easier document to complete, especially for those centres that undertook Phase One. It is comprehensive and will assist us to accurately document each centres methodology.

The Centre Report has been designed so that a standardised account of the ISAAC Phase Three study for for each centre is maintained for future international comparisons of the data. This Report when completed, should be submitted to the IIDC at the same time as you submit your data. The IIDC will then undertake some data and methodology checks and will communicate with you throughout this process.

To assist you in completing this Centre Report, we have written some instructions on completing this document. I have enclosed a copy of the page for your convenience as the instructions that can be found on page 64 of the ISAAC Phase Three Manual have now been revised.

We look forward to receiving your data and your Centre Report on completion of your study. Please do not hesitate to contact me if there is anything that I can assist you with.

Best wishes

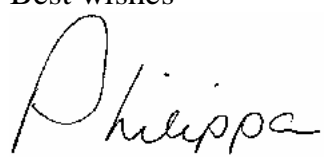

Philippa Ellwood ISAAC Research Manager 
Anexo B - Questionário Escrito (QE) do estudo ISAAC aplicado aos 3312 alunos de 6 -7 anos incluídos no estudo - página 1

\section{ESTUDO DE DOENÇAS RESPIRATORIAS (6 a 7 anos)}

Nesta folha estāo questb̄es a serem respondidas sobre seu(sua) filho(a). Nesta pesquisa sobre doenças respiratórias, preencha os dados de nome, escola e data de nascimento de criança. Escreva suas respostas nos espaços reservados. Todas as outras perguntas pedem que vocé marque sua resposta nos parénteses. Se vocé cometer um erro, circula os parénteses e remarque a resposta correta. Marque somente uma opcaio, a menos que seja instituido para o contrário.

Escola:

Data de hoje: 1

Nome da criança:

Idade da crianca: Data de nascimento: $1 \quad 1$

Sua criança é: ( ) Menino ( ) Menina

\section{- QUESTIONÁRIO 1}

MÓDULO 1

1) Alguma vez no passado, seu(sua) filino(a) teve sibilos (chiado no peito)? ( ) Sim ( ) Não

2) Nos últimos 12 (doze) meses, seu(sua) filho(a) teve sibilos (chiado no peito)? ( ) Sim ( ) Não

3) Nos últimos 12 (doze) meses, quantas crises de sibilos (chlado no peito) seu(sus) filho(a) teve? nenhuma crise 1 a 3 crises ()

4 a 12 crises () mais de 12 crises$$
\text { ( ) }
$$

4) Nos últimos 12 (doze) moses, com que frequencia seu(sua) filho(a) teve sono perturbado por chiado no peito?

Nunca acordou com chiaco Menos de 1 noite por semana Uma ou mais noites por semana

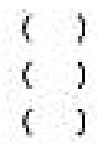

5) Nos ultimos 12 (doze) meses, seu chiado foi thio forte a ponto de impedir que seu (sua) filho(a) conseguisse dizer mais de 2 palavras entre cada respiraçăo? () $\operatorname{sim}($ ) Năo

6) Alguma vez na vida seu(sua) filho(a) teve asma? ( $) \operatorname{Sim}($ ) Nä

7) Nos últimos 12 (dozo) meses, teve chiado no peito após exercícios fislcos? ( ) Sim ( ) Năo

8) Nos ûltimos 12 (doze) meses, seu(sua) fllho(a) teve tosse seca à noite, sem estar gripado ou com infecção respiratćtia?

( ) $\sin ($ ) Nă 


\section{Anexo B - Questionário Escrito (QE) do estudo ISAAC aplicado aos 3312 alunos de 6 - 7 anos incluídos no estudo - página 2}

\section{QUESTIONÁRIO 2 (6 a 7 anos) MÓdULO 2}

1) Alguma vez na vida seu(sua) filho(a) teve problema com espirros ou coriza (corrimento nasal), quando nāo estava resfriado ou gripado?

( ) $\operatorname{Sim}($ ) Năo

Se a resposta foi năo, passe para a questáo 6 .

2) Nos últimos 12 (doze) meses, seu(sua) filho(a) teve algum problema com espirros, coriza (corrimento nasal) ou obstruçlo nasal quando nlo estava gripado ou resfriado? ( ) Sim ( ) Niio Se a resposta foi não, passe para para a questão 6 .

3) Nos últimos 12 (doze) meses esse problema nasal fol acompanhado de lacrimejamento ou coceira nos olhos?

( ) Sim ( ) Näo

4) Em qual dos últimos 12 (doze) meses esse problema nasal ocorreu? (Por favor, marque em qual ou quais meses isso ocorreu)
( ) Janeiro
() Fevereiro
( ) Maio
() Março
() Junho
( ) Setembro
( ) Abril
( ) Julho
( ) Agosto
() Outubro
( ) Novembro
( ) Dezembro

5) Nos últimos 12 (doze) meses, quantas vezes suas atividades diárias foram atrapalhadas por esse problema nasal?

$\begin{array}{ll}\text { Nada } & (\quad) \\ \text { Mod pouco } & (\text { ) } \\ \text { Muito } & (\text { ) }\end{array}$

6) Alguma vez na vida seu(sua) filho(a) teve rinite? ( ) Sim ( ) NGo

\section{QUESTIONÁRIO 3 (6 a 7 anOS) MÓDULO 3}

1) Alguma vez na vida seu(sua) filho(a) leve manchas com coceira na pele (eczema), que apareciam e desepareciam por pelo menos 6 meses?

( ) Sim ( ) Nâo

Se a resposta for năo, passe para a questäo 7.

2) Nos últimos 12 (doze) meses, seu(sua) filho(a) teve essas manches na pele (eczema)?

( ) $\operatorname{Sim}($ ) Nä́

Se a resposta for nalo, passe para a questle 7 .

3) Alguma vez essas manchas com ceceira (eczama) afetaram algum dos seguintes locais dobras dos cotovelos, atrás dos joelhos, na frente dos tornozelos, abaixo das nádegas ou em volta do pescoço, orelhas ou olhos?

( ) Sim ( ) Nảo

4) Com que idade essas manchas na pele (eczema) aparecem pela primeira vez? Menos de 2 anos ( )

Entre 2 e 4 anos ( )

5 anos ou mais ( )

5) Alguma vez estas manchas com coceira (eczema) desaparecem completamente nos ultimos 12 meses!

( ) $\operatorname{sim}($ ) Nầ

6) Nos últimos 12 (doze) meses, quantas vezes, aproximadamente, seu(sua) filho(a) ficou acordado à noite por causa dessa coceira na pele?

Nunca nos últimos 12 meses

Menos de 1 noite por semana

Uma ou mais noites por semana ( )

7) Alguma vez na vida seu(sua) filho(a) teve eczema? ( ) Sim ( ) Nao 

Anexo C - Questionário Complementar (QC) aplicado em 561 alunos
incluídos no estudo-página 1

\section{Q UESTIONÁRIO C O M P L E M E N T A}

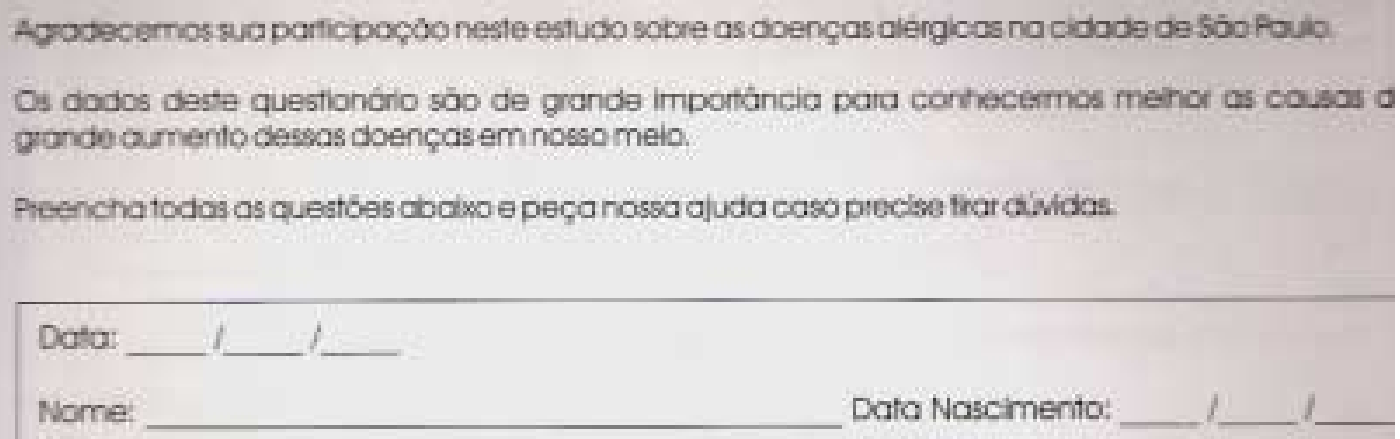

\section{DADOS PESSOAIS}

1. Oud o peso de nascimento do seu tho?

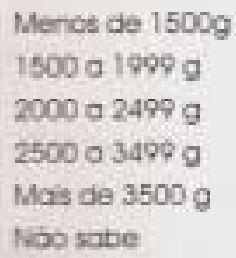

2. O seu tino nosceu na data provavel do parto?

Sm

Nibo. mais on 3 sernanas antes

Noo, mola de 3 semanas dopots Nao sabe

\section{O seu tino nosceu de:}

fato nomal de termo

Pono Nomal pretermo

Cescreana de semo

Cesareana pretema

4. Sou tho é gèmeo?

$5 \mathrm{~m}$

NoO

\section{Seu tiho fol amamentado no peito?}

$5 \mathrm{im}$

Se Sim, por quanto tompo? Manos de 6 meses

ba 12 meses:

Mas de um ano

se $5 \mathrm{~m}$, por quanto tempo ele mamou so o peito. sem outros aimentas ou sucos?

$$
\text { Menos de o meses }
$$

ba 12 meses

Moss de um ano

8. Seu tho tern imóos ou irrnçs mais velhos?

Sim

Nò̀

Quartios:

\section{Seu tho tert imbos ou irraćs mais novor?}

Sim

Nầ

Quantos: 
Anexo C - Questionário Complementar (QC) aplicado em 561 alunos incluídos no estudo - página 2

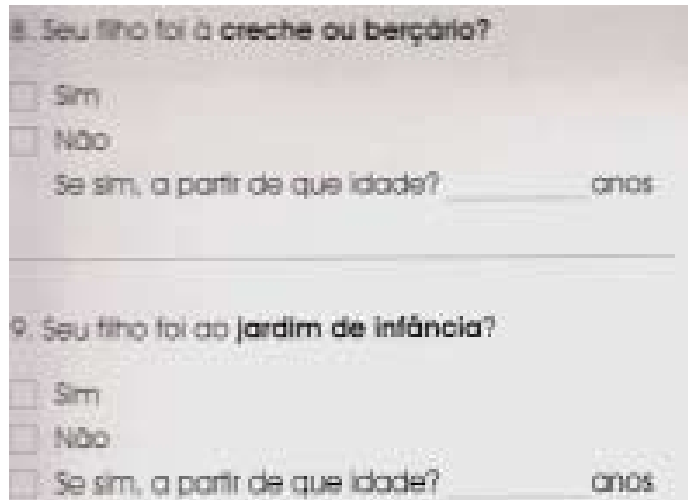

\section{DOENÇAS E IMUNIZAÇŌES}

10. A mb́o ou o pai da criança thesam algumas das soguintes ocenças? pow anirsa mas an und

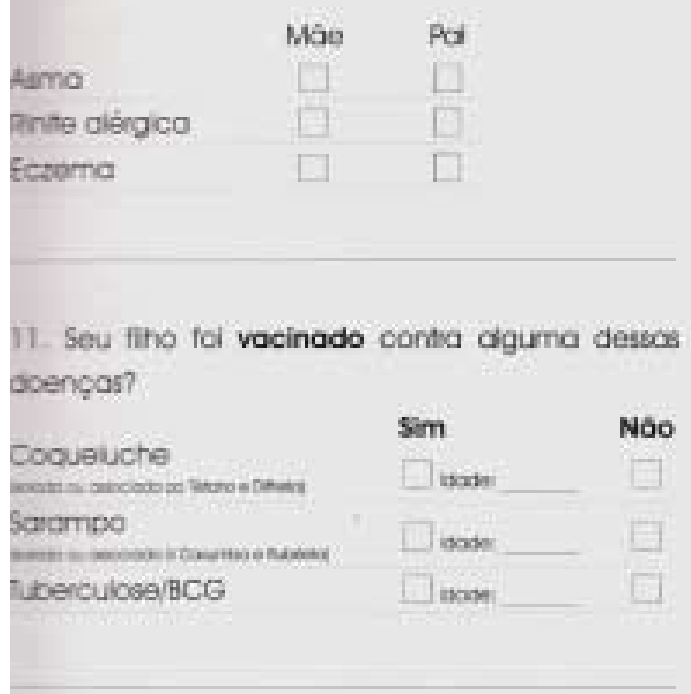

12. Seu tho tor veve aigurna descas doenças?

Gournoo

Coqualuche

libercucse

iemincse

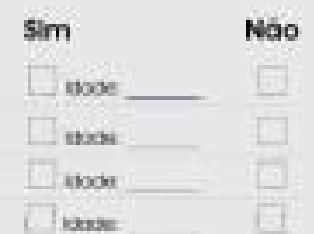

\section{SUA CASA}

Nessa seçóo perguntamos o nümero de crianças presentes em cosa. Para cada questó fomeca respostas sobre a casa ande a criança vive no presente momento e onde viveu durante o primeiro ano de vida lem caso de mudanca. escolha o bcal onde a crionça passou a maiar parte da sua vido durante o primelo ano de vida]. Náo debe de assinakr as duas coluncs.

13. O seu fiho divide ou dividiu o quarto com dquirm?

sm
Noo
suantos

\section{Presente Primelo ano}

14. Qucis dos seguinte animais foram mantidos no interior de sua casa?

Càes

Gotos

Cutios arimals de peio

Possarce

Outros

\section{Presente Pimelio ono}

15. Seu tho teve corituta, pelo menas uma ver por serncria, com algum desses animais, fora de sua casa?

\section{Cōes}

Gatos

Outos crimals de pelo Passaros

Oufros 

Anexo C - Questionário Complementar (QC) aplicado em 561 alunos
incluídos no estudo - página 3

16. A moe da crionça fumou ou fuma?

Presente Primeiro ano Gestapoo

$\sin$

NOO

17. Agguém fuma dentro da casa do criança?

$5 m$

Nà

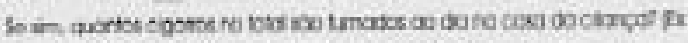

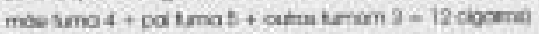

Menos delo ciganos

De 10 a 20 ciganos

Maks de 20 ciganos

18. Quxd combustivel è utlizado parc cozinhar?

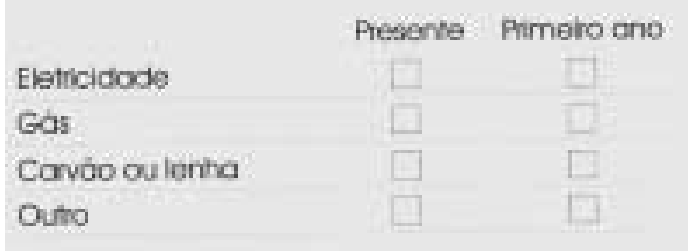

19. Como é aquecido o quarto de seu fiho?

Presente Pimerio ano

Un fogorboler

Mais de um fogoolboier

Aquecedor toro de casa

Sem oquecimanto

20. Eual combustivel é usodo para oq aquecimento?

Presente Pimerio ano

Gos

Cleo

Elatriciobade

Corvoo

Lenha

Outo-Qua?
21. A casa do chicnca postui nitoma de retigeropos

Presonte Parreiro ono

$5 m$

NOO

22. A casa da criança tem manchas de umidade na paredesounoteto?

Sim

Prescrite Primeto ano

Noo

23. A casa da criança tem moto visivel nos poredt ounoteto?

Sim

Nô

24. Que tipo de forroçáo há no quarto de domrar d criança?

Compele quatodo

Compete soto

Chao doscoberlo

Presente Pimero ano

25. Que tpo de janela há no quato de domre c

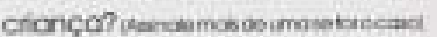

Presente Phrnobocro

Varo único

Janela secundita

Unidode selado neso ases

Serm jancios 


\section{Anexo C - Questionário Complementar (QC) aplicado em 561 alunos incluídos no estudo - página 4}

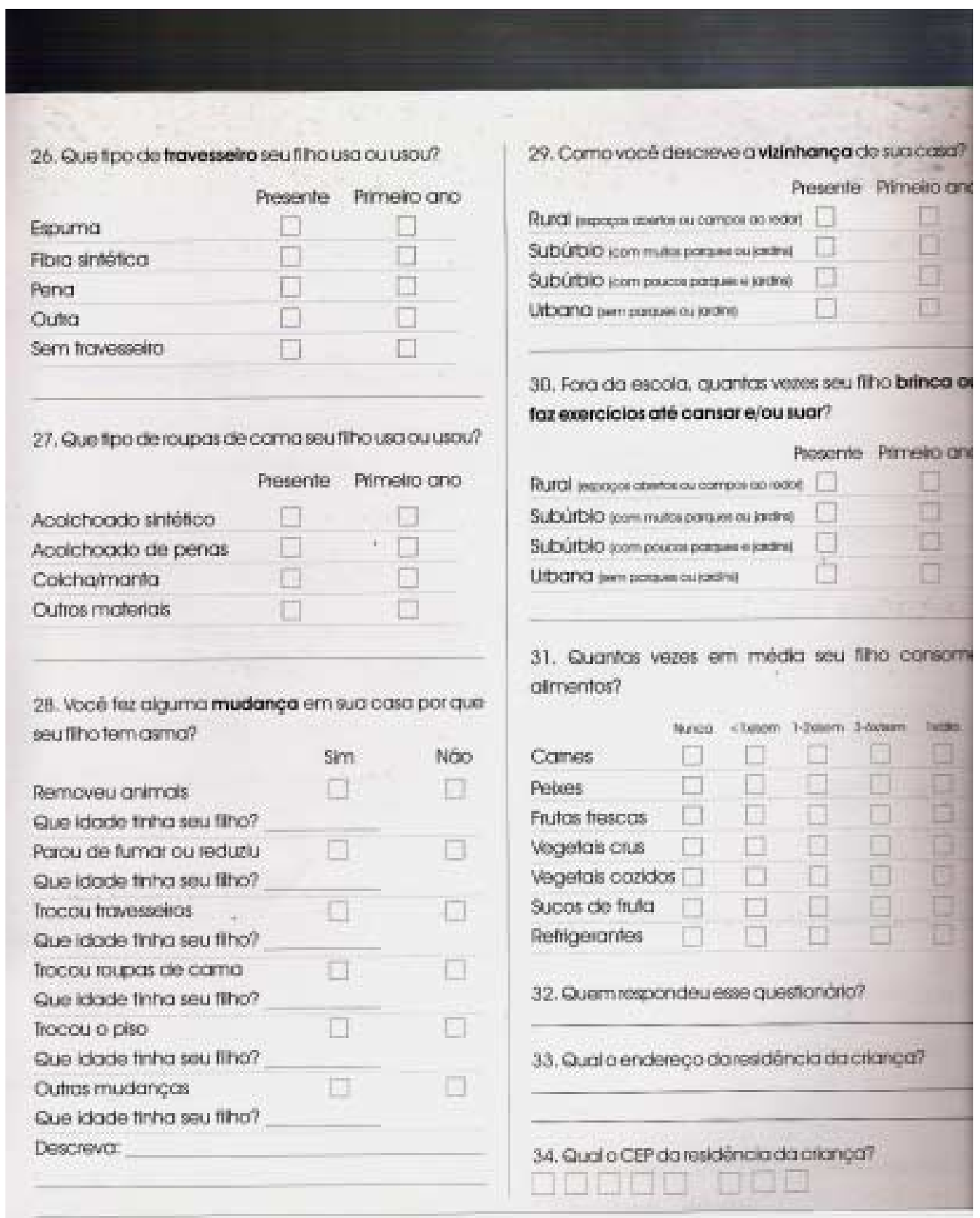


Anexo D - Mapa da cidade de São Paulo com sua distribuição de acordo com os núcleos de ação educativa (NAE) - Secretaria de Educação. Na ampliação a localização da NAE 12 - Bairros da Região Oeste, distribuição das escolas municipais de ensino fundamental (EMEFs), escolas municipais de ensino infantil ( EMEIs) e a localização das favelas em cada bairro.

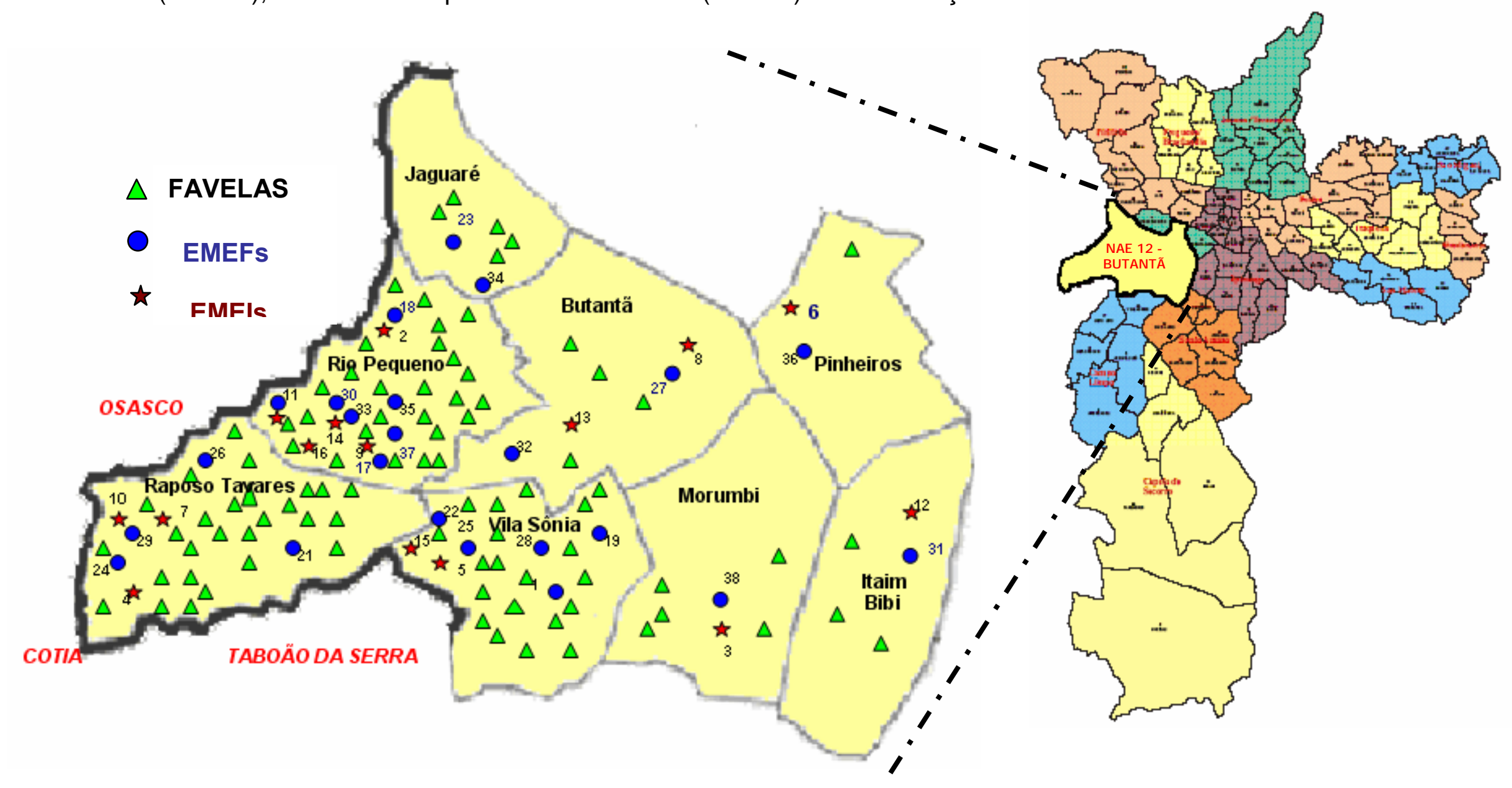


Anexo E - Escolas pertencentes a NAE-12 que não participaram do estudo ISAAC

\begin{tabular}{|c|c|}
\hline EMEI & EMEF \\
\hline 1. Monte Castelo (B) & $\begin{array}{l}\text { 1. Gen. Alcides Gonçalves } \\
\text { Etchegoyen (RT) }\end{array}$ \\
\hline 2. Prof $^{\circ}$ Antonio Branco Lefevre $(\mathrm{J})$ & 2. Tte. Alípio Andrada Serpa (RT) \\
\hline 3. Pedroso de Moraes $(\mathrm{P})$ & 3. Dep. César Arruda Castanho (RT) \\
\hline 4. Aluisio de Almeida (RT) & $\begin{array}{l}\text { 4. Prof }{ }^{a} \text { Eda Terezinha Chica } \\
\text { Medeiros (RT) }\end{array}$ \\
\hline 5. Profo $^{\circ}$ Camillo Sacar (RT) & 5. Educandário Dom Duarte (RT) \\
\hline 6. Prof $^{\mathrm{a}}$ Carolina Ribeiro ((RT) & 6. Prof ${ }^{a}$ lleusa Caetano da Silva (RT) \\
\hline 7. Cte. Moreno (RT) & 7. Sen. Alvaro Silva Braga (RP) \\
\hline 8. Carolina Maria de Jesus (RP) & 8. Prof ${ }^{\circ}$ Alípio Correa Neto (VS) \\
\hline $\begin{array}{l}\text { 9. Profo Antonio Carlos Pacheco e } \\
\text { Silva (VS) }\end{array}$ & \\
\hline
\end{tabular}



Anexo F - Carta aos diretores das escolas pertencentes a NAE-12
participantes do estudo ISAAC.

IImo(a). Sr(a). Diretor(a)

Prezado(a) Diretor(a):

Venho, por meio desta, me apresentar - Dr. Antonio Carlos Pastorino, e Dra. Rejane Rimazza Dalberto, médicos do Instituto da Criança - Unidade de Alergia e Imunologia do Depto. de Pediatria do Hospital das Clínicas da Faculdade de Medicina da USP.

Estamos realizando, em nosso Serviço, um estudo que faz parte de um projeto internacional, para avaliar a incidência das doenças alérgicas (asma, rinite e dermatite alérgica), em população de escolares do Estado de São Paulo. Serão utilizados questionários de avaliação respondidos pelos próprios alunos de 13 a 14 anos ou pelos familiares dos alunos entre 6 a 7 anos.

Este estudo dá prosseguimento a uma avaliação inicial, executada há 5 anos, que demonstrou aumento significante da incidência e prevalência dessas doenças, em nosso Estado e País.

Acreditamos que, desta maneira, poderemos conhecer melhor 0 perfil de nossas crianças alérgicas para, com isso, tentarmos instituir medidas preventivas e terapêuticas mais efetivas frente a doenças tão importantes.

Sua colaboração na realização desse estudo é fundamental.

Atenciosamente,

Dr Antonio Carlos Pastorino Dra. Rejane Rimaza Dalberto

Departamento de Pediatria

Instituto da Criança - Hospital das Clínicas

Faculdade de Medicina da Universidade de São Paulo 


\section{Anexo G - Termo de Consentimento Livre e Esclarecido - TCLE}

\section{TERMO DE CONSENTIMENTO LIVRE E ESCLARECIDO}

Prezados pais ou responsáveis,

Estamos realizando um estudo para pesquisar a presença de doenças alérgicas entre escolares da regional do Butantã, cidade de São Paulo. Será pedido para os alunos de 6 a 7 anos levarem um questionário escrito sobre essas doenças para ser preenchido pelos senhores e devolvido na escola. A participação do aluno é voluntária, mas precisamos de seu consentimento prévio por escrito. Informo também que será mantido sigilo sobre os dados de identificação fornecidos pelo aluno, sendo divulgados apenas os dados relacionados à pesquisa. Você receberá uma cópia deste documento assinado e datado.

Após ter lido este consentimento livre e esclarecido, eu

Nome do pai/mãe/responsável (em letra de forma)

declaro que entendi todas informações fornecidas sobre a participação de meu filho/filha na pesquisa.

Nome do aluno/aluna (em letra de forma)

Autorizo a divulgação dos dados das informações obtidos pela pesquisa de meu filho/filha para fins científicos

São Paulo, de de 2002

Dra Rejane Rimazza Dalberto

Médica da Unidade de Alergia e Imunologia Pediátrica do $\mathrm{ICr}$ Hospital das Clínicas da Faculdade de Medicina da USP

Responsável 


\begin{abstract}
Anexo H - Carta de orientação aos pais dos alunos que apresentaram respostas sugestivas de doenças alérgicas no estudo ISAAC, com os endereços dos serviços médicos mais próximos para atendimento especializado.
\end{abstract}

Sr Pais ou Responsáveis pelo aluno:

Responsável

Estamos agradecendo sua participação na Pesquisa sobre Doenças Respiratórias Alérgicas do Instituto da Criança - ICr do Hospital das Clínicas de São Paulo e estamos encaminhando esta carta para alertá-lo de que os resultados das respostas de seu filho mostraram que ele tem grandes chances de ser alérgico.

Desta forma, achamos conveniente que você procure atendimento por médico especialista em Alergia ou Pneumologia. Alguns locais onde existe atendimento destas especialidades seguem abaixo:

1. Posto de Pinheiros (vinculado ao ICr) - fone 3031.8407 / 3812.2268 / 3813.7462

2. PAM Centro; PAM Consolação; PAM Maria Zélia; PAM Várzea do Carmo marcação de consultas pelo telefone 0800 - 556331

3. Hospital Infantil Menino Jesus (Bela Vista) - fone 3253.2311 / 3253.5200

4. Hospital Infantil Darcy Vargas (Morumbi) - fone 3723.3700 / 3723.3760 / 3723. 3755

Projeto ISAAC - regional oeste São Paulo 
ANEXO I - Carta de aprovação na Comissão de Ética para Análise de Projetos de Pesquisa - CAPPesq da Diretoria Clínica do Hospital das Clínicas e da Faculdade de Medicina da Universidade de São Paulo
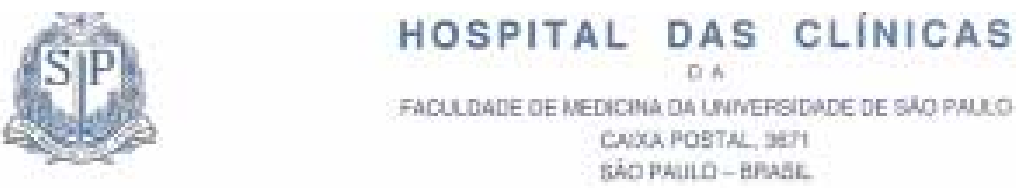

DIRETORIA CLINICA

\section{Comissão de Ética para Análise de Projetos de Pesquisa}

\section{APROVACẼO}

A Comissão de Ética para Análise de Projetos de Pesquisa - CAPPesq da Diretoria Clínica do Hospital das Clínicas e da Faculdade de Medicina da Universidade de São Paulo, em sessão de 08.05.02, APROVOU ○ Protocolo de Pesquisa $n^{\circ}$ 242/02, intitulado: "Estudo da prevalência das doenças alérgicas, da sensibilização a aeroalérgenos e da exposição a fatores ambientais em escolares com e sem asma", do Departamento de PEDIATRIA, bem como o Termo de Consentimento Livre e Esclarecido.

Pesquisador(a) Responsável: DR. ANTONIO CARLOS PASTORINO

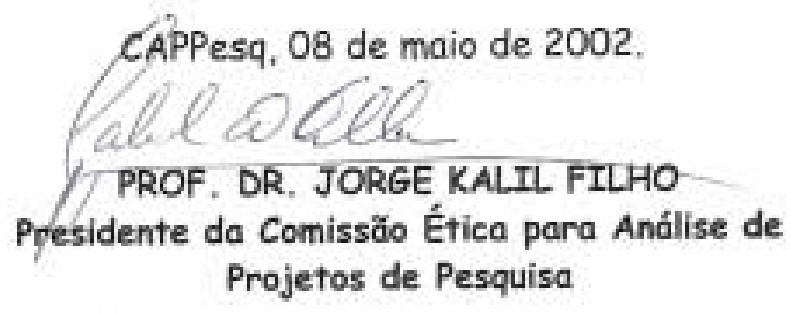

OBSERVAÇÃO: Cabe ao pesquisador elaborar e apresentar da CAPPesq, os relatórios parciais e final sobre a pesquisa (Resolugäo do Canselho Nacional de Saúde $n^{\circ} 196$, de 10.10.1996, inciso IX.2, letra "c"). 
Anexo J - Termo de Consentimento Livre e Esclarecido - TCLE

\author{
HOSPITAL DAS CLÍNICAS
}

DA

FACULDADE DE MEDICINA DA UNIVERSIDADE DE SÃO PAULO

TERMO DE CONSENTIMENTO LIVRE E ESCLARECIDO

(Instruções para preenchimento no verso)

\title{
I - DADOS DE IDENTIFICAÇÃO DO SUJEITO DA PESQUISA OU RESPONSÁVEL LEGAL
}

1. NOME DO PACIENTE .

DOCUMENTO DE IDENTIDADE № : SEXO : $M \quad F$

DATA NASCIMENTO: .........................

ENDEREÇO

№ APTO: .. ..

BAIRRO:

CEP:. CIDADE

TELEFONE: DDD ...)

2.RESPONSÁVEL LEGAL

NATUREZA (grau de parentesco, tutor, curador etc.)

DOCUMENTO DE IDENTIDADE :

SEXO: $M \quad F$

DATA NASCIMENTO.: .....................

ENDEREÇO

№

APTO:

BAIRRO: CIDADE:

CEP:

TELEFONE: DDD (

.).

\section{II - DADOS SOBRE A PESQUISA CIENTÍFICA}

1. TÍTULO DO PROTOCOLO DE PESQUISA:

"ESTUDO DA PREVALÊNCIA DAS DOENÇAS ALÉRGICAS, DA SENSIBILIZAÇÃO A AEROALÉRGENOS E DA EXPOSIÇÃO A FATORES AMBIENTAIS EM ESCOLARES COM OU SEM ASMA".

PESQUISADOR: ANTONIO CARLOS PASTORINO

CARGO/FUNÇÃO: MÉDICO CONSELHO REGIONAL № 41.829

UNIDADE DO HCFMUSP: UNIDADE DE ALERGIA E IMUNOLOGIA - DEPTO. PEDIATRIA

3. AVALIAÇÃO DO RISCO DA PESQUISA:

$\begin{array}{lll}\text { SEM RISCO RISCO MÍNIMO } & \text { RISCO MÉDIO }\end{array}$

RISCO BAIXO RISCO MAIOR

(probabilidade de que o indivíduo sofra algum dano como consequência imediata ou tardia do estudo)

4.DURAÇÃO DA PESQUISA : 2 (DOIS) ANOS. 
Anexo J - Termo de Consentimento Livre e Esclarecido - TCLE

\section{III - REGISTRO DAS EXPLICAÇÕES DO PESQUISADOR AO PACIENTE OU SEU REPRESENTANTE LEGAL SOBRE A PESQUISA, CONSIGNANDO:}

1. justificativa e os objetivos da pesquisa: as doenças alérgicas são muito frequentes entre as crianças e vem aumentando em todo o mundo. No Brasil cerca de 10 a $20 \%$ da população tem algum tipo de alergia. Vamos realizar um estudo em nosso meio usando questionários que já vem sendo usado em vários países, para conhecermos o número de escolares de 6 a 7 anos e de 13 a 14anos que podem ter alguma doença alérgica. Além disso, um grupo de crianças de 13 a 14anos poderá ser escolhido para realizar testes de alergia na pele para se conhecer o tipo de alérgeno responsável pelos seus sintomas.

2. procedimentos que serão utilizados e propósitos, incluindo a identificação dos procedimentos que são experimentais: Estaremos realizando este estudo nas escolas da rede pública de São Paulo, na área da regional do Butantã. Os escolares de 13 a 14 anos serão incluídos neste estudo em número de 3000 onde serão aplicados dois questionários: 0 primeiro será entregue em sala de aula e recolhido após preenchimento por parte dos alunos, que corresponde a um questionários contendo 8 questões referentes a asma, 6 referentes a rinite e 6 referentes a alergias na pele. Numa segunda etapa do estudo seu filho(a) poderá ser escolhido(a) para preencher um segundo questionário contendo 33 questões sobre as condições de vida, de saúde e do ambiente no primeiro ano de vida e atuais. Este questionário será preenchido pelos familiares junto com o pesquisador nos 500 alunos escolhidos e, nesta mesma ocasião, esse grupo de alunos realizará teste alérgico de pele. Para o grupo de 6 a 7 anos (3000 alunos) apenas o primeiro questionário será entregue em sala de aula e deverá ser preenchido pelos familiares e recolhido em outra oportunidade pelos pesquisadores.

3. desconfortos e riscos esperados: Somente os alunos de 13 a 14 anos e seus familiares ou responsáveis que concordarem em realizar a segunda parte do estudo irão realizar teste alérgico de pele e preencher o segundo questionário. $O$ teste alérgico de pele é um exame simples e realizado na superfície da pele, onde são colocadas algumas gotas que têm as substâncias que o indivíduo pode ser alérgico. O teste será realizado por médicos com experiência em realizar esse tipo de exame e com suas possíveis complicações, que em geral podem ser discreta dor e coceira local. Alguns indivíduos muito alérgicos podem ter vermelhidão no lugar ou em outras partes do corpo, com falta de ar e mal-estar. O teste vai ser feito sempre na pele do braço contrário ao usado para escrita do aluno e seu tempo de duração é de 20 minutos. Serão usadas lancetas descartáveis, esterilizadas e separadas para cada aluno e que tem a função de introduzir na pele as substâncias presentes nas gotas, não devendo provocar sangramento no lugar por terem um tamanho de 1 milímetro. Durante todo o teste alérgico de pele o médico responsável estará esclarecendo as dúvidas sobre o exame e está pronto para tratar as possíveis complicações.

4. benefícios que poderão ser obtidos: Os alunos que participarem do estudo deverão ser informados sobre a possibilidade de serem alérgicos e o grupo que realizar testes alérgicos de pele deverá receber este resultado e quando preciso, será orientado a procurar serviços médicos para sua avaliação mais completa. Os casos considerados de maior risco para alergia deverão ser encaminhados ao Instituto da Criança para sua avaliação e seguimento.

5. procedimentos alternativos que possam ser vantajosos para o indivíduo. 
Anexo J - Termo de Consentimento Livre e Esclarecido - TCLE

\section{IV - ESCLARECIMENTOS DADOS PELO PESQUISADOR SOBRE GARANTIAS DO SUJEITO DA PESQUISA:}

1. acesso, a qualquer tempo, às informações sobre procedimentos, riscos e benefícios relacionados à pesquisa, inclusive para dirimir eventuais dúvidas.

Os pesquisadores envolvidos estarão a qualquer tempo à disposição dos pacientes e responsáveis para esclarecimentos de dúvidas sobre os procedimentos e objetivos da pesquisa.

2. liberdade de retirar seu consentimento a qualquer momento e de deixar de participar do estudo, sem que isto traga prejuízo à continuidade da assistência.

Os familiares de alunos que não consentirem em participar do estudo não preencherão os questionários enviados e no caso de aceitarem participar do estudo, poderão a qualquer tempo desistir de continuar no estudo, sem prejuízo à sua assistência.

3. salvaguarda da confidencialidade, sigilo e privacidade.

Os dados obtidos pelos questionários serão utilizados apenas pelos participantes do estudo, não sendo permitido o acesso a outros indivíduos.

4. disponibilidade de assistência no HCFMUSP, por eventuais danos à saúde, decorrentes da pesquisa.

Os pacientes com problemas alérgicos considerados graves e sem possibilidade de acesso a serviços de saúde serão encaminhados ao ambulatório de Alergia e Imunologia de nossa Unidade, no Instituto da Criança, onde deverão ser avaliados clinicamente.

5. viabilidade de indenização por eventuais danos à saúde decorrentes da pesquisa.

\section{INFORMAÇÕES DE NOMES, ENDEREÇOS E TELEFONES DOS RESPONSÁVEIS PELO ACOMPANHAMENTO DA PESQUISA, PARA CONTATO EM CASO DE INTERCORRÊNCIAS CLÍNICAS E REAÇÕES ADVERSAS.}

Dr. Antonio Carlos Pastorino - fone 3069.8585

BIP 3444.4545 código: 108.0967

Dra. Rejane Rimazza Dalberto - fone 3069.8585

VI. OBSERVAÇÕES COMPLEMENTARES:

\section{VII - CONSENTIMENTO PÓS-ESCLARECIDO}

Declaro que, após convenientemente esclarecido pelo pesquisador e ter entendido o que me foi explicado, consinto em participar do presente Protocolo de Pesquisa

São Paulo, de de 2 . 


\section{Anexo $\mathrm{K}$ - Distribuição das respostas às questões de $\mathrm{N}^{0} 2$ dos módulos de Asma, Rinite e Eczema e suas associações em 3312 escolares de 6 a 7 anos na região oeste da cidade de São Paulo}

\begin{tabular}{ccccc}
\hline ASMA & RINITE & ECZEMA & TOTAL & $\%$ \\
\hline NÃO & NÃO & NÃO & 1662 & 50,1 \\
NÃO & SIM & NÃO & 394 & 11,8 \\
SIM & SIM & NÃO & 357 & 10,7 \\
SIM & NÃO & NÃO & 474 & 14,3 \\
NÃO & NÃO & SIM & 141 & 4,2 \\
NÃO & SIM & SIM & 82 & 2,4 \\
SIM & SIM & SIM & 125 & 3,7 \\
SIM & NÃO & SIM & 77 & 2,3 \\
\hline & TOTAL & & 3312 & 100,0 \\
\hline
\end{tabular}


Anexo $\mathbf{L}$ - Análise Univariada (Tabelas $2 \times 2$ ) dos fatores de risco incluídos na análise multivariada $(p<0,2)$ em relação à presença ou não

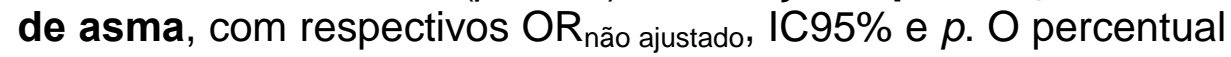
(\%) referem-se ao valor total da amostra.

\begin{tabular}{c|c|c|c}
\hline Fator de Risco & ASMA SIM & ASMA NÃO & Total \\
\hline $\begin{array}{c}\text { Rinite Isolada } \\
\text { SIM }\end{array}$ & $42(7 \%)$ & $58(10 \%)$ & $100(18 \%)$ \\
\hline $\begin{array}{c}\text { Rinite Isolada } \\
\text { NÃO }\end{array}$ & $126(22 \%)$ & $335(60 \%)$ & $461(82 \%)$ \\
\hline Total & $168(30 \%)$ & $393(70 \%)$ & $561(100 \%)$ \\
\hline ORnão ajustado $=1,9 \quad$ IC95\% $=1,2-3,0 \quad p=0,005$
\end{tabular}

\begin{tabular}{c|c|c|c}
\hline Fator de Risco & ASMA SIM & ASMA NÃO & Total \\
\hline $\begin{array}{c}\text { Rinoconjuntivite } \\
\text { Q3 SIM }\end{array}$ & $43(8 \%)$ & $39(7 \%)$ & $82(15 \%)$ \\
\hline $\begin{array}{c}\text { Rinoconjuntivite } \\
\text { Q3 NÃO }\end{array}$ & $125(22 \%)$ & $354(63 \%)$ & $479(85 \%)$ \\
\hline Total & $168(30 \%)$ & $393(70 \%)$ & $561(100 \%)$ \\
\hline ORnão ajustado $=3,1 \quad$ IC95\% $=1,9-5,0$ & $p<0,001$
\end{tabular}

\begin{tabular}{c|c|c|c}
\hline Fator de Risco & ASMA SIM & ASMA NÃO & Total \\
\hline Eczema Q2 SIM & $33(6 \%)$ & $30(5 \%)$ & $63(11 \%)$ \\
\hline Eczema Q2 NÃO & $135(24 \%)$ & $363(65 \%)$ & $498(89 \%)$ \\
\hline Total & $168(30 \%)$ & $393(70 \%)$ & $561(100 \%)$ \\
\hline ORnão ajustado $=3,0 \quad$ IC95\% $=1,7-5,0 \quad p<0,001$
\end{tabular}

\begin{tabular}{|c|c|c|c|}
\hline Fator de Risco & ASMA SIM & ASMA NÃO & Total \\
\hline $\begin{array}{c}\text { Eczema locais } \\
\text { característicos Q3 } \\
\text { SIM }\end{array}$ & $25(4 \%)$ & $21(4 \%)$ & $46(8 \%)$ \\
\hline $\begin{array}{c}\text { Eczema locais } \\
\text { característicos Q3 } \\
\text { NÃO }\end{array}$ & $143(25 \%)$ & $372(66 \%)$ & $515(92 \%)$ \\
\hline Total & $168(30 \%)$ & $393(70 \%)$ & $561(100 \%)$ \\
\hline
\end{tabular}


ANEXO L - Análise Univariada (Tabelas 2x2) dos fatores de risco incluídos na análise multivariada $(p<0,20)$ em relação à presença ou

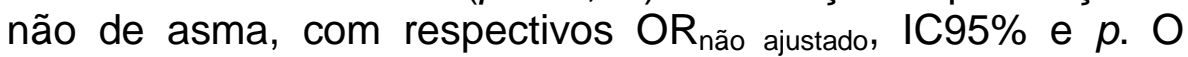
percentual (\%) referem-se ao valor total da amostra. (continuação)

\begin{tabular}{c|c|c|c}
\hline Fator de Risco & ASMA SIM & ASMA NÃO & Total \\
\hline $\begin{array}{c}\text { Mãe atópica } \\
\text { SIM }\end{array}$ & $67(12 \%)$ & $101(18 \%)$ & $168(30 \%)$ \\
\hline $\begin{array}{c}\text { Mãe atópica } \\
\text { NÃO }\end{array}$ & $85(15 \%)$ & $308(55 \%)$ & $393(70 \%)$ \\
\hline Total & $152(27 \%)$ & $409(73 \%)$ & $561(100 \%)$ \\
\hline
\end{tabular}

$\mathrm{OR}_{\text {não ajustado }}=2,4 \quad \mathrm{IC} 95 \%=1,6-3,6 \quad p<0,001$

\begin{tabular}{c|c|c|c}
\hline Fator de Risco & ASMA SIM & ASMA NÃO & Total \\
\hline Umidade SIM & $66(12 \%)$ & $87(16 \%)$ & $153(28 \%)$ \\
\hline Umidade NÃO & $100(18 \%)$ & $296(54 \%)$ & $396(72 \%)$ \\
\hline Total & $166(30 \%)$ & $383(70 \%)$ & $549(100 \%)$ \\
\hline ORnão ajustado $=2,2 \quad$ IC95\% $=1,5-3,3 \quad p<0,001$
\end{tabular}

\begin{tabular}{|c|c|c|c|}
\hline Fator de Risco & ASMA SIM & ASMA NÃO & Total \\
\hline $\begin{array}{c}\text { Divisão do } \\
\text { quarto NÂO }\end{array}$ & $2(1 \%)$ & $37(11 \%)$ & $39(12 \%)$ \\
\hline $\begin{array}{l}\text { Divisão do } \\
\text { quarto SIM }\end{array}$ & $100(29 \%)$ & 200 (59\%) & $300(88 \%)$ \\
\hline Total & $102(30 \%)$ & $237(70 \%)$ & $339(100 \%)$ \\
\hline
\end{tabular}

\begin{tabular}{c|c|c|c}
\hline Fator de Risco & ASMA SIM & ASMA NÃO & Total \\
\hline $\begin{array}{c}\text { Cão dentro de } \\
\text { casa 1 ano SIM }\end{array}$ & $40(7 \%)$ & $65(12 \%)$ & $105(19 \%)$ \\
\hline $\begin{array}{c}\text { Cão dentro de } \\
\text { casa 1 ano NÃO }\end{array}$ & $128(23 \%)$ & $328(58 \%)$ & $456(81 \%)$ \\
\hline Total & $168(30 \%)$ & $393(70 \%)$ & $561(100 \%)$ \\
\hline$R_{\text {não ajustado }=1,5 \quad \text { IC95\% }}=1,0-2,4 \quad p=0,045$
\end{tabular}


ANEXO L - Análise Univariada (Tabelas 2x2) dos fatores de risco incluídos na análise multivariada $(p<0,20)$ em relação à presença ou

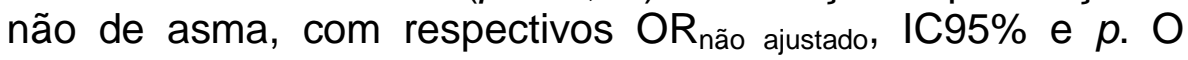
percentual (\%) referem-se ao valor total da amostra. (continuação)

\begin{tabular}{c|c|c|c}
\hline Fator de Risco & ASMA SIM & ASMA NÃO & Total \\
\hline $\begin{array}{c}\text { Mãe fumante } \\
\text { 1 ano SIM }\end{array}$ & $28(8 \%)$ & $44(13 \%)$ & $72(21 \%)$ \\
\hline $\begin{array}{c}\text { Mãe fumante } \\
\text { 1 ano NÃO }\end{array}$ & $79(23 \%)$ & $194(56 \%)$ & $273(79 \%)$ \\
\hline \multicolumn{1}{|c|}{ Total } & $107(31 \%)$ & $238(69 \%)$ & $345(100 \%)$ \\
\hline ORnão ajustado $=1,5 \quad$ IC95\% $=0,9-2,6 \quad p=0,11$
\end{tabular}

\begin{tabular}{c|c|c|c}
\hline Fator de Risco & ASMA SIM & ASMA NÃO & Total \\
\hline $\begin{array}{c}\text { Aleitamento } \\
\text { materno }<6 \mathrm{~m}\end{array}$ & $64(14 \%)$ & $128(27 \%)$ & $192(41 \%)$ \\
\hline $\begin{array}{c}\text { Aleitamento } \\
\text { materno }>6 \mathrm{~m}\end{array}$ & $75(16 \%)$ & $207(44 \%)$ & $282(59 \%)$ \\
\hline Total & $139(29 \%)$ & $335(71 \%)$ & $474(100 \%)$ \\
\hline ORnão ajustado $=1,3 \quad$ IC95\% $=0,9-2,0 \quad p=0,12$
\end{tabular}

\begin{tabular}{c|c|c|c}
\hline Fator de Risco & ASMA SIM & ASMA NÃO & Total \\
\hline $\begin{array}{c}\text { Peso nascimento } \\
<2500 \text { gr }\end{array}$ & $32(6 \%)$ & $55(10 \%)$ & $87(17 \%)$ \\
\hline $\begin{array}{c}\text { Peso nascimento } \\
\text { > 2500 gr }\end{array}$ & $127(24 \%)$ & $311(59 \%)$ & $438(83 \%)$ \\
\hline Total & $159(30 \%)$ & $366(70 \%)$ & $525(100 \%)$ \\
\hline ORnão ajustado $=1,4 \quad$ IC95\% $=0,9-2,3 \quad p=0,16$
\end{tabular}

\begin{tabular}{c|c|c|c}
\hline Fator de Risco & ASMA SIM & ASMA NÃO & Total \\
\hline Sexo masculino & $90(16 \%)$ & $184(33 \%)$ & $274(49 \%)$ \\
\hline Sexo feminino & $78(14 \%)$ & $209(37 \%)$ & $287(51 \%)$ \\
\hline Total & $168(30 \%)$ & $393(70 \%)$ & $561(100 \%)$ \\
\hline ORnão ajustado $=1,3 \quad$ IC95\% $=0,9-1,9 \quad p=0,16$
\end{tabular}


8. REFERÊNCIAS 


\section{REFERÊNCIAS}

1. Phelan PD. Asthma in children: epidemiology. BMJ. 1994;308:1584-5.

2. Weitzman M, Gortmaker SL, Sobol AM, Perrin JM. Recent trends in the prevalence and severity of childhood asthma. JAMA. 1992;268:2673-7.

3. Sly RM. Changing prevalence of allergic rhinitis and asthma. Ann Allergy Asthma Immunol. 1999;82:233-48.

4. Heinrich J, Hoelscher B, Frye C, Meyer I, Wjst M, Wichmann $\underline{\mathrm{HE}}$.Trends in prevalence of atopic diseases and allergic sensitization in children in Eastern Germany. Eur Respir J. 2002;19:1040-6.

5. Downs SH, Marks GB, Sporik R, Belosouva EG, Car NG, Peat JK. Continued increase in the prevalence of asthma and atopy. Arch Dis Child. 2001;84:20-3.

6. Nystad W, Magnus P, Gulsvik A, Skarpaas IJ, Carlsen KH. Changing prevalence of asthma in school children: evidence for diagnostic changes in asthma in two surveys 13 yrs apart. Eur Respir J. 1997 ;10:1046-51.

7. Braback L, Appelberg J, Jansson U, Kalvesten L. Changes in prevalence and severity of asthma among schoolchildren in a Swedish district between 1985 and 1995. Acta Paediatr. 2000;89:465-70.

8. Anthracopoulos M, Karatza A, Liolios E, Triga M, Triantou K, Priftis K. Prevalence of asthma among schoolchildren in Patras, Greece: three surveys over 20 years. Thorax. 2001;56:569-71. 
9. Ronchetti R, Villa MP, Barreto M, Rota R, Pagani J, Martella S, Falasca C, Paggi B, Guglielmi F, Ciofetta G. Is the increase in childhood asthma coming to an end? Findings from three surveys of schoolchildren in Rome, Italy. Eur Respir J. 2001:17:881-6.

10. Zöllner IK, Weiland SK, Piechotowski I, Gabrio T, von Mutius E, Link B, Pfaff G, Kouros B, Wuthe J. No increase in the prevalence of asthma, allergies, and atopic sensitisation among children in Germany: 1992-2001. Thorax. 2005;60:545-8.

11. Carter ER, Debley JS, Redding GJ. Changes in asthma prevalence and impact on health and function in Seattle middle-school children: 1995 vs 2003. Ann Allergy Asthma Immunol. 2005;94:634-9.

12. Getahun D, Demissie K, Rhoads GG. Recent trends in asthma hospitalization and mortality in the United States. J Asthma. 2005;42:373-8.

13. Robertson CF, HeycockE, Bishop J, Nolan T, Olinsky A, Phelan PD. Prevalence of asthma in Melbourne schoolchildren: changes over 26 years. BMJ. 1991;302:1116-8.

14. Carrasco E. Epidemiologic aspects of asthma in Latin America. Chest. 1987;91 (6 Suppl):93-7.

15. Ramos MC. Sintomas respiratórios na população da cidade de Ribeirão Preto, São Paulo, Brasil. Rev Saúde Publica. 1993;17:41-9.

16. Carandina L. Prevalência de sintomas sugestivos de doenças respiratórias crônicas inespecíficas na população urbana de Botucatu, 
São Paulo [Tese]. São Paulo: Faculdade de Saúde Pública, Universidade de São Paulo; 1986.

17. Braga CR, Juliani AP, Barba TFR, Yamada ES, Vanna AT, Toledo EC, Seki LRFA, Seki M, Sano F, Sole D, Naspiitz CK. Estudo multicentrico sobre prevalência da asma em escolares de São Paulo. Rev Pediatr Pern. 1997;10:ATL-28.

18. Rosario Filho NA, Sevilha E, Branco MEG. Prevalência de asma bronquica em consultas pediatricas. Rev Med. Paraná. 1986;44:57-9.

19. Ferrari FP, Rosario NA, Schimidt AV, Farias L. Prevalência de consultas por asma em pronto atendimento pediátrico. In: Anais do $\mathrm{V}$ Brazilian Congress of Pediatric Allergy and Immunology. São Paulo; 1995.

20. Fritscher CC, Chatkin JM. Prevalence of bronquial asthma in preteens and teenagers of Porto Alegre, Brazil. Eur Resp J. 1995;8:106S P0561.

21. Salto JJ, Wandalsen G, Naspitz C, Sole D. Asthma and respiratory disease mortality rates in the state of São Paulo, Brazil. Allergol Et Immunopathol. 2002;30:30-5.

22. Magnus $P$, Jaakkola JJ. Secular trend in the occurrence of asthma among children and young adults: critical appraisal of repeated cross sectional surveys. BMJ. 199721;314:1795-9.

23. Lebowitz MD, Burrows B. Comparison of questionnaires: the BMRC and $\mathrm{NHLI}$ respiratory questionnaires and the new self-completion questionnaire. Am Rev Resp Dis. 1976;113:627-35. 
24. Samet JM. A historical and epidemiologic perspective on respiratory symptoms questionnaires. Am J Epidemiol. 1978;108:435-46.

25. Ferris BG. Recommended respiratory disease questionnaires for use with adults and children in epidemiological research. Am Rev Respir Dis. 1978;118:1-35.

26. Asher MI, Keil U, Anderson HR, Beasley R, Crane J, Martinez F et al. The International Study of Asthma and Allergies in Childhood (ISAAC): Rationale and methods. Eur Respir J. 1995;8:483-91

27. Pearce N, Weiland S, Keil U, Langridge P, Anderson HR, Strachan D, Bauman A, Young L, Gluyas P, Ruffin D, et al. Self-reported prevalence of asthma symptoms in children in Australia, England, Germany and New Zealand: an international comparison using the ISAAC protocol. Eur Respir J. 1993;6:1455-61.

28. Sole D. Prevalência e mortalidade por asma na cidade de São Paulo. [tese livre-docência]. São Paulo: Universidade Federal de São Paulo, Escola Paulista de Medicina; 1997.

29. Yamada E. Prevalência de asma, rinite e eczema atópico em escolares da região centro-sul da cidade de São Paulo [dissertação]. São Paulo: Universidade Federal de São Paulo da Escola Paulista de Medicina; 1998.

30. International Study of Asthma and Allergies in Childhood. ISAAC Phase One Manual. Auckland (NZ)/ Münster (FRG), 1992. 47p. Disponível em:http://isaac.auckland.ac.nz/PhaseOne/Phs1Frame.html 
31. The International Study of Asthma and Allergies in Childhood (ISAAC) Steering Committee. Worldwide variation in prevalence of symptoms of asthma, allergic rhinoconjunctivitis, and atopic eczema: ISAAC. Lancet. 1998;351:1225-32.

32. Mallol J, Solé D, Asher I, Clayton T, Stein R, Soto-Quiroz M on behalf of the Latin American ISAAC Collaborators Group. Prevalence of Asthma Symptoms in Latin America: The International Study of Asthma and Allergies in Childhood (ISAAC). Pediatr Pulmonol. 2000;30:439-44.

33. Solé D, Yamada E, Vana AT, Werneck G, Solano de Freitas L, et al. International Study of Asthma and Allergies in Childhood (ISAAC): prevalence of Asthma and Asthma-related Symtoms among Brasilian Schoolchildren. J Invest Allergol Clin Immunol. 2001;11:123-8.

34. Solé D, Yamada E, Vana AT, Costa-Carvalho BT, Naspitz CK. Prevalence of Asthma and Related Symptoms in School-Age Children in São Paulo, Brazil - International Study of Asthma and Allergies in Childhood (ISAAC). J Asthma. 1999;36:205-12.

35. Solé D, Vanna AT, Yamanda E, Rizzo MCV, Naspitz CK. International Study of Asthma and Allergies in Childhood (ISAAC) written questionnaire: validation of the asthma component among Brazilian children. J Invest Allergol Clin Immunol. 1998;8:376-82.

36. Vanna AT, Yamada E, Arruda LK, Naspitz CK, Solé D. International Study of Asthma and Allergies in Childhood: Validation of the rhinitis 
symptom questionnaire and prevalence of rhinitis in schoolchildren in São Paulo, Brazil. Pediatr Allergy Immunol. 2001;12:95-101.

37. Yamada E, Vanna AT, Naspitz CK, Solé D. International Study of Asthma and Allergies in Childhood: Validation of the Written Questionnaire (Eczema Component) and prevalence of Atopic Eczema among Brazilian Children. J Invest Allergol Clin Immunol. 2002;12:34-41.

38. International Study of Asthma and Allergies in Childhood - ISAAC Phase Two Manual. Auckland (NZ)/ Münster (FRG), 1992. 47p. Disponível em: http://isaac.auckland.ac.nz/Phasetwo/Phs2Frame.html.

39. Camelo-Nunes IC, Wandalsen GF, Melo KC, Naspitz CK, Solé D. Prevalência de asma e de sintomas relacionados entre escolares de São Paulo, Brasil: 1996 a 1999 - Estudo da reatividade brônquica entre adolescentes asmáticos e não asmáticos - "International Study of Asthma and Allergies in Childhood (ISAAC)". Rev Bras Alerg Imunopatol. 2001;24:77-89.

40. Ellwood P, Asher MI, Beasley R, Clayton TO, Stewart AW, Writing Group. on behalf of the ISAAC Steering Committee and the ISAAC Phase Three Study Group. , New Zealand; ISAAC International Data Centre. Auckland; 2000.

Disponível em: http://isaac.auckland.ac.nz/Phasethr/Phs3Frame.html

41. Ellwood P, Asher MI, Beasley R, Clayton TO, Stewart AW, ISAAC Steering Committee. The international study of asthma and allergies in 
childhood (ISAAC): phase three rationale and methods. Int $J$ Tuberc Lung Dis. 2005;9:10-6.

42. Arruda LK, Sole D, Baena-Cagnani CE, Naspitz CK.Risk factors for asthma and atopy. Curr Opin Allergy Clin Immunol. 2005;5:153-9.

43. Peat JK, van den Berg RH, Green WF, Mellis CM, Leeder SR, Woolcock AJ. Changing prevalence of asthma in Australian children. BMJ. 1994;308:1591-6.

44. Aberg N, Hesselman B, Aberg B, Eriksson B. Increase of asthma, allergic rhinitis and eczema in Swedish schoolchildren between 1979 and 1991. Clin Exp Allergy. 1995;25:815-9.

45. Von Mutius E, Fritzch C, Weiland SK, Roll G, Magnussen H. Prevalence of asthma and allergic disorders among children in united Germany: a descriptive comparison. BMJ. 1992;305:1395 -99.

46. Matricardi PM. Prevalence of atopy and asthma in eastern versus western Europe: why the difference? Ann Allergy Asthma Immunol. 2001;87:24-7.

47. Strachan DP. Hay fever, hygiene, and household size. BMJ. 1989;299:1259-60.

48. Matricardi PM, Rosmini F, Ferigno L, Nisini R, Raoucetta M, Chionne P, Stroffolini T, Pasquini P, D'Amelio R. Cross sectional retrospective study of prevalence of atopy among Italian military student with antibodies against hepatitis A virus. BMJ. 1997;314:999-1003.

49. Matricardi PM, Rosmini F, Riondino S, Fortini M, Ferrigno L, Rapicetta M, Bonini S. Exposure to foodborne and orofecal microbes versus airborne viruses in relation to atopy and allergic asthma: epidemiological study. BMJ. 2000;320:412-7. 
50. Shirakawa T, Enomoto T, Shimazu S, Hopkin JM. The inverse association between tuberculin responses and atopic disorder. Science. 1997;275:77-9.

51. Alm JS, Lilja G, Pershagen G, Scheynius A. Early BCG vaccination and development of atopy. Lancet. 1997;350:400-3.

52. Shaheen SO, Aaby P, Hall AJ, Barker DJP, Heyes CB, Shiell AW et al. Measles and atopy in Guinea-Bissau. Lancet. 1996;347:1792-6.

53. Martinez FD, Wright AL, Taussig LM, Holberg CJ, Halonen M, Morgan WJ. Asthma and wheezing in the first six years of life. The Group Health Medical Associates. N Engl J Med. 1995;332:133-8.

54. Illi S, von Mutius E, Lau S, Bergmann R, Niggemann B, Sommerfeld C, Wahn U; MAS Group.Early childhood infectious diseases and the development of asthma up to school age: a birth cohort study. BMJ. 2001;322:390-5.

55. Strachan DP. Allergy and family size: a riddle worth solving. Clin Exp Allergy. 1997;27:235-6.

56. Bodner C, Godden D, Seaton A. Family size, childhood infections and atopic diseases. The Aberdeen WHEASE Group. Thorax. 1998;53:2832.

57. von Mutius E, Martinez FD, Fritzsch C, Nicolai T, Reitmeir P, Thiemann HH. Skin test reactivity and number of siblings. BMJ. 1994;308:692-5.

58. Kramer U, Heinrich J, Wist M, Wichmann HE. Age of entry to day nursery and allergy in later childhood. Lancet. 1999;353:450-4. 
59. Braun-Fahrlander C, Gassner M, Grize L, Neu U, Sennhauser FH, Varonier HS, Vuille JC, Wuthrich B. Prevalence of hay fever and allergic sensitization in farmer's children and their peers living in the same rural community. SCARPOL team. Swiss Study on Childhood Allergy and Respiratory Symptoms with Respect to Air Pollution. Clin Exp Allergy. 1999;29:28-34.

60. Von Ehrenstein OS, Von Mutius E, Illi S, Baumann L, Bohm O, von Kries R. Reduced risk of hay fever and asthma among children of farmers. Clin Exp Allergy. 2000;30:187-93.

61. Sepp E, Julge K, Vasar M, Naaber P, Bjorksten B, Mikelsaar M. Intestinal microflora of Estonian and Swedish infants. Acta Pediatr. 1997;86:956-61.

62. Björkstén B, Naaber P, Sepp E, Mikelsaar M. The intestinal microflora in allergic Estonian and Swedish 2-years-old children. Clin Exp Allergy. 1999;29:342-6.

63. McKeever TM, Britton J. Diet and asthma. Am J Respir Crit Care Med. 2004;170:725-9.

64. Devereux G, Seaton A. Diet as a risk factor for atopy and asthma. $J$ Allergy Clin Immunol. 2005;115:1109-17.

65. Dunder T, Kuikka L, Turtinen J, Rasanen L, Uhari M. Diet, serum fatty acids, and atopic diseases in childhood. Allergy. 2001;56:425-8.

66. Woods RK, Walters EH,$\underline{\text { Raven JM}}$, Wolfe R, Ireland PD, Thien FC, Abramson MJ. Food and nutrient intakes and asthma risk in young adults. Am J Clin Nutr. 2003;78:414-21. 
67. National Heart, Lung, and Blood Institute. Global Initiative for asthma: global strategy for asthma management and prevention. Bethesda,MD: National Institute of Health. Disponível em: http://www.ginasthma.org

68. Barnes KC. Evidence for common genetic elements in allergic disease. J Allergy Clin Immunol. 2000;106(5 Suppl):S192-200.

69. Wiesch DG, Meyers DA, Bleecker ER. Genetics of asthma. J Allergy Clin Immunol. 1999;104:895-901.

70. Redline S, Gold D. Challenges in interpreting gender differences in asthma. Am J Respir Crit Care Med. 1994;150:1219-21

71. Caracta CF. Gender differences in pulmonary disease. Mt Sinai J Med. 2003;70:215-24.

72. Bjornson CL, Mitchell I. Gender differences in asthma in childhood and adolescence. J Gend Specif Med. 2000;3:57-61.

73. PausJenssen ES, Cockcroft DW. Sex differences in asthma, atopy, and airway hyperresponsiveness in a university population. Ann Allergy Asthma Immunol. 2003;91:34-7.

74. Clarke CW, Aldons PM. The nature of asthma in Brisbane. Clin Allergy. 1979;9:147-52.

75. Litonjua AA, Carey VJ, Weiss ST, Gold DR. Race, socioeconomic factors, and area of residence are associated with asthma prevalence. Pediatr Pulmonol. 1999;28:394-401.

76. Duffy DL. Genetic epidemiology of asthma. Epidemiol Rev. 1997;19:129-43. 
77. Wittig HJ, McLaughlin ET, Leifer KL, Belloit JD. Risk factors for the development of allergic disease: analysis of 2,190 patient records. Ann Allergy. 1978;41:84-8.

78. Litonjua AA, Carey VJ, Burge HA, Weiss ST, Gold DR. Parental history and the risk for childhood asthma. Does mother confer more risk than father? Am J Respir Crit Care Med. 1998;158:176-81.

79. Wahn $U$, von Mutius E. Childhood risk factors for atopy and the importance of early intervention. $J$ Allergy Clin Immunol. $2001 ; 107: 567-74$.

80. Strachan DP, Butland BK, Anderson HR. Incidence and prognosis of asthma and wheezing illness from early childhood to age 33 in a national British cohort. BMJ. 1996;312:1195-9.

81. Plaschke PP, Janson C, Norrman E, Bjornsson E, Ellbjar S, Jarvholm B. Onset and remission of allergic rhinitis and asthma and the relationship with atopic sensitization and smoking. Am J Respir Crit Care Med. 2000;162(3 Pt 1):920-4.

82. Guerra S, Sherrill DL, Martinez FD, Barbee RA. Rhinitis as an independent risk factor for adult-onset asthma. J Allergy Clin Immunol. 2002;109:419-25.

83. Peroni DG, Piacentini GL, Alfonsi L, Zerman L, Di Blasi P, Visona' G, Nottegar F, Boner AL. Rhinitis in pre-school children: prevalence, association with allergic diseases and risk factors. Clin Exp Allergy. 2003;33:1349-54. 
84. Illi S, von Mutius E, Lau S, Nickel R, Gruber C, Niggemann B, Wahn

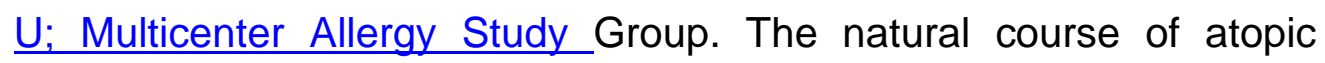
dermatitis from birth to age 7 years and the association with asthma. $J$ Allergy Clin Immunol. 2004;113:925-31.

85. Rhodes HL, Sporik R, Thomas P, Holgate ST, Cogswell JJ. Early life risk factors for adult asthma: a birth cohort study of subjects at risk. $J$ Allergy Clin Immunol. 2001;108:720-5.

86. Del Giudice MM, Pedulla M, Piacentini GL, Capristo C, Brunese FP, Decimo F, Maiello N, Capristo AF. Atopy and house dust mite sensitization as risk factors for asthma in children. Allergy. 2002;57:169-72.

87. Sporik R, Holgate ST, Platts-Mills TAE, Cogswell JJ. Exposure to house-dust mite allergen (Der $\mathrm{p} \mathrm{I}$ ) and the development of asthma in childhood. A prospective study. N Engl J Med. 1990;323:502-7.

88. Lau S, Illi S, Sommerfeld C, Niggemann B, Bergmann R, von Mutius E, Wahn U. Early exposure to house-dust mite and cat allergens and development of childhood asthma: a cohort study. Lancet. 2000;356:1392-7.

89. Hesselmar B, Aberg N, Aberg B, Eriksson B, Bjorksten B. Does early exposure to cat or dog protect against later allergy development? Clin Exp Allergy. 1999;29:611-7.

90. Ownby DR, Johnson CC. Does exposure to dogs and cats in the first year of life influence the development of allergic sensitization? Curr Opin Allergy Clin Immunol. 2003;3:517-22. 
91. Ownby DR, Johnson CC, Peterson EL. Exposure to dogs and cats in the first year of life and risk of allergic sensitization at 6 to 7 years of age. JAMA. 2002;288:963-72.

92. Liccardi G, Cazzola M, D'Amato M, D'Amato G. Pets and cockroaches: two increasing causes of respiratory allergy in indoor environments. Characteristics of airways sensitization and prevention strategies. Respir Med. 2000;94:1109-18.

93. Garrett MH, Rayment PR, Hooper MA, Abramson MJ, Hooper BM. Indoor airborne fungal spores, house dampness and associations with environmental factors and respiratory health in children. Clin Exp Allergy. 1998;28:459-67.

94. Downs SH, Mitakakis TZ, Marks GB, Car NG, Belousova EG, Leuppi JD, Xuan W, Downie SR, Tobias A, Peat JK.Clinical importance of Alternaria exposure in children. Am $J$ Respir Crit Care Med. $2001 ; 164: 455-9$.

95. Gdalevich M, Mimouni D, Mimouni M. Breast-feeding and the risk of bronchial asthma in childhood: a systematic review with meta-analysis of prospective studies. J Pediatr. 2001;139:261-6.

96. Sears MR, Greene JM, Willan AR, Taylor DR, Flannery EM, Cowan JO, Herbison GP, Poulton R. Long-term relation between breastfeeding and development of atopy and asthma in children and young adults: a longitudinal study. Lancet. 2002;360:901-7.

97. Takemura Y, Sakurai Y, Honjo S, Kusakari A, Hara T, Gibo M, Tokimatsu A, Kugai N. Relation between breastfeeding and the 
prevalence of asthma: the Tokorozawa Childhood Asthma and Pollinosis Study. Am J Epidemiol. 2001;154:115-9.

98. Wright AL, Holberg CJ, Taussig LM, Martinez FD. Factors influencing the relation of infant feeding to asthma and recurrent wheeze in childhood. Thorax. 2001;56:192-7.

99. DiFranza JR, Aligne CA, Weitzman M. Prenatal and postnatal environmental tobacco smoke exposure and children's health. Pediatrics. 2004;113(4 Suppl):1007-15.

100. Gilliland FD, Berhane K, Li YF, Rappaport EB, Peters JM. Effects of early onset asthma and in utero exposure to maternal smoking on childhood lung function. Am J Respir Crit Care Med. 2003;167:917-24.

101. Noakes PS, Holt PG, Prescott SL.Maternal smoking in pregnancy alters neonatal cytokine responses. Allergy. 2003;58:1053-8.

102. Macaubas C, de Klerk NH, Holt BJ, Wee C, Kendall G, Firth M, Sly PD, Holt PG. Association between antenatal cytokine production and the development of atopy and asthma at age 6 years. Lancet. 2003;362:1192-7.

103. Cook D, Strachan D. Summary of effects of parental smoking on the respiratory heath of children and implications for research. Thorax. 1999,54:357-66.

104. Chatkin MN, Menezes AM. The association between low birthweight and asthma: a systematic literature review. Rev Panam Salud Publica. $2005 ; 17: 102-9$. 
105. Bager P, Melbye M, Rostgaard K, Benn CS, Wesrwegaard T. Mode of delivery and risk of allergic rhinitis and asthma. J Allergy Clin Immunol. 2003;111:51-6.

106. Xu B, Pekkanen J, Hartikainen AL, Järvelin MR. Caesarean section and risk of asthma and allergy in adulthood. $J$ Allergy Clin Immunol. 2001;107:732-3.

107. McKeever TM, Lewis SA, Smith C, Hubbard R. Mode of delivery and risk of developing allergic disease. $J$ Allergy Clin Immunol. 2002;109:800-2.

108. Larrick JW, Buckley CE 3rd, Machamer CE, Schlagel GD, Yost JA, Blessing-Moore J, Levy D. Does hyperimmunoglobulinemia-E protect tropical populations from allergic disease? J Allergy Clin Immunol. $1983 ; 71: 184-8$

109. van den Biggelaar $A H$, van Ree $R$, Rodrigues LC, Lell $B$, Deelder AM, Kremsner PG, Yazdanbakhsh M. Decreased atopy in children infected with Schistosoma haematobium: a role for parasite-induced interleukin-10. Lancet. 2000;356:1723-7.

110. Yazdanbakhsh M, Kremsner PG, van Ree R. Allergy, parasites, and the hygiene hypothesis. Science. 2002;296:490-4.

111. Instituto Brasileiro de Geografia e Estatística. Anuário estatístico do Brasil. Rio de Janeiro: IBGE; 2000.

112. Tarifa JD; Armani G. Atlas ambiental do Município de São Paulo Secretaria do Verde e do Meio Ambiente SVMA/PMSP, Secretaria de Planej. SEMPLA/PMSP. Unidades Climáticas Urbanas da Cidade de 
São Paulo. São Paulo: Secretaria do Verde e do Meio Ambiente SVMA/PMSP; 2000. 86p.

113. ISAAC Phase Three Manual. Auckland (NZ); 2000. 100p.

114. Hosmer DW, Lemeshow S. Applied Logistic Regression. 2nd ed. New York: John Wiley and Sons; 2000.

115. Chan YH. Biostatistics 202: logistic regression analysis. Singapore Med J. 2004;45:149-53.

116. International Study of Asthma and Allergies in Childhood Steering Committee - Comparison of findings from ISAAC written and video questionnaires on asthma symptoms. Eur Respir J. 1996;9:230s.

117. Leser W, barbosa V, Baruzzi RG, Ribeiro MBP, Franco LJ . Elementos de epidemiologia geral. Rio de Janeiro: Atheneu; 1998. 190p.

118. Esteves AR. Adaptação e validação do questionário "ATS-DLD-78-C" para diagnóstico da asma em crianças com até 13 anos [dissertação]. São Paulo: Universidade Federal de São Paulo; 1995.

119. Wandalsen GF. Prevalência e fatores de risco para asma e doenças alérgicas em escolares da região centro-sul do município da São Paulo [dissertação]. São Paulo: Universidade Federal de São Paulo; 2003. 107p.

120. Carter-Pokras OD, Gergen PJ. Reported asthma among Puerto Rican, Mexican-American, and Cuban children, 1982 through 1984. Am J Public Health. 1993;83:580-82.

121. Burr M. Diagnosing asthma by questionnaire in epidemiological surveys. Clin Exp Allergy. 1992;22:509-10. 
122. Amorim AJ. Daneluzzi JC. Prevalence of asthma in school-age children. J Pediatr (Rio J). 2001;77:197-202.

123. Davies RJ, Rusznak C, Devalia JL. Why is allergy increasing?environmental factors. Clin Exp Allergy. 1998;28( Suppl 6):8-14.

124. Diaz-sanchez D, Tsein A, Fleming J, Saxon A.combined diesel exhaust particulate and ragweed allergen challenge markedly enhances human in vivo nasal ragweed-specific $\operatorname{lgE}$ and skews cytokine production to a $\mathrm{T}$ helper cell 2-type pattern. J Immunol. 1997;158:2406-13.

125. Diaz-sanchez D, Tsein A, Fleming J, Saxon. Enhanced nasal cytokine production in human beings after in vivo challenge with diesel exhaust particles.J Allergy Clin Immunol. 1996;98:114-23.

126. Boland S, Baeza-Squiban A, Fournier T, Houcine O, Gendron MC, Chevrier $\mathrm{M}$, et al.Diesel exhaust particles are taken up by human airway epithelial cells in vitro and alter cytokine production. $A m J$ Physiol. 1999;276(4 Pt 1):L604-13.

127. Fahy O, Tsicopoulos A, Hammad H, Pestel J, Tonnel AB, Wallaert B.Effects of diesel organic extracts on chemokine production by peripheral blood mononuclear cells. J Allergy Clin Immunol. 1999;103:1115-24.

128. Devalia JL, Rusznak C, Herdmen MJ. Effect of nitrogen dioxide and sulphur dioxide on the airway response of mild asthmatic patients to allergen inhalation. Lancet. 1994;344:1668-71. 
129. Habbick BF, Pizzichini MM, Taylor B, Rennie D, Senthilselvan A, Sears MR. Prevalence of asthma, rhinitis and eczema among children in 2 Canadian cities: the International Study of Asthma and Allergies in Childhood. CMAJ. 1999;160:1824-8.

130. Boulay ME, Boulet LP. The relationships between atopy, rhinitis and asthma: pathophysiological considerations. Curr Opin Allergy Clin Immunol. 2003;3:51-3

131. Bousquet J, Van Cauwenberge P, Khaltaev N; Aria Workshop Group; World Health Organization. Allergic rhinitis and its impact on asthma. $J$ Allergy Clin Immunol. 2001;108(5 Suppl):S147-334.

132. Lundbäck B. Epidemiology of rhinitis and asthma. Clin Exp Allergy. 1998;28(Suppl 2):3-10.

133. Lombardi C, Passalacqua G, Gargioni S, Senna G, Ciprandi G, Scordamaglia A, Canonica GW. The natural history of respiratory allergy: a follow-up study of 99 patients up to 10 years. Respir Med. 2001;95:9-12.

134. Fletcher R, Fletcher S, Wagner E. Epidemiologia clínica: elementos essenciais. 3a ed. Porto alegre: Artes Médicas; 1996. 103p.

135. Sears MR. Epidemiology of childhood asthma. Lancet. 1997;350:1015-20.

136. Von Mutius E. The environmental predictors of allergic disease. $J$ Allergy Clin Immunol. 2000;105(1 Pt 1):9-19.

137. Howart PH. Is allergy increasing?early life influences. Clin Exp Allergy. 1998;28 Suppl 6:2-7. 
138. Crane J, O Donnel TV, Prior IAM, Waite DA. Symptoms of asthma, methacoline airway responsiveness and atopy in migrant Tokelauan children. NZ Med J. 1989; 102: 36-8.

139. Peat JK, van den Berg RH, Green WF, Mellis CM, Leeder SR, Woolcock AJ. Changing prevalence of asthma in Australian children. BMJ. 1994;308(6944):1591-6.

140. Martinez FD, Wright AL, Taussig LM, Holberg CJ, Halonen M, Morgan WJ. Asthma and wheezing in the first six years of life. The Group Health Medical Associates. N Engl J Med. 1995;332:133-8.

141. Guerra S, Sherrill DL, Martinez FD, Barbee RA. Rhinitis as an independent risk factor for adult-onset asthma. J Allergy Clin Immunol. 2002;109:419-25.

142. Lau S, Nickel R, Niggemann B, Gruber C, Sommerfeld C, Illi S, Kulig M, Forster J, Wahn U, Groeger M, Zepp F, Kamin W, Bieber I, Tacke

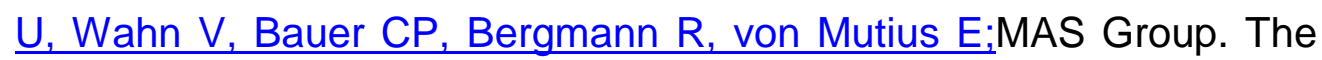
development of childhood asthma: lessons from the German Multicentre Allergy Study (MAS). Paediatr Respir Rev. 2002;3:265-72.

143. Spergel JM. Atopic march: link to upper airways. Curr Opin Allergy Clin Immunol. 2005;5:17-21.

144. Solé D, Camelo-Nunes IC, Wandalsen GF, Melo KC, Naspitz CK. Is rhinitis alone or associated with atopic eczema a risk factor for severe asthma in children? Pediatr Allergy Immunol. 2005;16:121-5.

145. Rusconi F, Galassi C, Corbo GM, Forastiere F, Biggeri A, Ciccone G, Renzoni E. Risk factors for early, persistent, and late-onset wheezing 
in young children. SIDRIA Collaborative Group. Am J Respir Crit Care Med. 1999;160(5 Pt 1):1617-22.

146. Illi S, von Mutius E, Lau S, Nickel R, Gruber C, Niggemann B, Wahn U; Multicenter Allergy Study Group. The natural course of atopic dermatitis from birth to age 7 years and the association with asthma. $J$ Allergy Clin Immunol. 2004;113:925-31.

147. Edfors-Lubs M. Allergy in 7000 twin pairs. Acta Allergol. 1971;26:24985.

148. Palmer LJ, Burton PR, Faux JA, James AL, Musk AW, Cookson WO. Independent inheritance of serum immunoglobulin E concentrations and airway responsiveness. Am $J$ Respir Crit Care Med. 2000;161:1836-43.

149. Gray L, Peat JK, Belousova E, Xuan W, Woolcock AJ. Family patterns of asthma, atopy and airway hyperresponsiveness: an epidemiological study. Clin Exp Allergy. 2000;30:393-9.

150. Ronmark E, Lundback B, Jonsson E, Jonsson AC, Lindstrom M, Sandstrom T. Incidence of asthma in adults--report from the Obstructive Lung Disease in Northern Sweden Study. Allergy. 1997;52:1071-8.

151. Arruda LK, Sole D, Baena-Cagnani CE, Naspitz CK. Risk factors for asthma and atopy. Curr Opin Allergy Clin Immunol. 2005;5:153-9.

152. Arshad SH. Development of allergic disease in children. Clin Exp Allergy. 1997;27:1231-3. 
153. Aberg N. Familial occurrence of atopic disease: genetic versus environmental factors. Clin Exp Allergy. 1993;23:829-34.

154. Alford SH, Zoratti E, Peterson EL, Maliarik M, Ownby DR, Johnson CC. Parental history of atopic disease: disease pattern and risk of pediatric atopy in offspring. J Allergy Clin Immunol. 2004;114:1046-50.

155. Brussee JE, Smit HA, van Strien RT, Corver K, Kerkhof M, Wijga AH, Aalberse RC, Postma D, Gerritsen J, Grobbee DE, de Jongste JC, Brunekreef B.Allergen exposure in infancy and the development of sensitization, wheeze, and asthma at 4 years. J Allergy Clin Immunol. 2005;115:946-52.

156. Remes ST, Castro-Rodriguez JA, Holberg CJ, Martinez FD, Wright AL. Dog exposure in infancy decreases the subsequent risk of frequent wheeze but not of atopy. J Allergy Clin Immunol. 2001;108:509-15.

157. Perzanowski MS, Ronmark E, Platts-Mills TA, Lundback B. Effect of cat and dog ownership on sensitization and development of asthma among preteenage children. Am $J$ Respir Crit Care Med. 2002;166:696-702.

158. Apelberg BJ, Aoki Y, Jaakkola JJ. Systematic review: Exposure to pets and risk of asthma and asthma-like symptoms. $J$ Allergy Clin Immunol. 2001;107:455-60.

159. Wahn U, Lau S, Bergmann R, Kulig M, Forster J, Bergmann K, Bauer

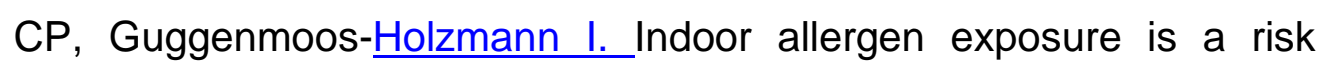


factor for sensitization during the first three years of life. J Allergy Clin Immunol. 1997;99(6 Pt 1):763-9.

160. Lau S, Illi S, Platts-Mills TA, Riposo D, Nickel R, Gruber C, Niggemann B, Wahn U; Multicentre Allergy Study Group. Longitudinal study on the relationship between cat allergen and endotoxin exposure, sensitization, cat-specific $\lg G$ and development of asthma in childhood--report of the German Multicentre Allergy Study (MAS 90). Allergy. 2005;60:766-73.

161. Ownby DR, Johnson CC, Peterson EL. Exposure to dogs and cats in the first year of life an risk of allergic sensitization at 6 to 7 years of age. JAMA. 2002;288:963-72.

162. Waser M, von Mutius E, Riedler J, Nowark D, Maisch S, Carr D, Eder W, Tebow G, Schieri R, Schreuer M, Braun-Fahrlander C and TheALEX Study Team. Exposure to pets, and association with hay fever, asthma, and atopic sensitization in rural children. Allergy. 2005;60:177-84.

163. Platts-Mills TA, Erwin EA, Allison AB, Blumenthal K, Barr M, Sredl D, Burge H, Gold D. The relevance of maternal immune responses to inhalant allergens to maternal symptoms, passive transfer to the infant, and development of antibodies in the first 2 years of life. J Allergy Clin Immunol. 2003;111:123-30.

164. Cook DG, Strachan DP. Parental smoking, bronchial reactivity and peak flow variability in children. Thorax. 1998;53:295-301. 
165. Martinez FD, Cline M, Burrows B. Increased incidence of asthma in children of smoking mothers. Pediatrics. 1992;89:21-6.

166. Lau S, Nickel R, Niggeman Bodo, Gruber C, Sommerfeld C, Illi S, Kulig M, Forster J, Wanh U and MAS Group. The development of childhood asthma: lessons from the German Multicentre Allergy Study (MAS). Paediatr Resp Rev. 2002;3:265-72.

167. Strachan DP, Cook DG. Parental smoking and childhood asthma: longitudinal and case-control studies. Thorax.1998;53:204-12.

168. von Mutius E. Environmental factors influencing the development and progression of pediatric asthma. J Allergy Clin Immunol. 2002;109(6 Suppl):S525-32.

169. Saarinen UM, Kajosaari M. Breastfeeding as prophylaxis against atopic disease: prospective follow-up study until 17 years old. Lancet. 1995;346:1065-9.

170. Oddy WH, Holt PG, Sly PD, Read AW, Landau LI, Stanley FJ, Kendall GE, Burton PR. Association between breast feeding and asthma in 6 year old children: findings of a prospective birth cohort study. BMJ. 1999;319:815-9.

171. Friedman NJ, Zeiger RS. The role of breast-feeding in the development of allergies and asthma. J Allergy Clin Immunol. 2005;115:1238-48.

172. van Odijk J, Kull I, Borres MP, Brandtzaeg P, Edberg U, Hanson LA, Host A, Kuitunen M, Olsen SF, Skerfving S, Sundell J, Wille S. Breastfeeding and allergic disease: a multidisciplinary review of the 
literature (1966-2001) on the mode of early feeding in infancy and its impact on later atopic manifestations. Allergy. 2003;58:833-43.

173. Annesi-maesano I, Moreau D, Strachan D. In utero and perinatal complications preceding asthma. Allergy. 2001;56:491-7.

174. Simoni M, Lombardi E, Berti G, Rusconi F, La Grutta S, Piffer S, Petronio MG, Galassi C, Forastiere F, Viegi G; SIDRIA-2 Collaborative Group. Mould/dampness exposure at home is associated with respiratory disorders in Italian children and adolescents: the SIDRIA-2 Study. Occup Environ Med. 2005;62:616-22.

175. Jedrychowski W, Flak E. Separate and combined effects of the outdoor and indoor air quality on chronic respiratory symptoms adjusted for allergy among preadolescent children. Int $J$ Occup Med Environ Health. 1998;11:19-35.

176. Yang CY, Chiu JF, Chiu HF, Kao WY. Damp housing conditions and respiratory symptoms in primary school children. Pediatr Pulmonol. 1997;24:73-7.

177. Dales RE, Zwanenburg H, Burnett R, Franklin CA. Respiratory health effects of home dampness and molds among Canadian children. Am J Epidemiol. 1991;134:196-203.

178. Rogers CA. Indoor fungal exposure. Immunol Allergy Clin North Am. 2003;23:501-18.

179. Billings CG, Howard P. Damp housing and asthma. Monaldi Arch Chest Dis. 1998;53:43-9. 
180. Bresciani M, Parisi C, Menghi G, Bonini S.The hygiene hypothesis: does it function worldwide? Curr Opin Allergy Clin Immunol. 2005;5:147-51.

181. Kemp A, Bjorksten B. Immune deviation and the hygiene hypothesis: a review of the epidemiological evidence. Pediatr Allergy Immunol. 2003;14:74-80.

182. Platts-Mills TA, Erwin E, Heymann P, Woodfolk J. Is the hygiene hypothesis still a viable explanation for the increased prevalence of asthma? Allergy. 2005;60( Suppl 79):25-31.

183. Jarvis MJ. The association between having children, family size and smoking cessation in adults. Addiction. 1996;91:427-34.

184. Svanes C, Jarvis D, Chinn S, Omenaas E, Gulsvik A, Burney P; European Community Respiratory Health Survey.Early exposure to children in family and day care as related to adult asthma and hay fever: results from the European Community Respiratory Health Survey. Thorax. 2002;57:945-50.

185. Mattes J, Karmaus W, Moseler M, Frischer T, Kuehr J. Accumulation of atopic disorders within families: a sibling effect only in the offspring of atopic fathers. Clin Exp Allergy. 1998;28:1480-6.

186. Strachan DP, Taylor EM, Carpenter G. Family structure, neonatal infection, and hay fever in adolescence. Arch Dis Child.1996;74:422-6.

187. Cardoso MR, Cousens SN, de Goes Siqueira LF, Alves FM, D'Angelo LA. Crowding: risk factor or protective factor for lower respiratory disease in young children? BMC Public Health. 2004;4:19-26. 
188. Nafstad P, Hagen JA, Oie L, Magnus P, Jaakkola JJ. Day care centers and respiratory health. Pediatrics . 1999;103:753-8.

189. Marbury MC, Maldonado G, Waller L. Lower respiratory illness, recurrent wheezing, and day care attendance. Am J Respir Crit Care Med. 1997;155:156-61.

190. Ball TM, Castro-Rodriguez JA, Griffith KA, Holberg CJ, Martinez FD, Wright AL. Siblings, day-care attendance, and the risk of asthma and wheezing during childhood. N Engl J Med. 2000;343:538-43.

191. Celedon JC, Wright RJ, Litonjua AA, Sredl D, Ryan L, Weiss ST, Gold DR. Day care attendance in early life, maternal history of asthma, and asthma at the age of 6 years. Am $J$ Respir Crit Care Med. 2003;167:1239-43.

192. Rullo VE, Rizzo MC, Arruda LK, Sole D, Naspitz CK. Day care centers and schools as sources of exposure to mites, cockroach, and endotoxin in the city of São Paulo, Brazil. J Allergy Clin Immunol. 2002;110:582-8.

193. Eder W, von Mutius E. Hygiene hypothesis and endotoxin: what is the evidence? Curr Opin Allergy Clin Immunol. 2004;4:113-7

194. von Mutius E, Braun-Fahrlander C, Schierl R, Riedler J, Ehlermann S, Maisch S, Waser M, Nowak D.Exposure to endotoxin or other bacterial components might protect against the development of atopy. Clin Exp Allergy. 2000;30:1230-4.

195. Gereda JE, Leung DY, Thatayatikom A, Streib JE, Price MR, Klinnert MD, Liu AH. Relation between house-dust endotoxin exposure, type 1 
T-cell development, and allergen sensitisation in infants at high risk of asthma. Lancet. 2000;355:1680-3.

196. Park JH, Gold DR, Spiegelman DL, Burge HA, Milton DK. House dust endotoxin and wheeze in the first year of life. Am J Respir Crit Care Med. 2001;163:322-8.

197. Nagakura T, Matsuda S, Shichijyo K, Sugimoto H, Hata K. Dietary supplementation with fish oil rich in omega-3 polyunsaturated fatty acids in children with bronchial asthma. Eur Respir J. 2000;16:861-5.

198. Fogarty A, Britton J. The role of diet in the aetiology of asthma. Clin Exp Allergy. 2000;30:615-27

199. Smit HA. Chronic obstructive pulmonary disease, asthma and protective effects of food intake: from hypothesis to evidence? Respir Res. $2001 ; 2: 261-4$.

200. Romieu I, Trenga C. Diet and obstructive lung diseases. Epidemiol Rev. $2001 ; 23: 268-87$ 